CENTRO UNIVERSITÁRIO FEI

CARLOS JOSÉ ANDRIOLI

ANÁLISE DISCRIMINANTE DO RUÍDO DE FUNDO EM IMAGENS DE RESSONÂNCIA MAGNÉTICA DE EXTREMIDADES

São Bernardo do Campo 
CARLOS JOSÉ ANDRIOLI

\section{ANÁLISE DISCRIMINANTE DO RUÍDO DE FUNDO EM IMAGENS DE RESSONÂNCIA MAGNÉTICA DE EXTREMIDADES}

Dissertação de Mestrado, apresentada ao Centro Universitário da FEI para obtenção do título de Mestre em Engenharia Elétrica, orientada pelo Prof. Dr. Carlos Eduardo Thomaz.

São Bernardo do Campo 
Andrioli, Carlos José.

Análise discriminante do ruído de fundo em imagens de ressonância magnética de extremidades / Carlos José Andrioli. São Bernardo do Campo, 2021.

89 p. : il.

Dissertação - Centro Universitário FEI.

Orientador: Prof. Carlos Eduardo Thomaz.

1. Ressonância de Extremidades. 2. Ruído. 3. SNR. 4. PCA. 5. MLDA.

I. Thomaz, Carlos Eduardo, orient. II. Título.

Elaborada pelo sistema de geração automática de ficha catalográfica da FEI com os dados fornecidos pelo(a) autor(a). 
Título do Trabalho: ANÁLISE DISCRIMINANTE DO RUÍDO DE FUNDO EM IMAGENS DE RESSONÂNCIA MAGNÉTICA DE EXTREMIDADES.

Área de Concentração: Processamento de Sinais e Imagens

Orientador: Prof. ${ }^{\circ}$ Dr. ${ }^{\circ}$ Carlos Eduardo Thomaz

Data da realização da defesa: 20/08/2021

\section{ORIGINAL ASSINADA}

Avaliação da Banca Examinadora:

São Bernardo do Campo,

\section{MEMBROS DA BANCA EXAMINADORA}

Prof. ${ }^{\circ}$ Dr. ${ }^{\circ}$ Carlos Eduardo Thomaz

Dr. ${ }^{\circ}$ Marcos Duchene

Prof. o Dr.o Paulo Sérgio Silva Rodrigues
Ass. :

Ass. :

Ass. :

A Banca Julgadora acima-assinada atribuiu ao aluno o seguinte resultado:

APROVADO \ REPROVADO

\section{VERSÃO FINAL DA DISSERTAÇÃO}

APROVO A VERSÃO FINAL DA DISSERTAÇÃO EM QUE FORAM INCLUÍDAS AS RECOMENDAÇÕES DA BANCA EXAMINADORA
Aprovação do Coordenador do Programa de Pós-graduação

Prof. Dr. Carlos Eduardo Thomaz 
A quem eu quero dedicar o texto.

Dedico este texto primeiramente a Deus, por ser o criador de tudo; à minha esposa Margareth, incentivadora, companheira, solidária comigo em todas as horas e circunstâncias; e às minhas filhas, Yria e Erina, por serem minhas fontes inspiradoras. 


\section{AGRADECIMENTOS}

Agradeço, em especial, ao meu orientador, Prof. Dr. Carlos Eduardo Thomaz, pela excelência com que conduziu a orientação deste trabalho, sempre incentivando-me a continuálo, assim como seguir em busca de novos desafios, e ao Prof. Dr. Paulo Sérgio e ao Prof. Dr. Ivandro Sanchez pelas sugestões apresentadas durante a qualificação.

Aos amigos da FEI, pela dedicação, paciência e cooperação inigualáveis que recebi. 
"Quem faz pode cometer falhas, mas a falha maior de todas as falhas , é não fazer nada."

Benjamin Franklin

“A verdadeira sabedoria consiste em saber como aumentar o bem estar do mundo."

Benjamin Franklin

"Diz-me e o esqueço, ensina-me e o recordo, envolva-me e o aprendo."

Benjamin Franklin 


\section{RESUMO}

Especialistas estudam a melhoria contínua da qualidade de imagem de ressonância magnética (RM) desde a criação do primeiro equipamento para aquisição desse tipo de imagem, em 1974. Este trabalho tem como objetivo analisar o ruído de fundo de imagens de RM de extremidades de alto campo (1 Tesla), causado principalmente por radiofrequência e interferências eletromagnéticas presentes na Gaiola de Faraday desses equipamentos. Para a realização deste estudo e a parametrização das imagens, utilizou-se de um dispositivo denominado phantom (usado para calibração desses equipamentos de RM) e o protocolo de referência para este fim chamado DQA (Daily Quality Assurance). Foram adquiridas 45 imagens de RM, pré-classificadas por especialista de RM como contendo ou não ruído de fundo, e posteriormente analisadas pelo método estatístico multivariado PCA (Principal Components Analysis) + MLDA (Maximum uncertaintly Linear Discriminant Analysis) e pelo SNR (Signal to Noise Ratio), índice padrão que quantifica a relação entre o sinal e o ruído da imagem. O PCA serviu como um filtro estatístico, diminuindo consideravelmente a quantidade de informação de entrada para o classificador MLDA. Quando utilizadas todas as componentes principais do PCA, o MLDA apresentou acurácia de 93,33\% e resultados que permitiram discriminar o ruído de fundo dessas imagens em complementaridade com o SNR.

Palavras-chave: Imagens de ressonância magnética; sinal; ruído; ressonância de extremidades; SNR; phantom, PCA e MLDA. 


\begin{abstract}
Since the creation of the first magnetic resonance imaging (MRI) equipment in 1974, experts have been studying the continuous improvement of image quality. This work aims to study the types of background noise in images from extremity MRI system of high-field, mainly caused by Faraday Cage problems. Phantom images of 1T equipment were investigated for this study. For the acquisition of these images, a protocol called DQA (Daily Quality Assurance) was used. For this work, 45 MRI images were acquired, which were pre-classified by an expert, and analyzed by SNR, an index that quantifies the ratio between signal and image noise, and by the multivariate statistical methods PCA + MLDA. PCA served as a statistical filter, which considerably decreased the amount of input information for MLDA. When all main components were used, MLDA showed an accuracy of $93.33 \%$ and results that allowed to discriminate background noise from these images in complementarity with SNR.
\end{abstract}

Keywords: Magnetic resonance images; signal; noise; extremity resonance; SNR; IS; IR; phantom PCA and MLDA. 


\section{LISTA DE ILUSTRAÇÕES}

Figura 1 - Figura do Spin da molécula de Hidrogênio. . . . . . . . . . . . . 18

Figura 2 - Demonstração de Larmor. . . . . . . . . . . . . . . . . . . 19

Figura 3 - Equipamento de Mansfield. . . . . . . . . . . . . 20

Figura 4 - Método de Mansfield. . . . . . . . . . . . . . 21

Figura 5 - Patologia do corte axial do dedo. . . . . . . . . . 21

Figura 6 - Corte axial do dedo obtido por Mansfield em preto e branco. . . . . . . . 22

Figura 7 - Corte axial do dedo obtido por Mansfield em colorido. . . . . . . . . 22

Figura 8 - Ressonâncias de baixo campo. . . . . . . . . . . 23

Figura 9 - Ressonância de alto campo magnético. . . . . . . . . . . . . . 24

Figura 10 - Ressonância de Extremidades de alto campo magnético. . . . . . . . . . 25

Figura 11 - Sistemas de temperatura da ressonância de extremidades. . . . . . . . . 26

Figura 12 - Sistema completo da ressonância de extremidades. . . . . . . . . . . . 28

Figura 13 - Exemplo de ghost em ressonância magnética. . . . . . . . . . . . . . 30

Figura 14 - Exemplo de artefato de radio frequência em ressonância magnética. . . . . 31

Figura 15 - Exemplo de artefato de interferência eletromagnética em ressonância magnética. ............................ 32

Figura 16 - Exemplo de vareta de shim. . . . . . . . . . . . . 33

Figura 17 - Processo de shimming em ressonância magnética de extremidades. . . . . 33

Figura 18 - Imagens de patologias com próteses e partes metálicas. . . . . . . . . . 34

Figura 19 - Imagem de exemplo de vibração. . . . . . . . . . . . . . . . 35

Figura 20 - Exemplo de artefato de fluxo1. . . . . . . . . . . . 36

Figura 21 - Exemplo de artefato de fluxo2 . . . . . . . . . . . 37

Figura 22 - Exemplo de artefato de movimento do paciente. . . . . . . . . . 38

Figura 23 - Definição de bobina cilindrica. . . . . . . . . . . . . . 40

Figura 24 - Exemplo perda usando bobinas cilíndricas. . . . . . . . . . . . 40

Figura 25 - Exemplo diminuição do SNR pela diminuição do FOV. . . . . . . . . . . . 43

Figura 26 - Bobina utilizada por Ohliger em sua tese. . . . . . . . . . . . . 44

Figura 27 - Gráfico da resposta da bobina da tese de Ohliger. . . . . . . . . . . . . 44

Figura 28 - Gráfico dos estudos de Dietrich. . . . . . . . . . . . . . 46

Figura 29 - Tabela dos estudos de Dietrich. . . . . . . . . . . . . . 47

Figura 30 - Imagens dos estudos de Dietrich. . . . . . . . . . . . . . 47 
Figura 31 - Resposta da bobina de Li. . . . . . . . . . . . . . . . 48

Figura 32 - Phantoms usados por McCann. . . . . . . . . . . . . . . . 49

Figura 33 - Imagens usadas por McCann. . . . . . . . . . . . . . . . 50

Figura $34-$ Tabela de Jin. . . . . . . . . . . . . . . . . . 51

Figura 35 - Sistema MSK/Orthone 1.0T. . . . . . . . . . . . . 55

Figura 36 - Imagem de DQA. . . . . . . . . . . . . . . 57

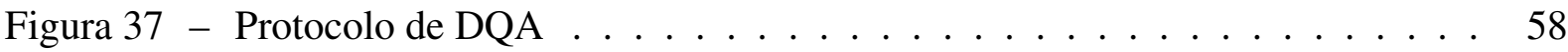

Figura 38 - Imagens boas de phantons. . . . . . . . . . . . . . . . . . 60

Figura 39 - Imagens ruins de phantons. . . . . . . . . . . . . . 61

Figura 40 - Dados de DQA. . . . . . . . . . . . . . . 62

Figura 41 - Gráfico PCA. . . . . . . . . . . . . . . . 65

Figura 42 - Processo PCA. . . . . . . . . . . . . . . . 67

Figura 43 - Exemplo MLDA. . . . . . . . . . . . . . 70

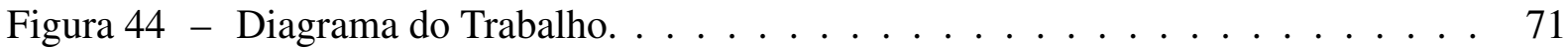

Figura 45 - Imagem Primeira Componente PCA. . . . . . . . . . . . . . . . 72

Figura 46 - Imagem Segunda Componente PCA. . . . . . . . . . . . . 73

Figura 47 - Imagem 43a Componente PCA. . . . . . . . . . . . . 73

Figura 48 - Imagem 44a Componente PCA. . . . . . . . . . . . . . . . 74

Figura 49 - Gráfico PCA 1a (x 1) e 2a (o 2) componentes. . . . . . . . . . . . . . . 74

Figura 50 - Gráfico PCA 3a (x 3) e 4a (o 4) componentes. . . . . . . . . . . . 75

Figura 51 - Gráfico MLDA para todas as componentes principais. . . . . . . . 75

Figura 52 - Gráfico da Variância e Discriminância para todas as imagens. . . . . . . . 76

Figura 53 - Gráfico SNR x MLDA para todas as imagens. . . . . . . . . . . . . . 77

Figura 54 - Gráfico SNR x MLDA Boas e Ruins. . . . . . . . . . . . . . 78

Figura 55 - Gráfico SNR e MLDA das Imagens Boas e Ruins. . . . . . . . . . . . 79

Figura 56 - Detalhe do gráfico SNR e MLDA das Imagens Boas e Ruins. . . . . . . . 80

Figura 57 - Imagens ruins pelo MLDA mas boas pelo SNR . . . . . . . . . . . . 80

Figura 58 - Imagem boa pelo MLDA mas ruim pelo SNR. . . . . . . . . . . 81

Figura 59 - Processo Leave-one-out . . . . . . . . . . . . . . . 81

Figura 60 - Gráfico Leave-one-out . . . . . . . . . . . . . . . . . 82

Figura 61 - Análise Leave-one-out . . . . . . . . . . . . . . . 83

Figura 62 - Gráfico do MLDA para uma amostra boa. . . . . . . . . . . . . 84

Figura 63 - Gráfico MLDA para as 10 Componentes principais. . . . . . . . . . . . 85 
Figura 64 - Gráfico MLDA para as 5 componentes principais. . . . . . . . . . 86 



\section{SUMÁRIO}

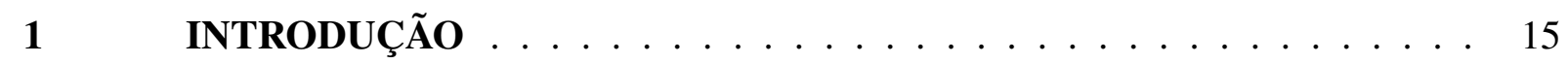

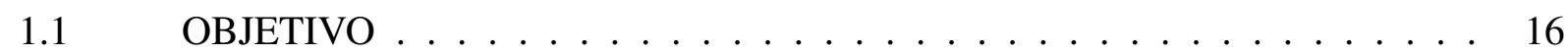

1.2 ESTRUTURA DESTE TRABALHO $\ldots \ldots \ldots \ldots \ldots$

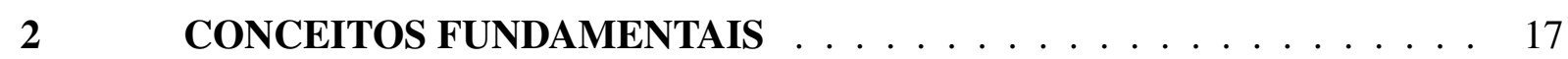

2.1 BREVE HISTÓRICO SOBRE A DESCOBERTA DE RM . . . . . . . . . 17

2.1.1 Lei de LARMOR . . . . . . . . . . . . . . . . . . . . . . . . . . . . 19

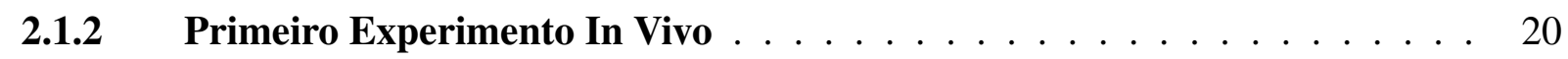

2.2 TIPOS DE EQUIPAMENTOS DE RM COMERCIAIS . . . . . . . . . . 22

2.2.1 RM de Campo Baixo $\ldots \ldots \ldots \ldots \ldots$

2.2.2 RM de Campo Alto . . . . . . . . . . . . . . . . . . . . . . . 23

2.2.3 RM de Corpo Inteiro . . . . . . . . . . . . . . . . . . . . . . . . . 24

2.2.4 RM de Extremidades . . . . . . . . . . . . . . . . . . . . . . . . . . 24

2.3 FUNCIONAMENTO DO EQUIPAMENTO DE RM DE CAMPO ALTO . . . 25

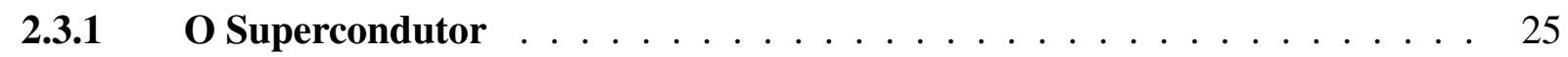

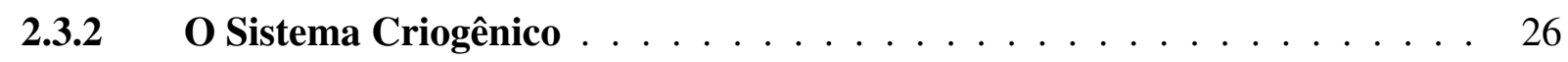

2.3.3 O Campo Magnético $\ldots \ldots \ldots \ldots \ldots$

2.3.4 Bobinas de Gradiente . . . . . . . . . . . . . . . . . . . . . . . 27

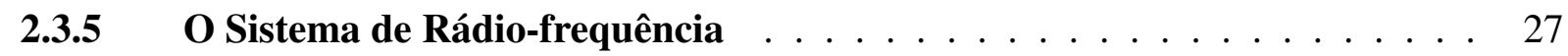

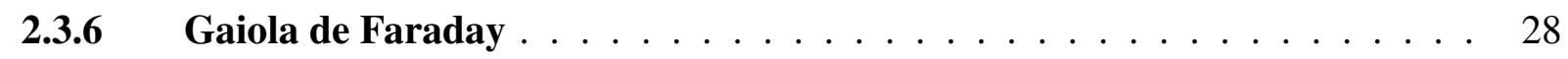

2.3.7 O Rú́do da Imagem . . . . . . . . . . . . . . . . . . . . . . . . . . . . . 29

$2.4 \quad$ TIPOS DE RUÍDO DA IMAGEM . . . . . . . . . . . . . . . . . . . . . . . 29

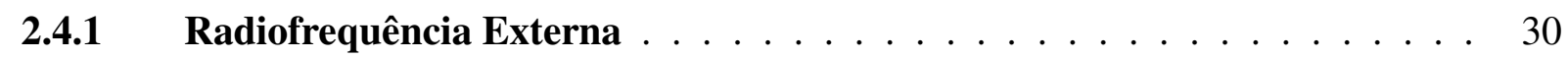

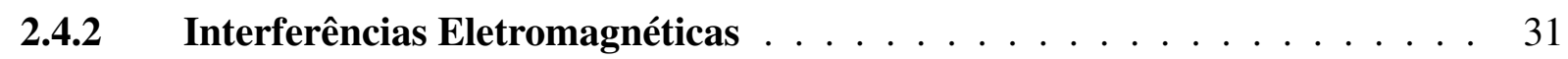

2.4.3 Interferências Ferromagnéticas . . . . . . . . . . . . . . . . 32

2.4.4 Interferências por Vibração $\ldots \ldots \ldots \ldots$

2.4.5 Interferências pelo Paciente $\ldots \ldots \ldots \ldots \ldots \ldots$

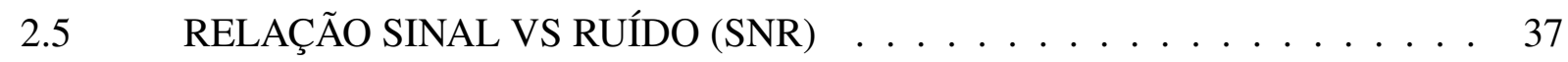

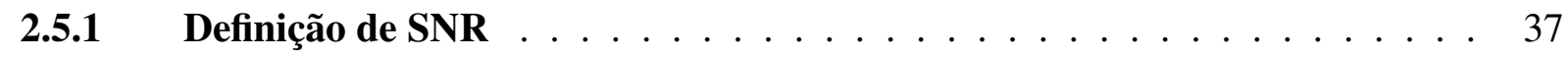

2.5.2 Trabalhos Relacionados . . . . . . . . . . . . . . . . . . . . . 42

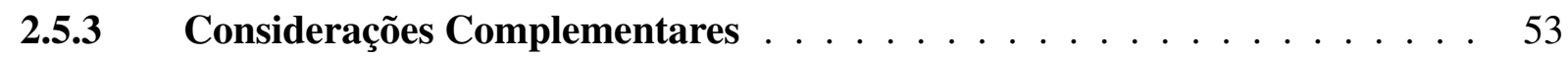




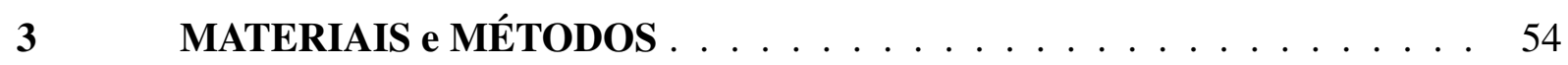

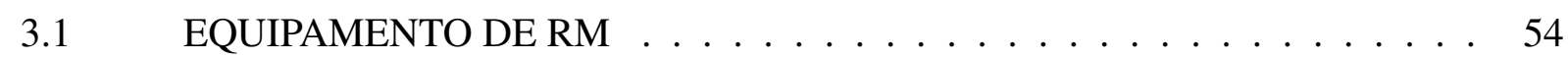

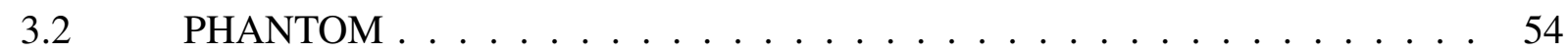

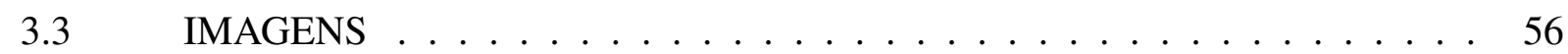

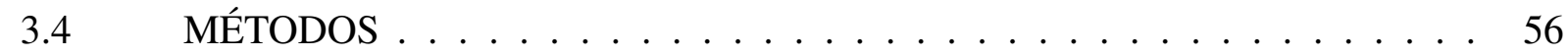

3.4.1 Aquisição e Pré-classificação de Imagens . . . . . . . . . . . . . . . 57

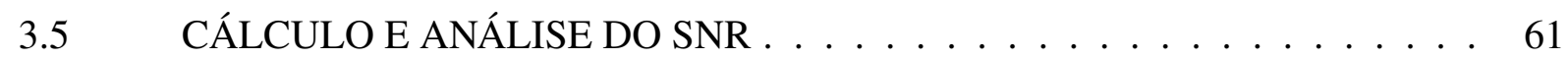

3.6 ANÁLISE ESTATÍSTICA MULTIVARIADA . . . . . . . . . . . . . 63

3.6.1 Análise de Componentes Principais (PCA) $\ldots \ldots \ldots$

3.6.2 Análise de Discriminantes Lineares (LDA) . . . . . . . . . . . . . . 67

3.6.3 Análise de Máximos Discriminantes Lineares (MLDA) . . . . . . . . . . . 69

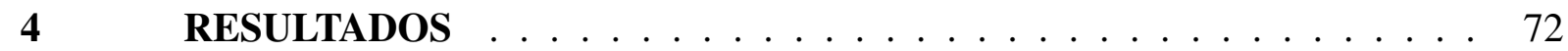

4.1 ANÁLISE DOS COMPONENTES PRINCIPAIS (PCA) . . . . . . . . . 73

4.2 ANÁLISE DO SNR e MLDA . . . . . . . . . . . . . . 76

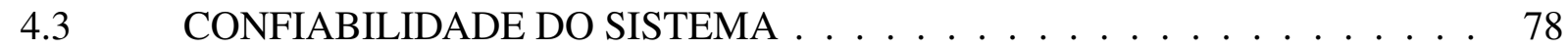

4.3.1 Processo Leave One Out $\ldots \ldots \ldots \ldots$

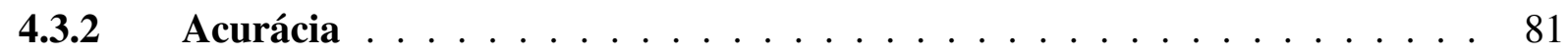

4.3.3 Redução do Sistema pelos dez e cinco valores mais discriminantes . . . . . 82

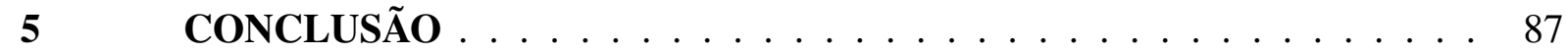

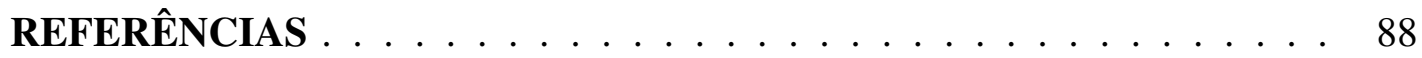




\section{INTRODUÇÃO}

Em 1974 foi criado o primeiro equipamento de ressonância magnética pelo grupo do Sr. Peter Mansfield na Universidade de Nothingham (MCROBBIE et al., 2006). Em reconhecimento pela contribuição prestada por suas descobertas, devido a sua concepção de utilizar campo magnético e ondas de rádio para obtenção das imagens, juntamente com o químico americano Paul Larterbur, recebem da Academia Sueca o Prêmio Nobel de Medicina em 2003.

Desde então, cientistas, médicos e especialistas trabalham constantemente na melhora da qualidade da aquisição e processamento dessas imagens (CONSTANTINIDES; ATALAR; MCVEIGH, 1997, KUPERMAN, 2000, JIN;SAYBASILI;BI,2015).

Esta qualidade é medida principalmente pela relação entre o sinal emitido e a quantidade de ruído obtida na imagem, chamada de SNR (Signal to Noise Ratio). O valor do SNR decorre de vários fatores que influenciam diretamente o sinal e o ruído da imagem como, por exemplo:
a) Intensidade do Campo Magnético;
b) Situação da homogeneização do campo;
c) Tipo de bobina de recepção;
d) Eficiência da gaiola de Faraday;
e) Interferências eletromagnéticas;
f) Temperatura.

Embora os primeiros trabalhos visando o cálculo da SNR tenham sido publicados já na década de 1970 (MCROBBIE et al., 2006), foi na década de 1990 que trabalhos mais relevantes sobre o assunto começaram a ser publicados ( MARCOVSKI, 1996, CONSTANTINIDES; ATALAR; MCVEIGH, 1997, GOENER; CLARKE, 2011; GUERIN et al., 2017). Basicamente todos esses trabalhos estão relacionados com os seguintes tópicos:
a) Definição da SNR;
b) Comportamento da SNR em relação à intensidade de campo magnético;
c) Comportamento da SNR em relação ao tipo de bobina utilizada;
d) SNR em paralelismo de imagens (pós-processamento das imagens).

A maioria dos autores(CONSTANTINIDES; ATALAR; MCVEIGH, 1997, KUPERMAN, 2000, JIN;SAYBASILI;BI,2015), utiliza em seus estudos ressonâncias de corpo inteiro com as mais variadas intensidades de campo magnético. Por mais que tenham tentado adotar um outro procedimento para a qualificação da qualidade de imagem, o SNR ainda é a principal. 
O melhor processo de medida do SNR é realizado por meio da análise de amostras de fundo da imagem e amostra da imagem principal. De acordo com (GUERIN et al., 2017), este processo somente não é aconselhado para o caso de paralelismo de imagens (pós- processamento), visto que, neste caso, o fundo da imagem também será processado, perdendo a referência. Até o momento na literatura, não foi constatado metodologia de melhorar o SNR através da diminuição do índice de ruído do fundo da imagem. Também não foi encontrado trabalho acadêmico referente ao cálculo da SNR para equipamentos de ressonância magnética de extremidades de campo alto (a partir de 1.0 Tesla), sendo apresentados apenas trabalhos referentes a equipamentos de baixo campo ou de alto campo de corpo inteiro.

\subsection{OBJETIVO}

Este trabalho tem como objetivo estudar os tipos de ruído de fundo das imagens de ressonância magnética de extremidades de alto campo, causados principalmente por problemas na Gaiola de Faraday (gaiola de RF). Logo, haverá a análise das imagens e seus ruídos através da aplicação da aplicação da análise discriminante da qualidade de imagem e pela SNR, índice que indica a relação entre o sinal e ruído em imagens de ressonância magnética.

\subsection{ESTRUTURA DESTE TRABALHO}

O capítulo 2 apresenta os conceitos fundamentais sobre a teoria e funcionamento da ressonância magnética, bem como, uma descrição detalhada dos componentes mais importantes do equipamento, como, por exemplo, magneto, supercondutor, criogenia, campo magnético, partes de rádio frequência e os tipos de ruído mais importantes. O capítulo 3 apresenta Materiais e Métodos utilizados, de forma a criar uma parametrização para análise e comparação dos resultados. O capítulo 4 verifica os resultados obtidos, e por fim, o capítulo 5 conclui esta pesquisa e, em função dos resultados apresentados, há a proposição de trabalhos futuros. 


\section{CONCEITOS FUNDAMENTAIS}

Este capítulo descreve os principais conceitos fundamentais relacionados a equipamentos de ressonância magnética (RM) de alto campo, objeto central de investigação deste trabalho, que são construídos utilizando o processo criogênico para resfriamento do material da bobina de campo magnético. Estes conceitos também podem ser aplicados para ressonâncias magnéticas de baixo campo, e para isso, exclui-se os conceitos referentes à parte de criogenia, porque nas ressonâncias magnéticas de baixo campo, o campo magnético é formado diretamente por um imã permanente.

\subsection{BREVE HISTÓRICO SOBRE A DESCOBERTA DE RM}

De acordo com (SCHNELL; RENZ; VESTER MARKUS ERMERT, 2000), o processo da ressonância magnética nuclear foi descoberto por Bloch (BLOCH et al., 1946) e Purcell (PURCELL; TORREY; POUND, 1946) em 1946. Eles constataram que certos núcleos de átomos após serem estimulados por um campo magnético externo, emitiam ondas eletromagnéticas que poderiam ser detectadas por antenas de rádio-frequências. Estas frequências dependiam da intensidade do campo magnético e do tipo de núcleo estimulado.

De 1973 a 1975, (LAUTERBUR, 1973) e (KUMAR; WELTI; ERNST, 1975) desenvolveram o processo de reconstrução de imagens tomográficas, utilizando as coordenadas de Fourier para aquisição de imagens de RM.Precisava-se, na ocasião, determinar o melhor núcleo atômico a ser utilizado em processos de RM.

O corpo humano é composto por, aproximadamente, de 50 a $75 \%$ de parte líquida (MCROBBIE et al., 2006), e esta porcentagem diminui com o evoluir da idade. Geralmente, após os 60 anos, a proporção é de aproximadamente 50\%. Sendo que, a maior parte líquida é formada principalmente por água, que é composta por duas moléculas de Hidrogênio e uma de Oxigênio, dessa forma, pode-se concluir que a composição corporal é composta, em sua maioria, por moléculas de Hidrogênio.

Assim, definiu-se (MCROBBIE et al., 2006) que a RM nuclear seria sintonizada na molécula de Hidrogênio, mais precisamente em seu spin, para análise direta de $75 \%$ do corpo humano (partes moles), com alta precisão, pois a imagem de RM é formada pela representação da densidade dos spins de Hidrogênio, no espaço analisado. Os outros $25 \%$ seriam analisados de forma indireta (exclusão de água - exclusão do spin de Hidrogênio)(MCROBBIE et al., 2006). 
Normalmente, o spin da molécula de Hidrogênio tem rotação e translação em todas as direções. A frequência de rotação e translação deste spin é de 42,6 MHz, conforme ilustrado na Figura 1. Ao se aplicar este spin a uma energia magnética de mesma frequência, observou-se que os mesmos ficam alinhados às linhas do campo magnético externo e, ao retirar este campo magnético externo, os spins voltam às suas características iniciais, não perdendo e nem diferenciando-se de suas características. Portanto, o exame de RM é totalmente não invasivo, contrário ao exame de tomografia computadorizada, por exemplo, e de medicina nuclear, por meio dos quais o corpo recebe uma alta dose de radiação em suas respectivas energias (NGUYEN PATRICIA K.AND WU, 2011).

Figura 1 - Figura do Spin da molécula de Hidrogênio.

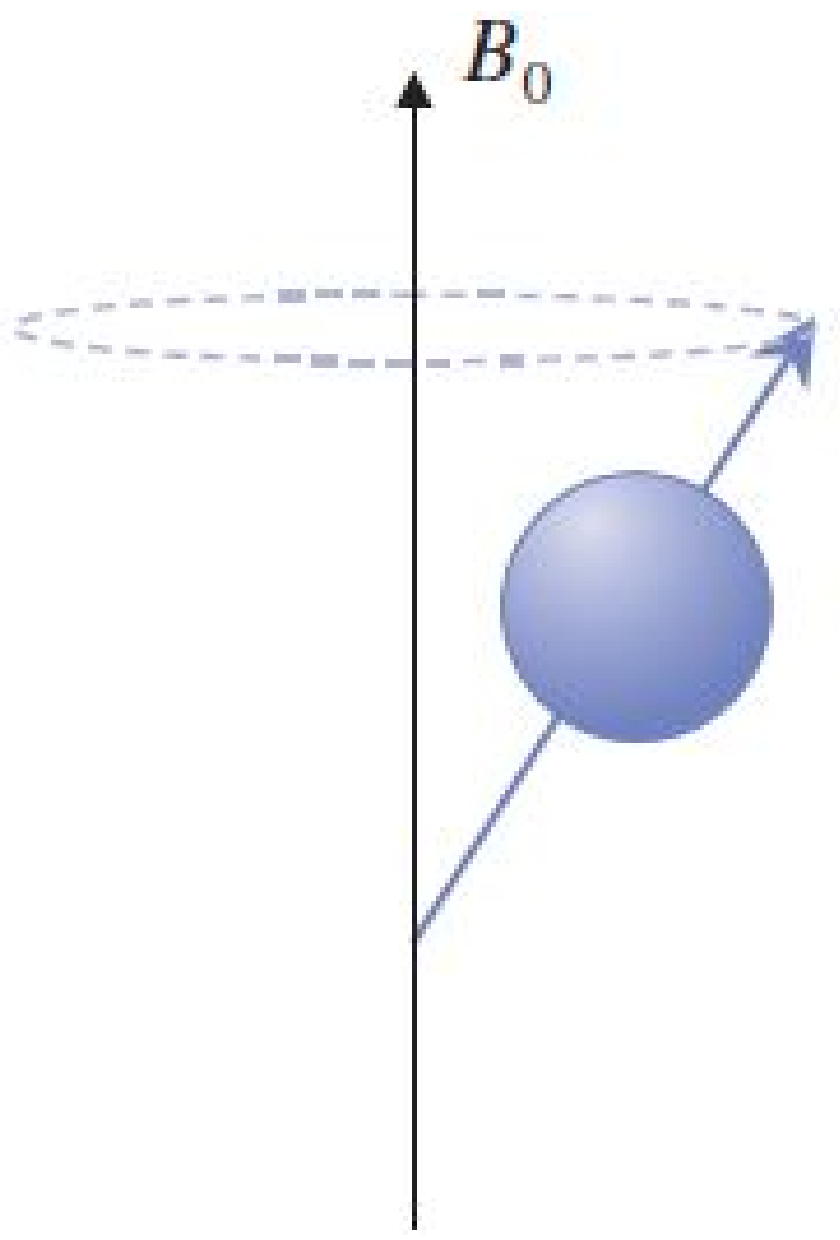

Fonte: McRobbie et al., 2006. 


\subsubsection{Lei de LARMOR}

De acordo com a Lei de Larmor, demonstrada na Figura 2, é possível relacionar a frequência de oscilação do spin da molécula de Hidrogênio ao campo magnético. Logo, podese determinar que para uma frequência de $42,6 \mathrm{MHz}$ há a necessidade de se construir um campo magnético de 1Tesla (T) (MCROBBIE et al., 2006).

Figura 2 - Demonstração de Larmor.

$$
\begin{aligned}
& \text { Derivation of the Larmor frequency: classical } \\
& \text { mechanics } \\
& \text { We use vector notation in the boxes in this chapter } \\
& \text { because direction is important. Vectors are written } \\
& \text { in bold upright font, while their corresponding mag- } \\
& \text { nitudes are in italics, with subscripts to show com- } \\
& \text { ponent magnitudes where appropriate. } \\
& \text { The magnetic moment } \mu \text { is directly proportional } \\
& \text { to the angular momentum J } \\
& \boldsymbol{\mu}=\gamma \mathbf{J} \\
& \text { where } \gamma \text { is the gyromagnetic ratio. When this } \\
& \text { moment is in an external field } \mathbf{B} \text { it experiences a } \\
& \text { torque and precesses about the field, its angular } \\
& \text { momentum changing according to the equation } \\
& \left|\frac{d \mathbf{J}}{d t}\right|=|\boldsymbol{\mu} \times \mathbf{B}|=\mid \gamma \mathbf{J} \times \mathbf{B}=\gamma / \text { Bsin } \theta
\end{aligned}
$$

where $\theta$ is the angle between the magnetic moment and the main field. From basic geometry (figure 8.1) we can see that $\mathrm{d} J$ is given by

$d J=J \sin \theta d \phi$

Combining these two results we can show that the precessional frequency is given by

$\omega=\frac{d \phi}{d t}=-\frac{d \phi}{d \mathbf{J}}, \frac{d \mathbf{J}}{d t}=\frac{1}{\mathbf{J} \sin \theta} \cdot-\gamma / B \sin \theta$

$\omega_{0}=\gamma B_{0}$

The minus sign, which we quietly dropped just before the last line, is there to make sure that $\omega_{0}$ defines a clockwise rotation about the $z$ axis. So the magnetic moment precesses clockwise about $B_{0}$ at an angular frequency of $\omega_{0}$ or a scalar frequency of $f_{0}$ if you prefer to use $\gamma=42.57 \mathrm{MHz}^{-1}$.

Fonte: McRobbie et al., 2006. 


\subsubsection{Primeiro Experimento In Vivo}

Em 1976, Mansfield e Maudsley (MANSFIELD; MAUDSLEY, 1976) realizaram o primeiro experimento em ser vivo, utilizando bobinas de gradiente para estímulo dos spins da molécula de Hidrogênio. O sistema utilizado foi de $15 \mathrm{MHz}$, equivalente a um campo magnético de aproximadamente 0,35T, de acordo com a Lei de Larmor. O esquema básico do equipamento utilizado por Mansfield é mostrado na Figura 3. Pelo equipamento, conseguiram separar, via Figura 3 - Equipamento de Mansfield.

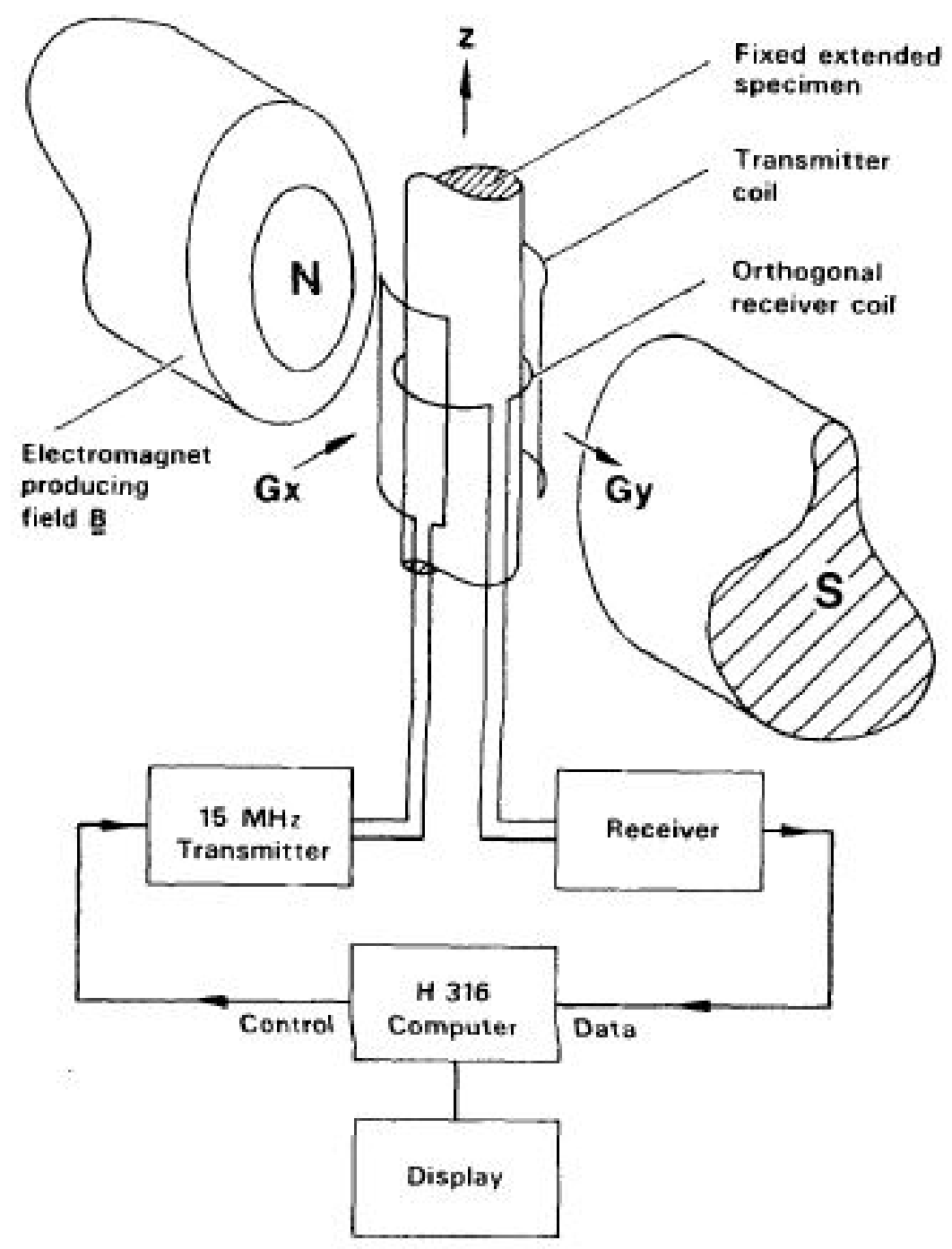

Simplified representation of the $15 \mathrm{MHz}$ NMR imaging apparatus, The field gradient coils producing $\mathrm{G}_{\mathbf{x}}$ and $G_{\mathbf{y}}$ are not shown.

Fonte: MAnsfield e MAudsley, 1976.

rádio-frequência, os spins relacionados a uma área tridimensional, sendo que os gradientes $\mathrm{x}$ 
e y determinavam a área, e o gradiente $\mathrm{z}$ determinava a espessura, informando o volume a ser analisado, conforme Figura 4. A patologia de um corte axial feito na área do dedo é ilustrada na Figura 5 e as imagens obtidas pelo experimento em preto e branco e colorido nas Figuras 6 e 7 respectivamente.

Figura 4 - Método de Mansfield.

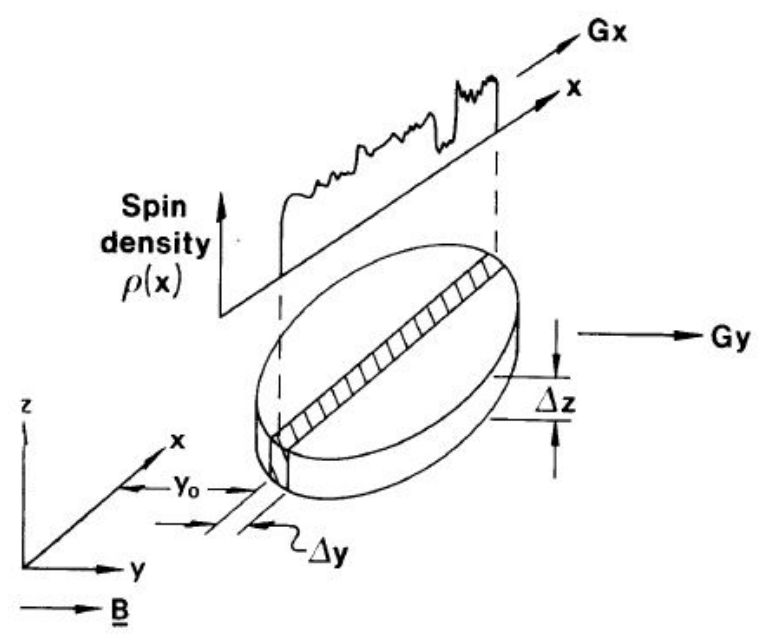

Sketch illustrating the principle of line scanning by selectively irradiating a narrow strip within an isolated slice of magnetization.

Fonte: MAnsfield e MAudsley, 1976.

Figura 5 - Patologia do corte axial do dedo.

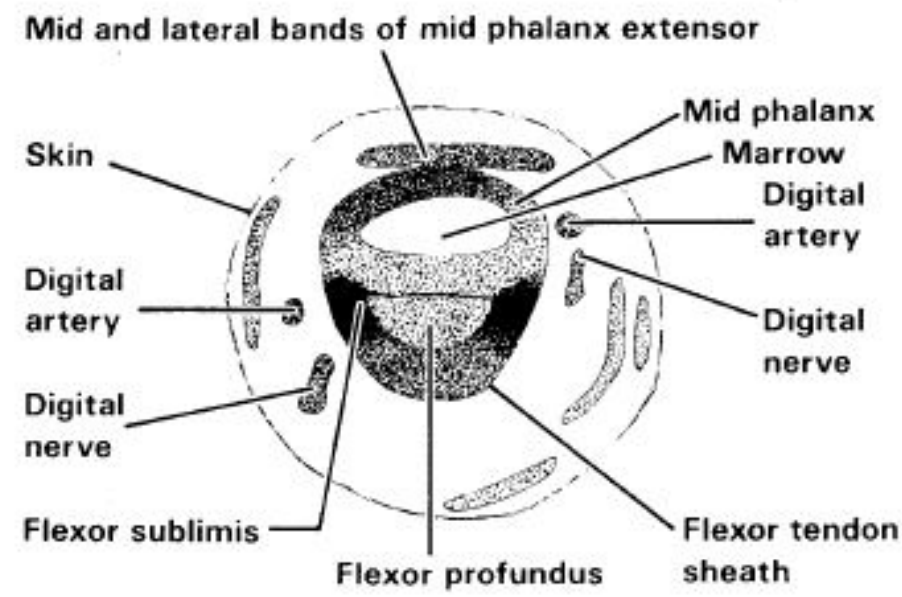

A reduced tracing from Fig. $4 \mathrm{~A}$ showing the recognizable anatomical detail that we have been able to obtain from it.

Fonte: MAnsfield e MAudsley, 1976. 
Figura 6 - Corte axial do dedo obtido por Mansfield em preto e branco.

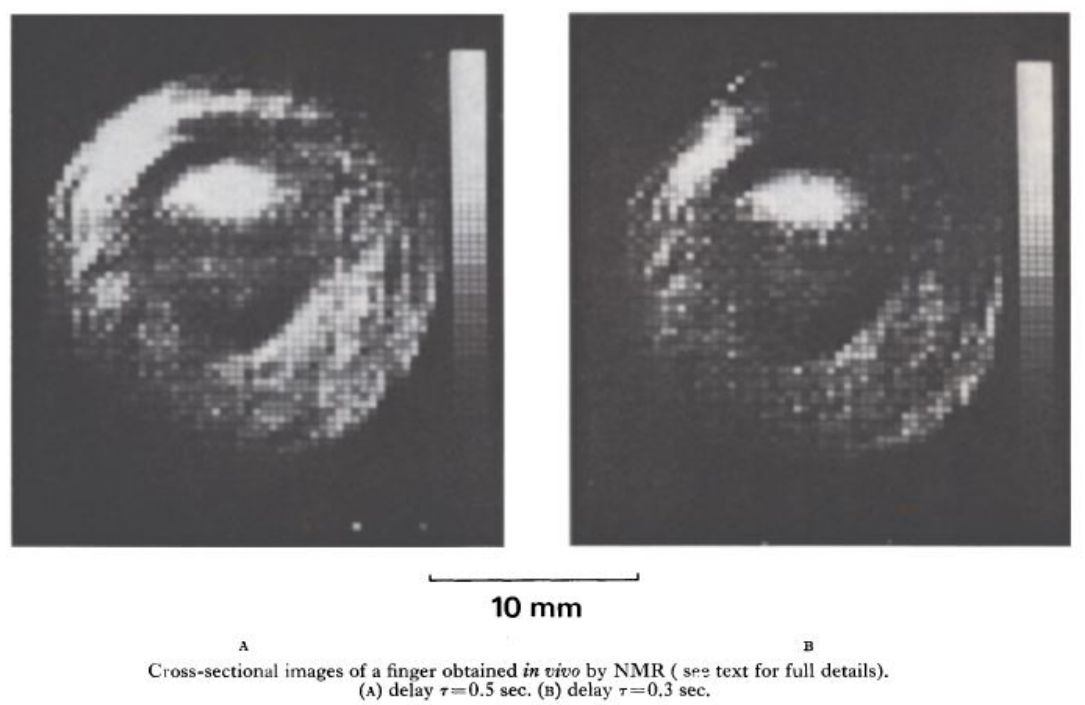

Fonte: MAnsfield e MAudsley, 1976.

Figura 7 - Corte axial do dedo obtido por Mansfield em colorido.

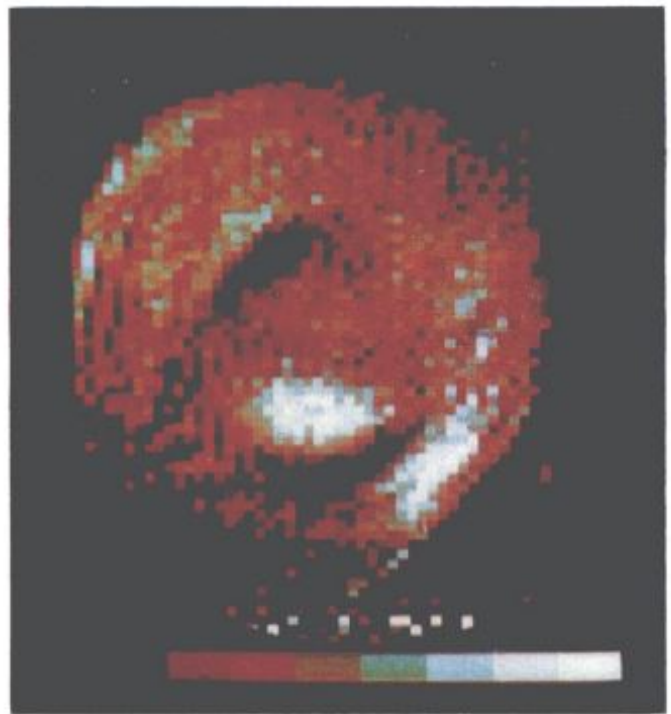

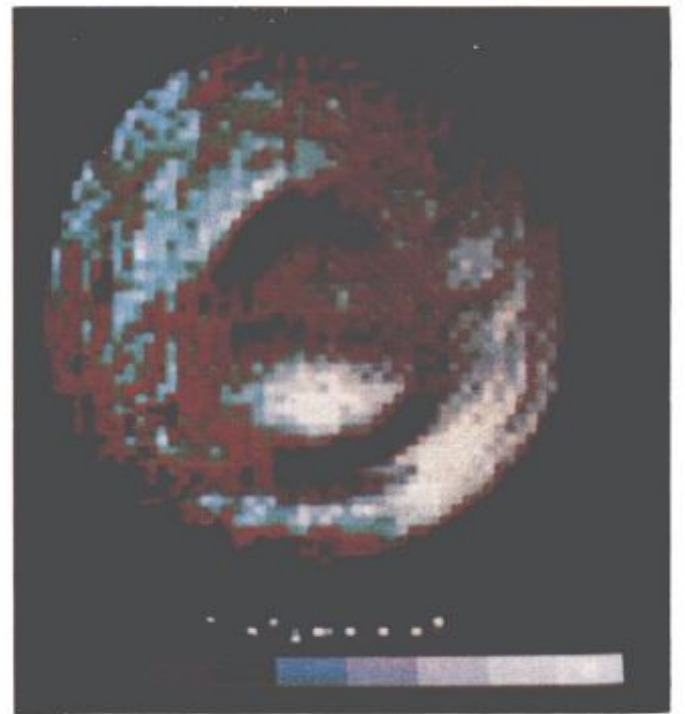

B

Colour versions of the finger images shown in Figs. $4 \mathrm{~A}$ and $\mathrm{B}$.
(A) The eight colours black through to white correspond to data levels $6-13$. The delay time $r=0.5 \mathrm{sec}$ (B) The eight colours black through to white correspond to data levels 2-9. In both pictures, data falling outside the window limits are presented as all black or all white as appropriate.

Fonte: MAnsfield e MAudsley, 1976.

\subsection{TIPOS DE EQUIPAMENTOS DE RM COMERCIAIS}

Em relação à intensidade do campo magnético, há equipamentos de RM denominados de campo baixo (até 1.0T) e de campo alto (acima de 1.0T) disponíveis no âmbito comercial. 


\subsubsection{RM de Campo Baixo}

Os campos abaixo de 1.0T são, em sua grande maioria, construídos de imãs permanentes. O maior campo obtido através destes modelos de RM é de 0,35T (MCROBBIE et al., 2006). Devido a este tipo de aparelho ter um campo magnético de menor potência, as imagens obtidas são de menor qualidade, pois é menor a força magnética necessária para a movimentação dos spins de Hidrogênio. Estas ressonâncias podem ser de extremidades ou de corpo inteiro, conforme exemplificado na Figura 8.

Figura 8 - Ressonâncias de baixo campo.

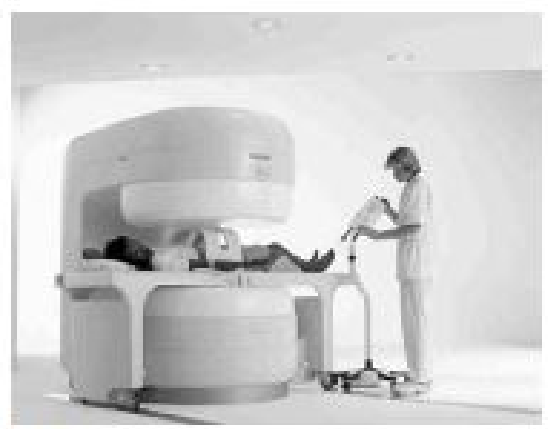

(a)

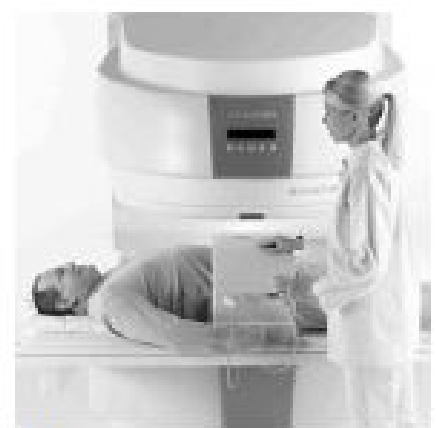

(b)

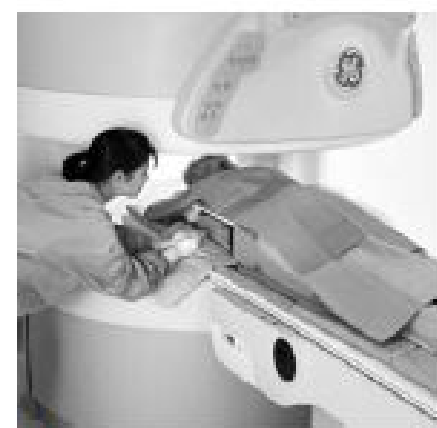

(c)

Figure 9.2 Commercial examples of resistive, permanent and superconducting magnets. (a) 0.23 T Philips Panorama, (b) $0.23 \mathrm{~T}$ Siemens Magnetom C, (c) $0.7 \mathrm{~T}$ General Electric 0penSpeed. All three systems are "oper" and have vertical main fields B.

Fonte: McRobbie et al., 2006.

\subsubsection{RM de Campo Alto}

As RM de campos, acima de 1T, são construídas por eletroímãs. Para se obter esta intensidade de campo magnético, há a necessidade de se aplicar uma corrente elétrica de intensidade muito alta, entre 170 à 250 Ampéres, de acordo com cada fabricante do equipamento. Além disso, a fonte de corrente deve ser muito precisa, pois a diferença de alguns mili Ampéres seria suficiente para alterar o campo magnético, e, consequentemente, a frequência de trabalho (ONI, S., 2007). Esta ressonância de campo alto, esquematicamente exemplificada na Figura 9, pode ser de corpo inteiro ou de extremidades. 
Figura 9 - Ressonância de alto campo magnético.

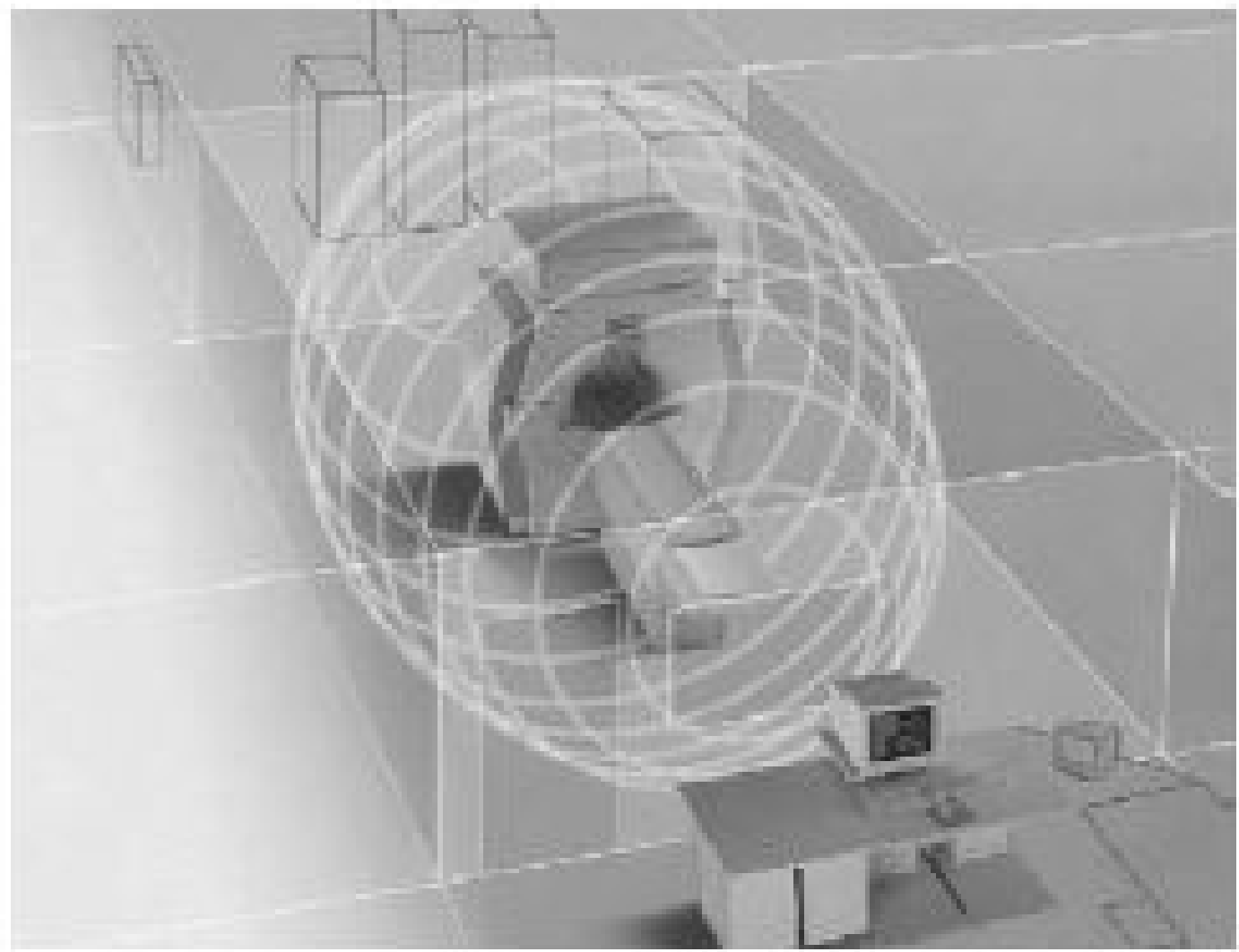

Fonte: McRobbie et al., 2006.

\subsubsection{RM de Corpo Inteiro}

As RM de corpo inteiro são equipamentos construídos para a realização de exames de todas as partes do corpo. Composto de um grande eletroímã, contém um cilindro em seu centro de, aproximadamente, $70 \mathrm{~cm}$ de diâmetro por $220 \mathrm{~cm}$ de comprimento (para os equipamentos de alto campo - criogênicos), e uma abertura de, aproximadamente, $50 \mathrm{~cm}$ para os equipamentos de baixo campo, com imã permanente, de acordo com a especificação de cada fabricante. $\mathrm{O}$ paciente é introduzido nesta abertura, de forma que a parte a ser analisada fique, se possível, no centro espacial desta abertura, onde a homogeneidade do campo deve ser a mais correta possível.

\subsubsection{RM de Extremidades}

A partir da ressonância de alto campo, construiu-se a ressonância para exames de extremidades humanas. 
Este equipamento tem as mesmas características principais do equipamento de campo inteiro, mas em dimensões reduzidas. No caso da ressonância de alto campo para extremidades, o cilindro interno é de $20 \mathrm{~cm}$ de diâmetro por $60 \mathrm{~cm}$ de comprimento, garantindo um campo muito mais homogêneo e permitindo exames de todas as extremidades do corpo humano, como exemplificado na Figura 10.

Este tipo de equipamento é que será investigado e utilizado nesta dissertação.

Figura 10 - Ressonância de Extremidades de alto campo magnético.

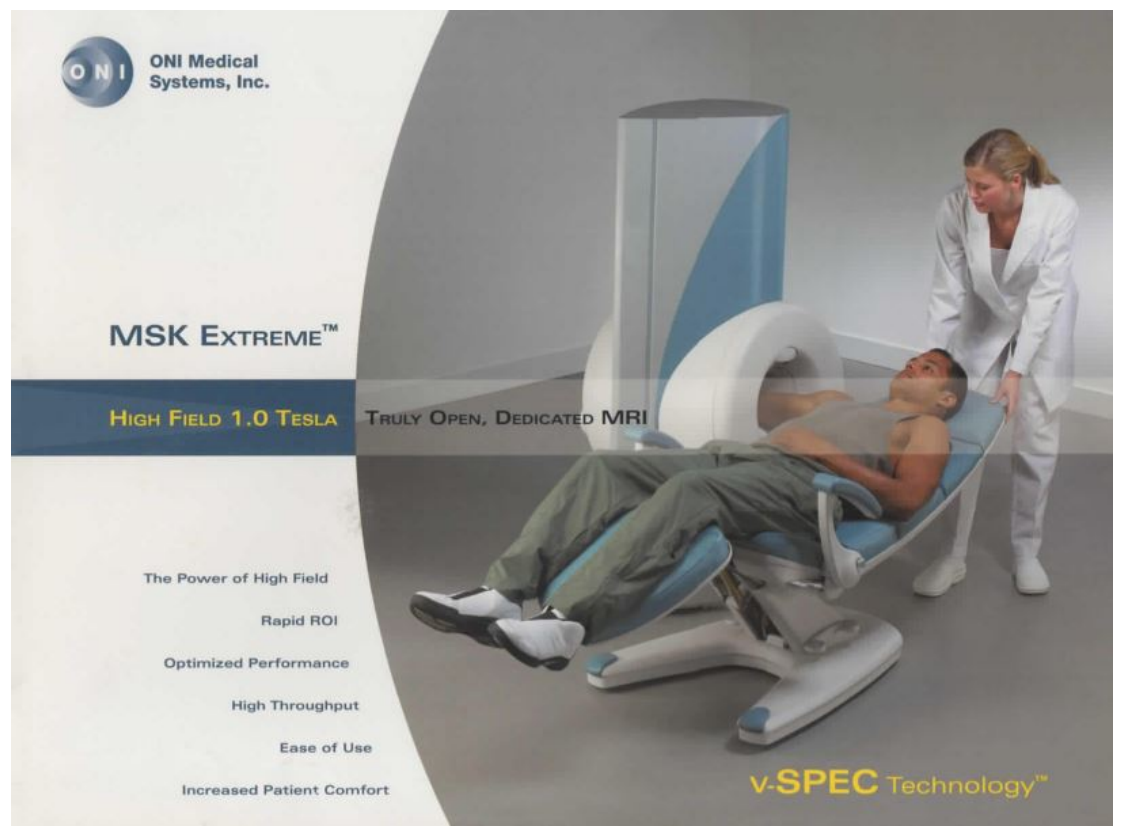

Fonte: Systems Oni, 2007.

\subsection{FUNCIONAMENTO DO EQUIPAMENTO DE RM DE CAMPO ALTO}

\subsubsection{O Supercondutor}

Para solucionar o problema da instabilidade de corrente, e consequentemente a instabilidade do campo magnético, criou-se uma bobina para criar o campo magnético de material supercondutor (MCROBBIE et al., 2006). Basicamente, aplica-se uma corrente elétrica e ao chegar ao campo magnético desejado fecham-se os terminais da bobina. A corrente elétrica aplicada permanecerá circulando pela bobina, mantendo o campo magnético constante, estável e independente do fornecimento de energia externa, devido ao material supercondutor. 


\subsubsection{O Sistema Criogênico}

Para se obter o material supercondutor, há a necessidade de colocar o material não supercondutor em temperatura de aproximadamente 0 Kelvin (zero absoluto) (MCROBBIE et al., 2006). Este zero absoluto é obtido imergindo o material da bobina de campo magnético em Hélio líquido, pois o ponto de ebulição do Hélio está em aproximadamente 4K (JUNIOR, 2010). Figura 11 - Sistemas de temperatura da ressonância de extremidades.

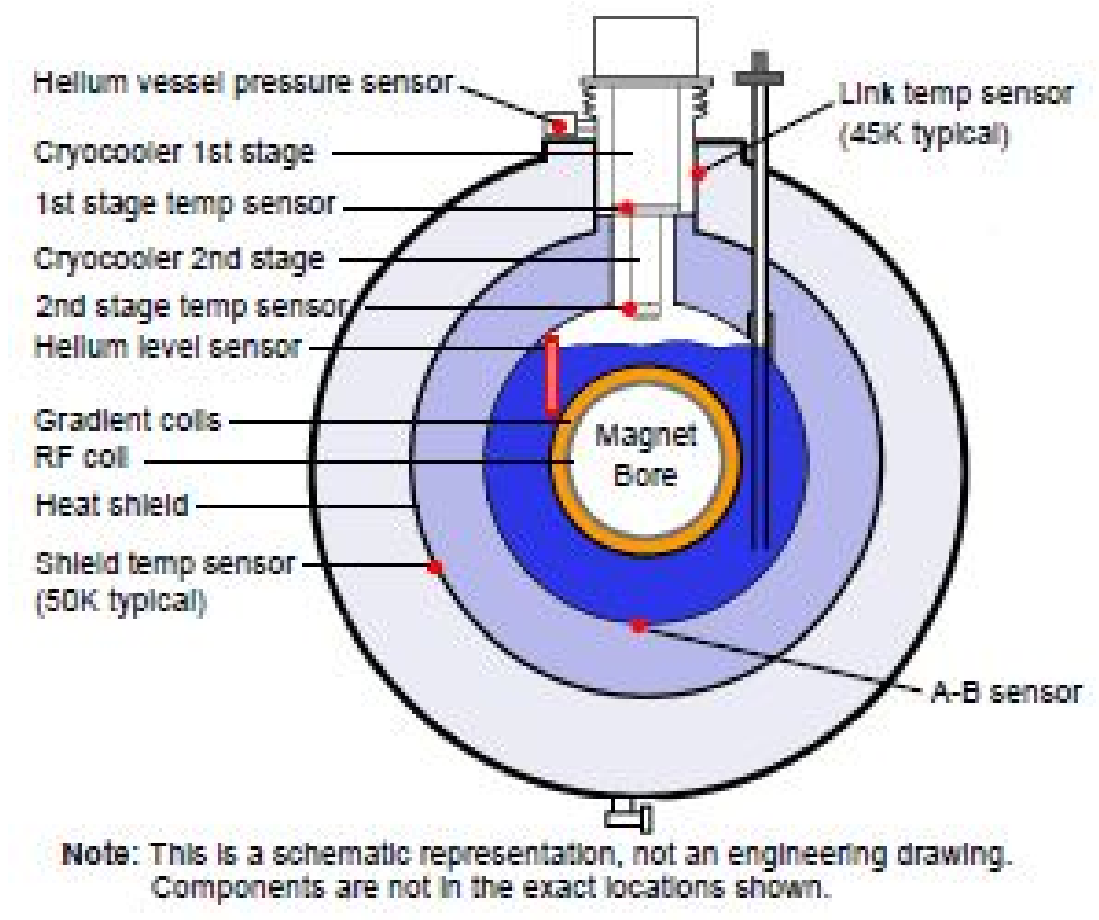

Fonte: M. S. Oni, 2005.

Por meio de um compressor e um dispositivo expansor de gás Hélio (chamado de cold head), realiza-se uma reação isovolumétrica ou isocórica, em que mantem-se o mesmo volume do gás Hélio e varia-se a sua pressão em dois estágios (SUMITOMO, 2003). O compressor comprime o gás Hélio (elevando sua temperatura) e o Hélio comprimido é expandido internamente na cold head. Pela diminuição da pressão, ocorre também a diminuição da temperatura, fazendo com que a extremidade inferior da cold head fique mantida em 4 Kelvin, temperatura que é utilizada para resfriar o Hélio líquido, mantendo o material da bobina de campo magnético na temperatura do Hélio líquido, sem ocorrer a evaporação do mesmo. A Figura 11 ilustra o sistema de temperaturas em equipamento de extremidades.

Para que o Hélio líquido sofra menos com a temperatura externa (temperatura ambiente acima de 300 Kelvin), usa-se o princípio da garrafa térmica, isolando o recipiente de Hélio 
líquido interno no magneto, através de um sistema espelhado feito de folha de papel alumínio adicionado a um vácuo extremo na faixa de micro a nano Bar.

\subsubsection{O Campo Magnético}

Com a bobina de campo energizada, por uma corrente elétrica constante, haverá um campo magnético de extrema potência (1.0 T) também constante (MCROBBIE et al., 2006). Ao colocar o corpo humano dentro deste campo, garante-se que todos os spins da molécula de Hidrogênio fiquem alinhados em função das linhas deste campo magnético aplicado (MANSFIELD; MAUDSLEY, 1976).

\subsubsection{Bobinas de Gradiente}

Um segundo campo magnético externo pulsado, gerado pelas bobinas de gradiente na mesma frequência de $42,6 \mathrm{MHz}$, em contraposição ao campo principal, irá deslocar os spins das moléculas de Hidrogênio em 90 graus em relação ao campo principal (MCROBBIE et al., 2006).

Com a finalidade de criar uma imagem 2D, sempre haverá a energização de duas das três bobinas de gradiente. A terceira bobina de gradiente sempre será usada para definir a faixa de spins que serão deslocados de 90 graus. A esta faixa de spins fornece-se o nome de espessura de corte. Com plano formado pelas duas bobinas iniciais e a espessura realizada pela terceira bobina, define-se o volume a ser analisado (MCROBBIE et al., 2006).

\subsubsection{O Sistema de Rádio-frequência}

No momento em que a energia das bobinas de gradiente é retirada, os spins tenderão a retornar seus movimentos de rotação e translação na direção do campo magnético principal. Neste processo de retorno, translação e rotação na direção do campo principal, os spins de Hidrogênio liberam energia.

Esta energia é captada pela bobina de radiofrequência que também fica ao redor do corpo humano. São captadas do mesmo modo que os equipamentos de rádio captam as energias através das antenas dos sistemas receptores. Assim, todo equipamento de RM tem em sua construção um gerador de radiofrequência, um amplificador de radiofrequência, um receptor 
Figura 12 - Sistema completo da ressonância de extremidades.

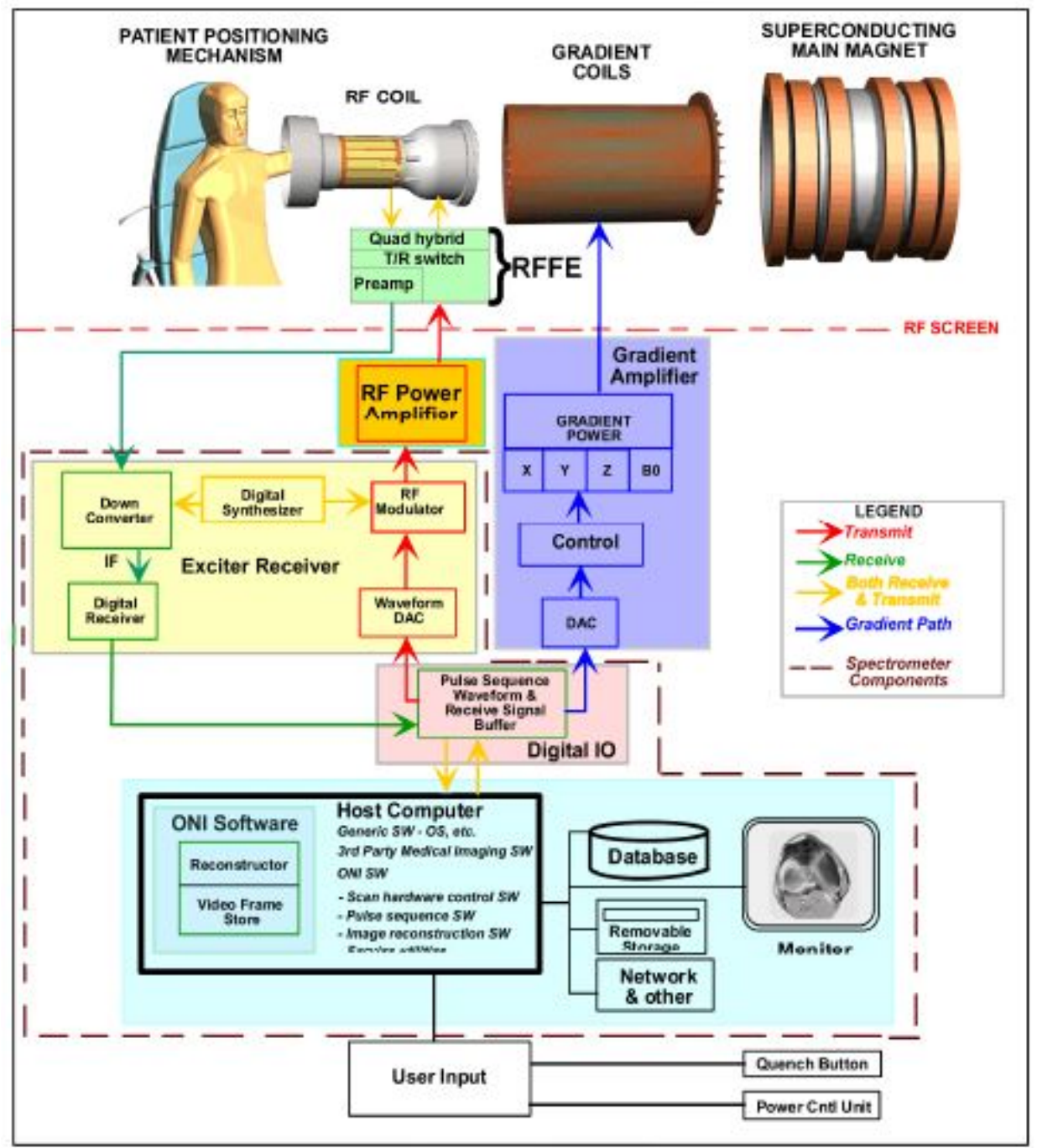

Fonte: M. S. Oni, 2005.

de radiofrequência e um decodificador que funcionam baseados nas teorias de Fourier, como ilustrado esquematicamente na Figura 12 (ONI, S., 2007).

\subsubsection{Gaiola de Faraday}

Devido ao equipamento usar radiofrequências em sua operação, há a necessidade de que o mesmo seja todo envolto em uma gaiola de Faraday, para não permitir que radiofrequências externas cheguem ao equipamento.

Ao términano da construção da gaiola de Faraday (ou, como comercialmente chamadas, gaiola de RF) todos os fabricantes devem fazer os testes de confirmação de que a gaiola está atenuando pelo menos $80 \mathrm{~dB}$ para frequências até 100MHz (ONI, M. S., 2005). Para fazê-lo, 
utiliza-se um gerador de RF externamente à gaiola e uma antena instalada em seu interior. Com a porta aberta, ou seja, com a gaiola sem efeito, verifica-se o valor obtido pela antena receptora. Fecha-se a gaiola e faz-se o mesmo teste e há a conferência do valor obtido verificando se está no mínimo 80dB, menor que o anterior (ONI, M. S., 2005).

\subsubsection{O Ruído da Imagem}

Mesmo com a melhor gaiola possível de RF, pode ocorrer de entrar na sala algumas frequências indesejáveis, e que quase sempre são impossíveis de retirar. Estas frequências indesejáveis são denominadas ruído (MCROBBIE et al., 2006).

Desde a invenção da RM, os maiores problemas e estudos realizados são no sentido de diminuir os ruídos da imagem, diminuir os tempos dos exames e melhorar a qualidade das imagens. Estes três fatores estão diretamente relacionados.

Para melhorar a qualidade de imagem, pode-se aumentar a quantidade de amostragem, capturando para o mesmo ponto duas a três amostras e fazendo a média do ponto. Se uma sequência com uma amostra demorar 5 minutos para ser realizada, capturando duas amostras, esta sequência passará para 10 minutos e consecutivamente para 3 amostras, passará para 15 minutos. Este tempo é muito longo, considerando que cada exame completo deve ter no mínimo 6 sequências. Um exame completo poderá demorar 90 minutos para ser realizado, implicando em 90 minutos da pessoa sem se mover, dentro de um túnel, muitas vezes claustrofóbico e, se ocorrer do paciente se mexer, a sequência deverá ser totalmente repetida, aumentando ainda mais o tempo de aquisição da imagem.

Obviamente, se for diminuído o tempo de aquisição, diminuindo a quantidade de amostragem da imagem, a qualidade de imagem final será piorada, pois a interferência dos ruídos será ressaltada na imagem final.

\subsection{TIPOS DE RUÍDO DA IMAGEM}

Todo exame de RM nuclear tem como resultado final uma imagem da patologia que se deseja analisar.

Esta imagem é composta de sinais referentes aos spins de Hidrogênio pertencentes à patologia que foi submetida ao campo magnético e aos pulsos de rádio frequência e também 
pelos sinais referentes a outras fontes que estão dentro da sala de exames, que inclui o aparelho de RM nuclear.

Se os ruídos de fundo são constantes, de baixa intensidade, de forma a não serem vistos diretamente na imagem e independentes do tipo de exame, chamamos de fantasmas (ghost), como mostra a Figura 13.

Figura 13 - Exemplo de ghost em ressonância magnética.

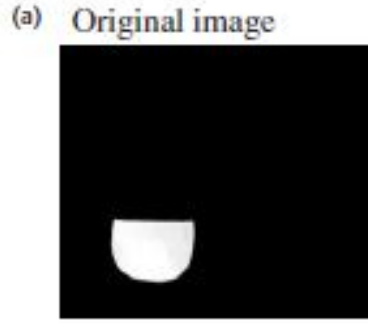

\section{Windowed image}

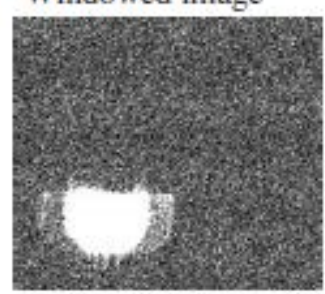

(b) Measurement ROIs

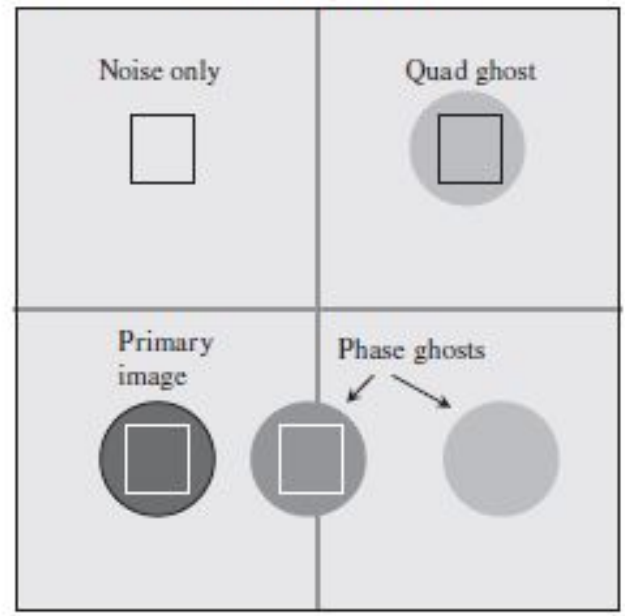

Figure 11.10 Ghosting. (a)

Extreme windowing is

usually required to see the

ghosts. (b) Schematic

diagram of ROI positions

for signal-ghost ratio

measurement.

Fonte: McRobbie et al., 2006.

Entre alguns tipos de ruídos, pode-se citar (GONCALVES, 2011):
a) Radio frequência externa;
b) Interferências eletromagnéticas;
c) Interferências ferromagnéticas;
d) Interferências por vibração;
e) Interferências pelo paciente.

\subsubsection{Radiofrequência Externa}

Como os sinais captados pelo equipamento de RM nuclear se referem aos spins das moléculas de Hidrogênio da patologia analisada e como estes spins recebem sinais de rádiofrequência da máquina que fazem os mesmos mudarem suas translações e rotações, qualquer interferência de rádio frequência externa que chegue nestes spins fará com que os mesmos mudem suas rotações e translações de forma diferente, ocasionando efeitos indesejados e modificações na imagem (artefatos) (ONI, S., 2007). 
Caso as radiofrequências sejam operadas em frequências diferentes da frequência central do equipamento, pode haver ruídos ainda maiores na imagem, conforme exemplificado na Figura 14 (ONI, 2003).

Figura 14 - Exemplo de artefato de radio frequência em ressonância magnética.

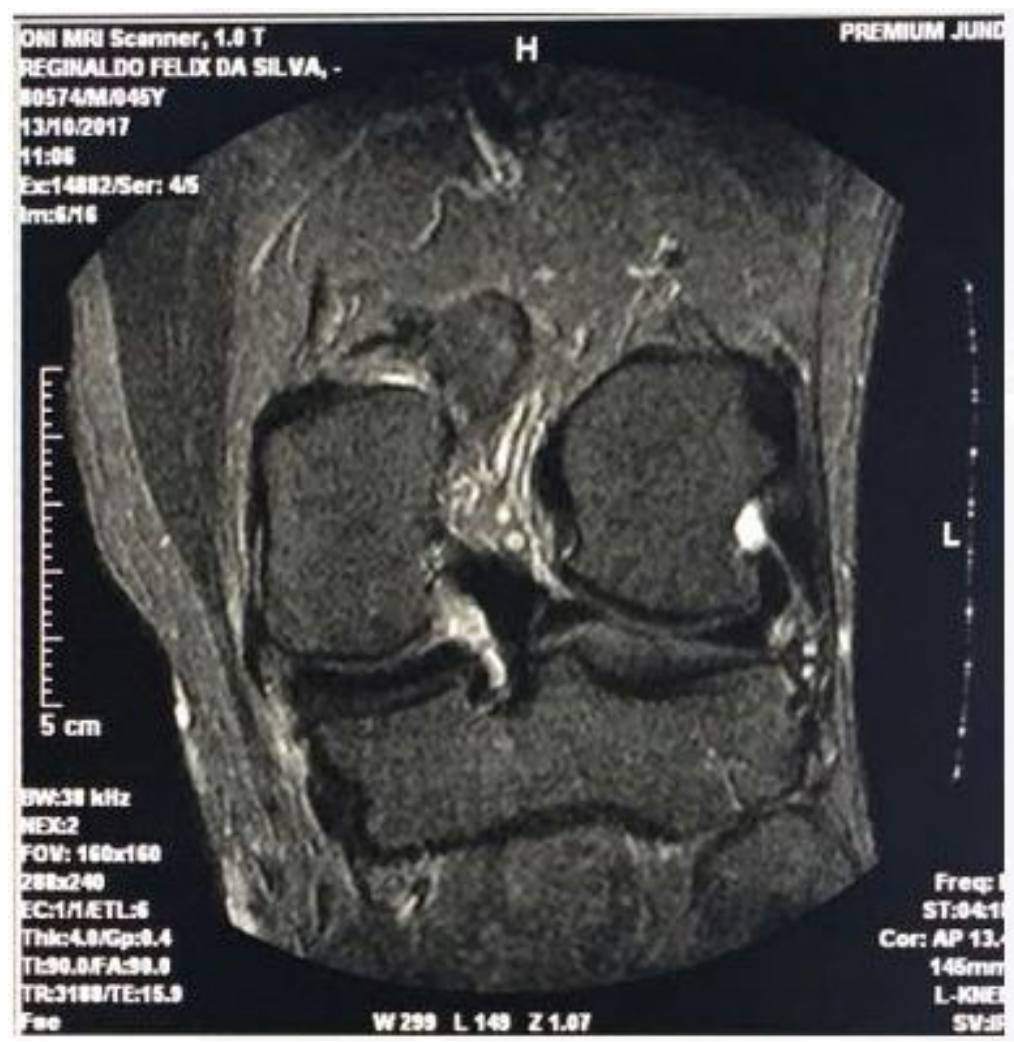

Fonte: Oni, 2003.

\subsubsection{Interferências Eletromagnéticas}

Segundo (GONCALVES, 2011), as interferências eletromagnéticas são as mais difíceis de serem solucionadas, pois podem ser de várias fontes, como, por exemplo:

a) Corrente elétrica próxima ao magneto;

b) Filamentos das lâmpadas incandescentes movendo durante a realização dos exames;

c) Instalação de transformadores ou motores próximos da gaiola de rádio frequência após a instalação e calibração da ressonância;

d) Problemas com a gaiola de rádio-frequência. 
Estas interferências provocam vários tipos de artefatos na imagem. Podem ocorrer linhas verticais ou horizontais (dependendo do protocolo de aquisição da imagem que define como a imagem está sendo adquirida). Podem ocorrer artefatos do tipo cruz na imagem, ou artefatos tipo persiana (imagem mais clara e mais escura) na direção vertical ou horizontal (GONCALVES, 2011) (ONI, 2003).

Geralmente, quando há problemas com a gaiola de radiofrequência, os artefatos são em forma de linhas ou cruz. Quando os artefatos são provenientes de corrente elétrica, estes são geralmente em formato de persiana ou de movimento do paciente, como exemplificado na Figura 15.

Figura 15 - Exemplo de artefato de interferência eletromagnética em ressonância magnética.

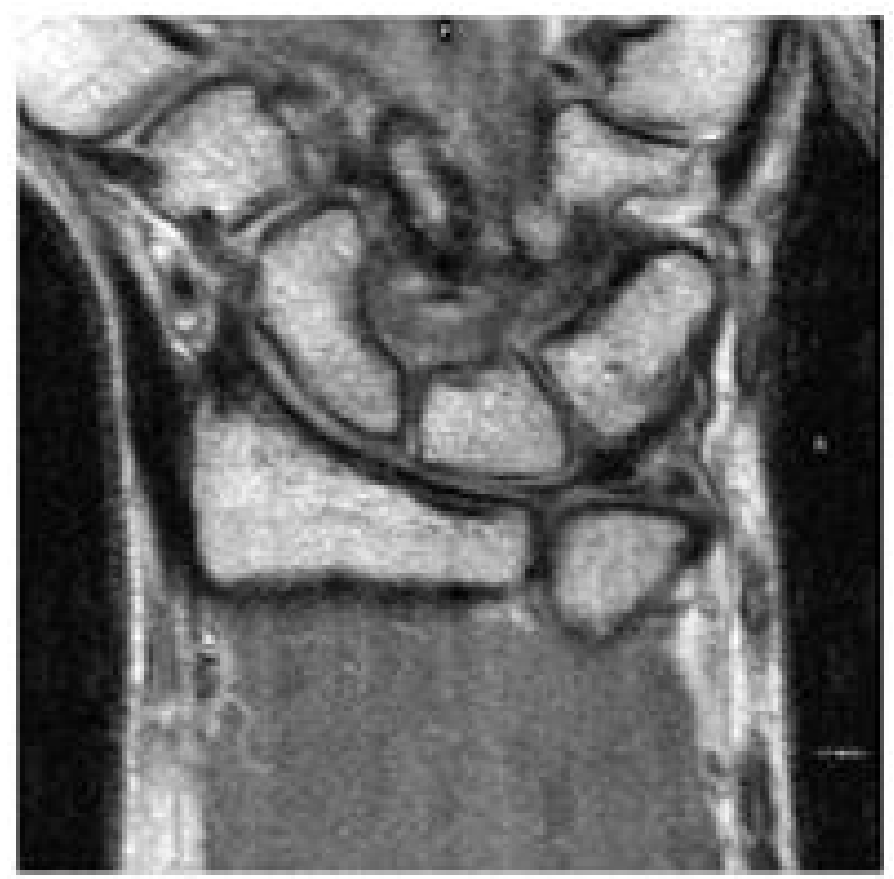

Fonte: Oni, 2003.

\subsubsection{Interferências Ferromagnéticas}

As linhas de campo magnético no interior do equipamento de ressonância magnética devem ser as mais retilíneas possível, de forma a garantir com exatidão as dimensões da patologia que está sendo analisada. 
Como estas linhas são invisíveis, para garantir que estão realmente retilíneas no espaço, usa-se de peças especiais de tamanho e forma conhecidos para checar se o campo está uniforme, como mostrado na Figura 16 (ONI, 2003).

Para realizar ajustes finos no campo magnético, há aberturas em torno do túnel externo ao redor da bobina de campo magnético onde são colocadas varetas com furos para poder fixar metal ou imãs para o ajuste deste campo.

Figura 16 - Exemplo de vareta de shim.

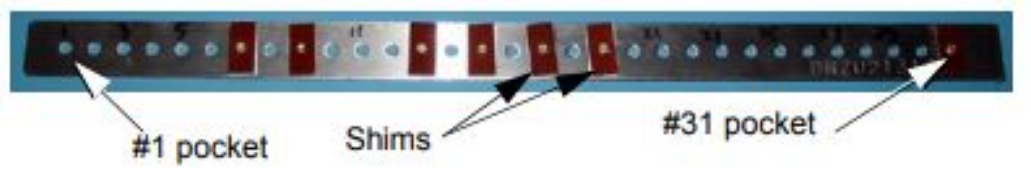

Fonte: Medical, 2007.

Através de um software específico para cada equipamento, sabe-se a quantidade e localização espacial de onde colocar os imãs ou metais para corrigir o campo. Para este processo de calibração das linhas de campo no interior do magneto, chama-se de shimming, ilustrado na Figura 17 (ONI, S., 2007). Após a realização do shimming, todas as linhas de campo deverão estar retilíneas no espaço dentro do túnel de captura de imagens.

Figura 17 - Processo de shimming em ressonância magnética de extremidades.

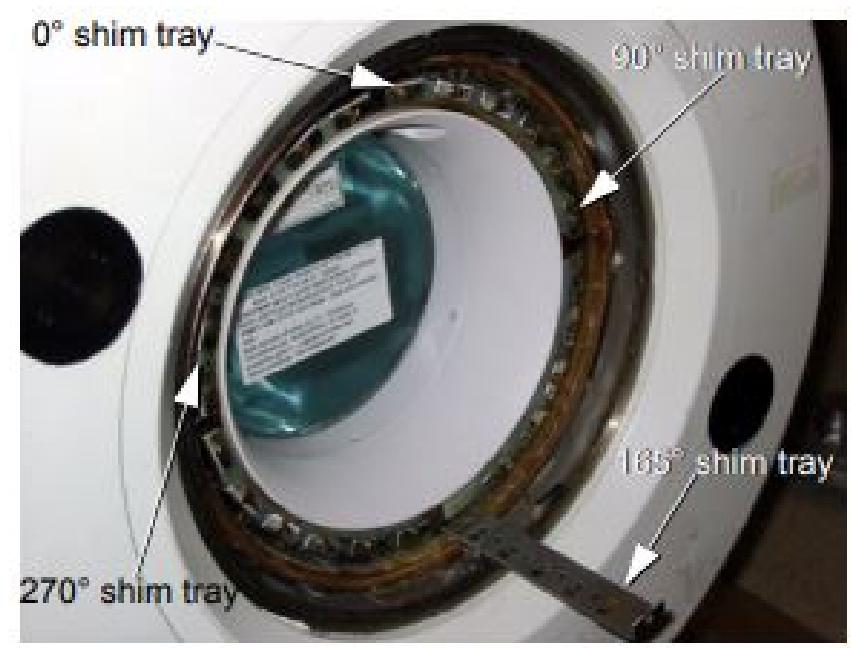

Fonte: Medical, 2007.

O corpo humano não é formado de partes metálicas, desta forma, não afeta as linhas de campo magnético. 
No entanto, uma massa metálica ferromagnética, como ferro, alguns tipos de aço e alguns tipos de metais, podem afetar internamente e/ou externamente o campo magnético do magneto, afetando diretamente suas linhas de campo.

Uma vez alteradas, até que esta massa metálica seja removida, as linhas permanecerão afetadas gerando imagens distorcidas, como mostrado na Figura 18 (MEDICAL, 2007).

Figura 18 - Imagens de patologias com próteses e partes metálicas.

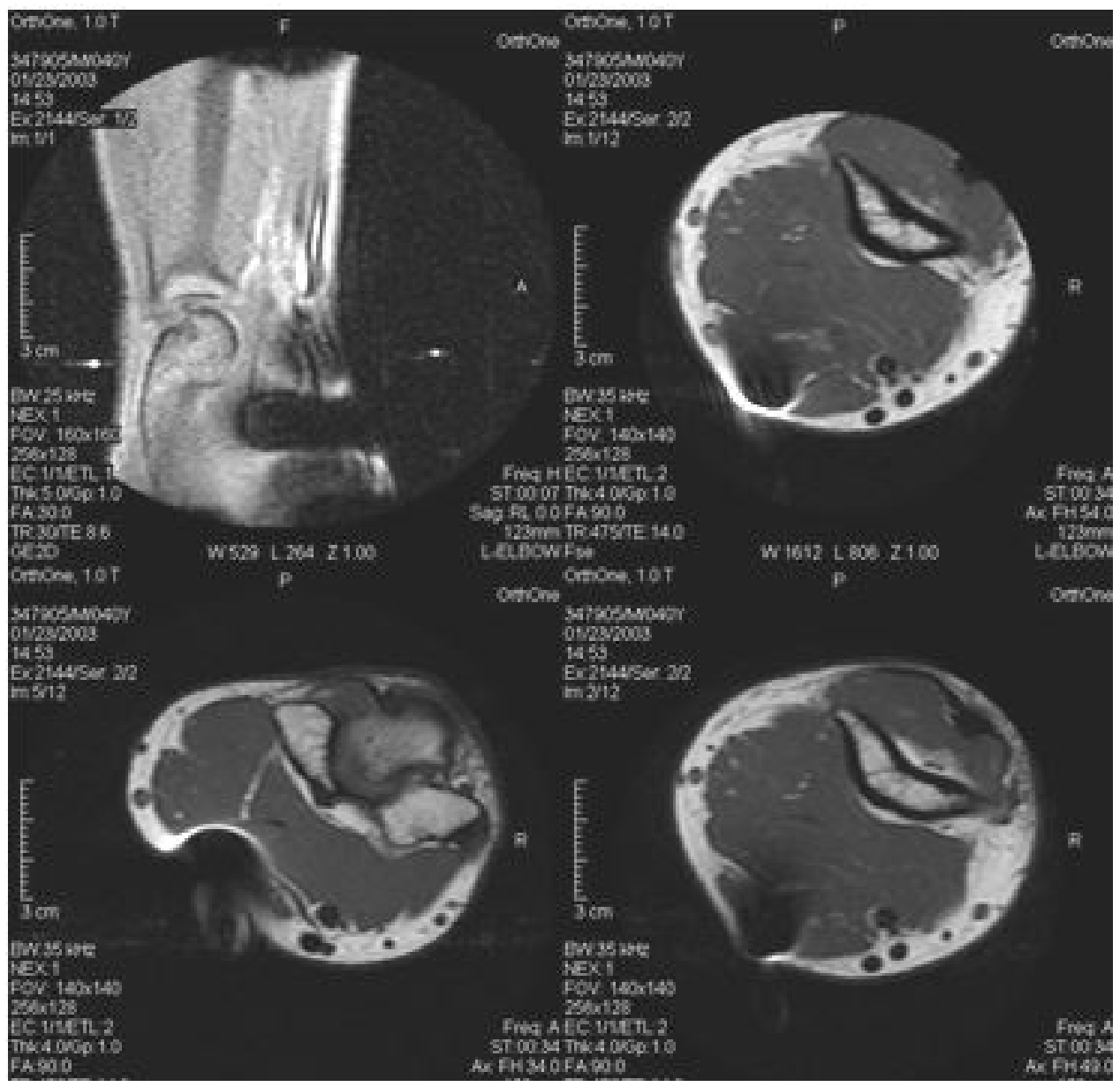

Fonte: Medical, 2007.

\subsubsection{Interferências por Vibração}

No equipamento de ressonância magnética, há alguns itens que funcionam a base de motores e processos mecânicos, como compressores, cold head, motores para entrar e sair o paciente do túnel de análise, entre outros. No caso da RM de extremidades, este item é muito importante, pois devido ao seu tamanho reduzido a sua massa é de apenas $650 \mathrm{~kg}$, muito reduzida se comparada com a massa da ressonância de corpo inteiro de $20.000 \mathrm{~kg}$. 
Pela redução do tamanho, a cold head trabalha muito próxima do corpo do magneto, e seu movimento interno é parecido com o de um pistão de carro, numa frequência de aproximadamente $1 \mathrm{~Hz}$, ou seja, um movimento por segundo (SUMITOMO, 2003).

A massa da cold head (aproximadamente $25 \mathrm{~kg}$ ) deve ser levada em consideração em relação à massa do magneto. Se o magneto sentir a vibração da cold head, ou alguma vibração externa (carros, ônibus, caminhões, trens, ou qualquer outro elemento que faça o chão vibrar, a imagem final poderá aparecer como se o paciente estivesse se movimentado.

Para descobrir se o magneto ou o paciente se moveu, basta colocar um calibrador na máquina e verificar como sai a imagem. O calibrador não se move e neste caso se a imagem aparecer mexida é porque alguma vibração foi sentida, conforme exemplificado na Figura 19 (ONI, 2003).

Figura 19 - Imagem de exemplo de vibração.

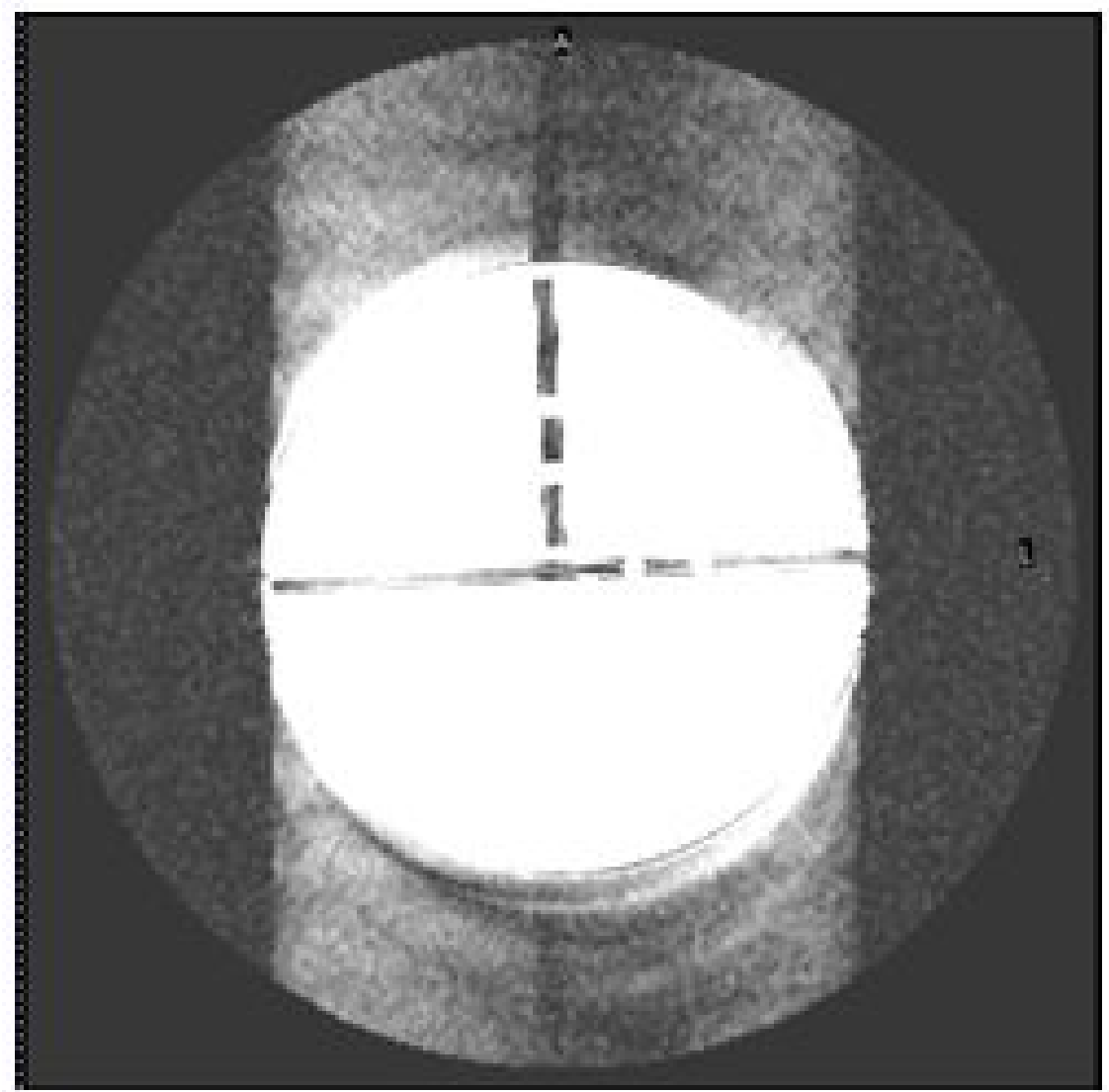

Fonte: Oni, 2003. 


\subsubsection{Interferências pelo Paciente}

Além dos artefatos gerados externamente, há também os artefatos gerados pelo paciente, como por exemplo:

a) Artefato de fluxo;

b) Artefato de movimento.

Há artefatos de movimento de pacientes que podem ser solucionados, enquanto outros não (ONI, 2003). Os artefatos de fluxo, por exemplo, são movimentos involuntários do paciente. Neste caso, nada pode ser feito pelo paciente ou pelo equipamento para resolver. Então, devese aplicar a imagem adquirida a um processamento digital para remover o aspecto de fluxo apresentado na imagem conforme ilustrado nas Figuras 20 e 21 (ONI, 2003).

Figura 20 - Exemplo de artefato de fluxo1.

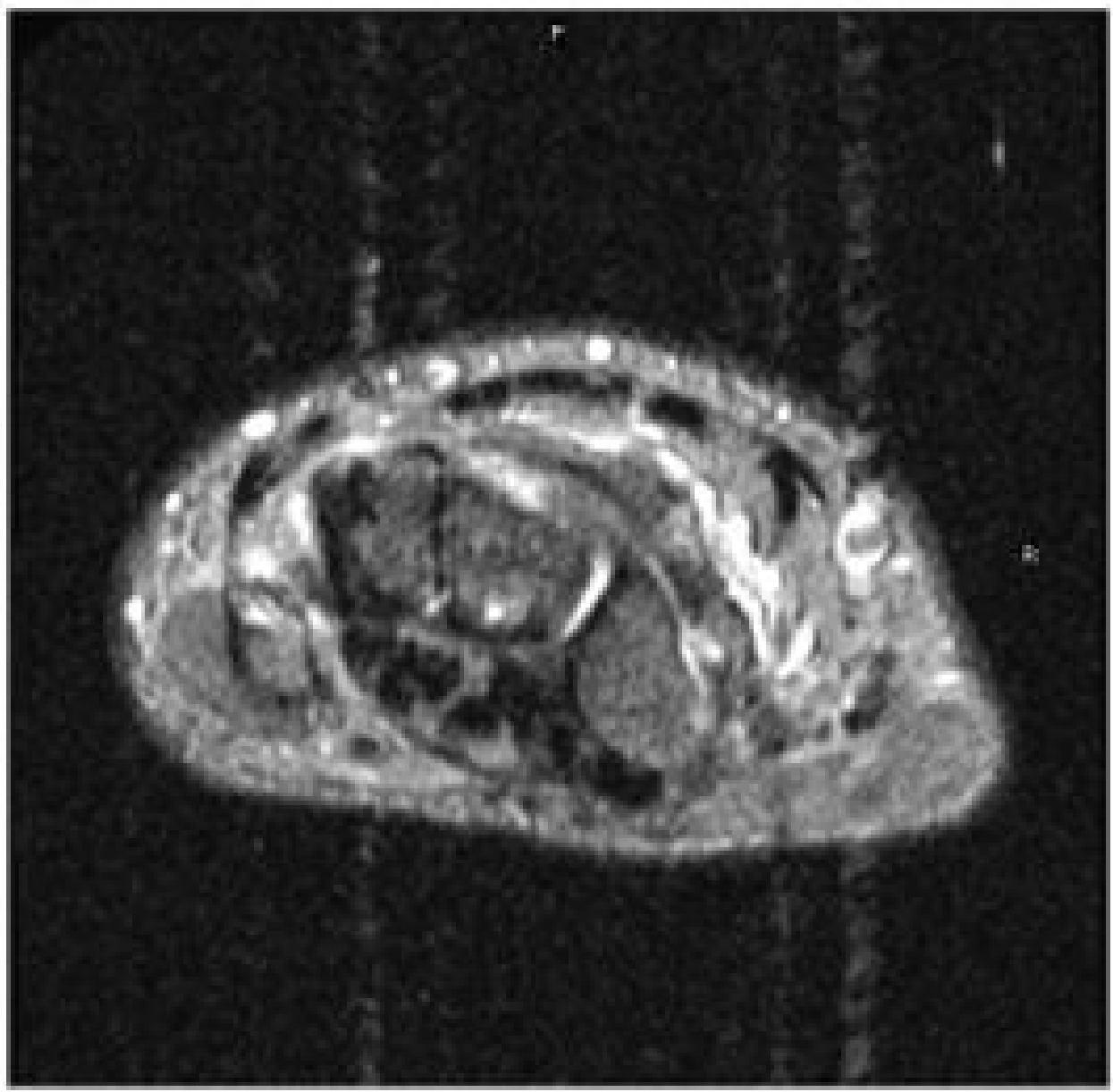

Fonte: Oni, 2003.

No caso do artefato de movimento do paciente, o operador da máquina avisa ao paciente de que ele está se movimentando e terá de repetir a sequência que apareceu ruim. Algumas 
Figura 21 - Exemplo de artefato de fluxo2.

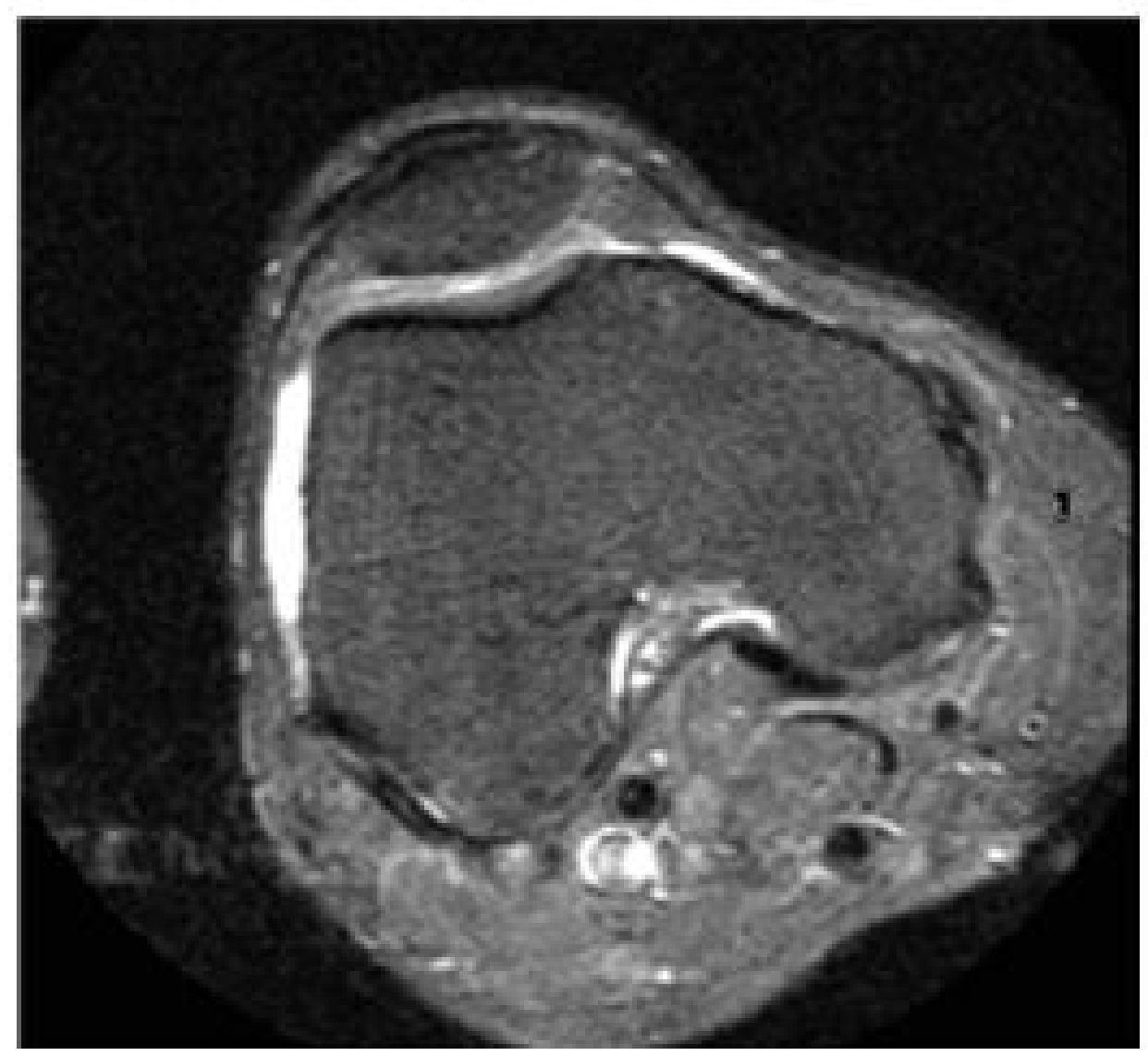

Fonte: Oni, 2003.

vezes, o paciente se mexe por estar com medo, frio, cansado da posição, nervoso, e o operador deve verificar caso a caso para solucionar o problema. Segue na Figura 22 um exemplo de imagem de movimentação do paciente.

\subsection{RELAÇÃO SINAL VS RUÍDO (SNR)}

Nesta seção, será abordada a definição da relação Sinal vs. Ruído (SNR) para imagens de RM, e os principais trabalhos relacionados com tal relação.

\subsubsection{Definição de SNR}

Pela equação de Larmor, os spins de uma molécula transladam e rotacionam em direção às linhas de campo quando aplicados a um campo magnético externo específico, e em uma frequência constante e proporcional ao campo aplicado (MCROBBIE et al., 2006). 
Figura 22 - Exemplo de artefato de movimento do paciente.

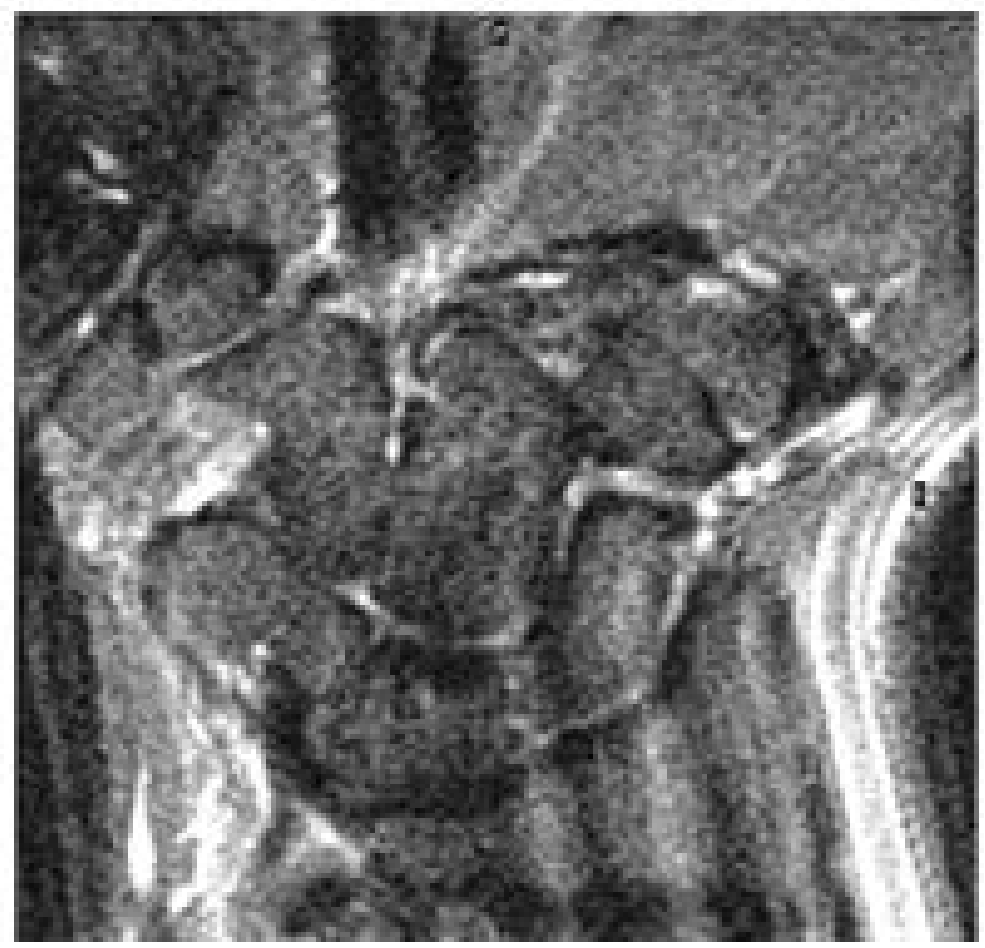

Fonte: Oni, 2003.

Ao se retirar o campo magnético externo aplicado, estes spins tendem a voltar para a sua posição inicial, liberando energia. As bobinas de captação presentes no centro do campo magnético do equipamento de RM captam as energias destes spins e também energias provenientes do ambiente de dentro da gaiola de Faraday, que não foram devidamente isoladas do meio externo, ou geradas dentro da gaiola.

Estas energias totais são captadas pelas bobinas receptoras e transferidas para o sistema eletrônico do equipamento, para serem processadas gerando as imagens.

Às energias provenientes dos spins das moléculas que foram submetidas ao campo magnético denomina-se de sinal e às energias referentes aos sinais provenientes do ambiente interno da gaiola de Faraday denomina-se ruído (ONI, 2003).

O principal fator para determinar a qualidade da imagem de aparelhos de RM é a SNR, que é a relação entre a quantidade de sinal recebido pela quantidade de ruído recebido.

Para Kuperman (KUPERMAN, 2000), define-se matematicamente SNR como sendo a relação entre a média da intensidade de imagem em uma região de interesse escolhida (ROI) pela raiz quadrada da variância do ruído, ou seja: 


$$
S N R=\frac{\text { intensidade média }}{\sqrt{(\text { variância do ruído })}}
$$

De acordo com Marcovisk (MARCOVSKI, 1996), a relação SNR em sistemas de RM nuclear pode ser calculado em detalhes pela seguinte equação:

$$
S N R=\frac{w_{o}^{2} N \chi V_{h} / y}{\sqrt{(2 K \vartheta R / T)}}
$$

Sendo:
a) $\quad w_{o}=$ frequência de recepção da bobina;
b) $\quad \vartheta=$ temperatura em Kelvin;
c) $\quad \chi=$ impulso no campo magnético (sinal);
d) $\quad K=$ constante de Boltzman;
e) $\quad R=$ resistência efetiva;
f) $\quad N=$ número de espiras da bobina receptora;
g) $\quad V_{h}=$ volume do voxel de aquisição;
h) $\quad T=$ tempo de aquisição;
i) $\quad y=$ constante de Larmor.

Como para a ressonância de extremidades todas as bobinas são cilíndricas, tem-se a definição de bobina cilíndrica exemplificada na Figura 23. As perdas em uma bobina cilíndrica são exemplificadas pela Figura 24.

A expressão fundamental do SNR para uma bobina cilíndrica, definida por Marcovski (MARCOVSKI, 1996) é:

$$
S N R=\frac{M_{s}}{\sigma_{n}}=\frac{w_{o}^{2} N \chi V_{h} / y}{\frac{w_{0} \mu_{0} N r_{0}^{2}}{2} \sqrt{\frac{K \vartheta \pi * l}{\rho T}}}
$$

Sendo:

a) $\quad M_{s}=$ sinal; 
Figura 23 - Definição de bobina cilindrica.

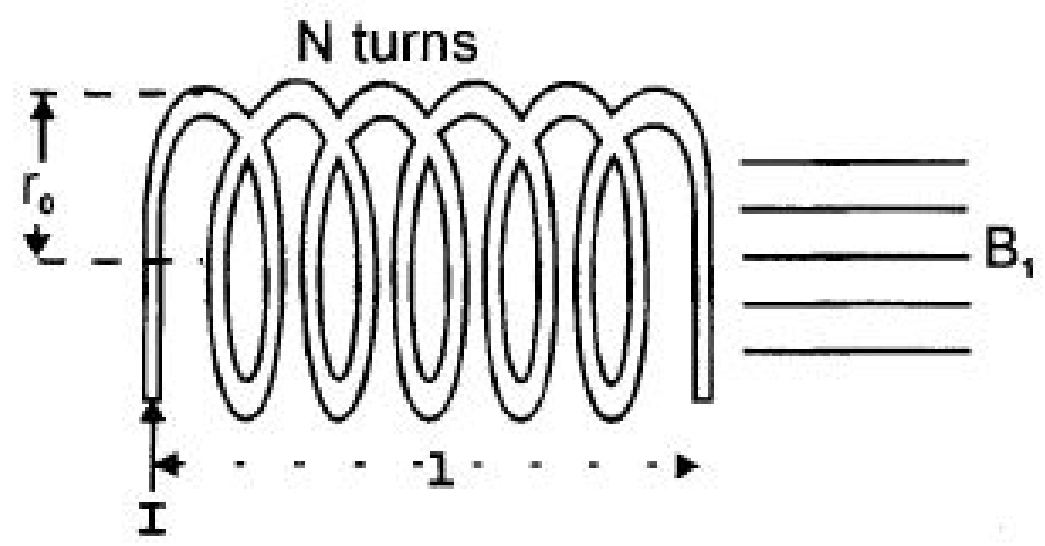

Cylindrical body coil.

Fonte: Marcovski, 1996.

Figura 24 - Exemplo perda usando bobinas cilíndricas.

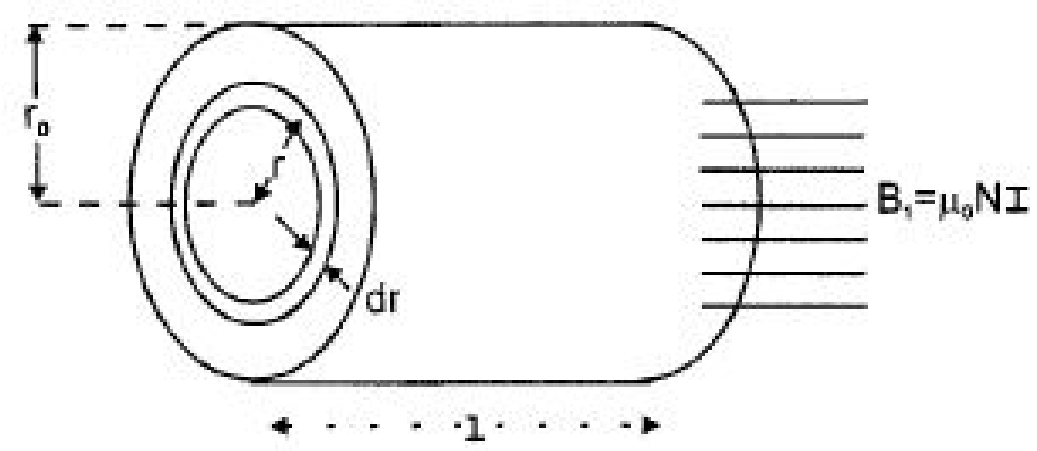

Calculating body losses using resistive shells.

Fonte: Marcovski, 1996.

b) $\quad \sigma_{n}=$ variância do ruído;

c) $\quad \chi=$ impulso no campo magnético (sinal);

d) $\quad w_{o}=$ frequência de recepção da bobina;

e) $\quad \vartheta=$ temperatura em Kelvin;

f) $\quad K=$ constante de Boltzman;

g) $\quad R=$ resistência efetiva;

h) $\quad N=$ número de espiras da bobina receptora;

i) $\quad V_{h}=$ volume do voxel de aquisição;

j) $\quad T=$ tempo total de aquisição;

k) $y=$ constante de Larmor; 
1) $\quad l=$ comprimento da bobina;

m) $\quad \mu_{0}=$ permeabilidade magnética no interior da bobina;

n) $\quad r_{0}=$ raio da bobina

o) $\quad \rho=$ resistividade do material da bobina;

p) $\quad \pi=$ constante 3,1415 .

Ou (MARCOVSKI, 1996):

$$
\begin{gathered}
=\left[\frac{2 X \sqrt{\rho}}{y \mu_{0} \sqrt{K \vartheta \pi}}\right]\left[\frac{1}{r_{0}^{2} \sqrt{l}}\right]\left[w_{0} V_{h} \sqrt{T}\right] \\
=C_{f}(O b) f(I m)
\end{gathered}
$$

Pode-se observar, através da equação (5), que o SNR da imagem está dividido em três fatores, sendo o primeiro representado pela primeira parte da expressão em colchetes que representa as constantes físicas, e como já mensionado, são constantes e não podem ser alteradas.

O segundo termo em colchetes refere-se às dimensões do objeto em análise, mais precisamente ao raio e comprimento da bobina receptora, conforme exemplificado na Figura 24.

O terceiro termo refere-se ao campo magnético, ao tamanho do voxel e ao tempo de aquisição da imagem. Observa-se, pela simplificação da equação (3), que o número de espiras da bobina foi eliminado.

Analisando a fórmula do SNR (equação 4), pode-se afirmar que:

a) O tempo de aquisição é fundamental no cálculo do SNR, pois o ruído irá diminuir pela proporção da raiz quadrada do tempo de aquisição. Quanto maior o tempo, maior será a relação final do SNR.

b) A importância da proporcionalidade do Voxel analisado, pois quanto menor for o voxel $V_{h}$ (unidade de imagem volumétrica) menor será a intensidade de sinal e menor será o SNR. Se forem feitas aquisições muito pequenas, para se obter maior detalhe da imagem, menor será o SNR e a imagem será mais ruidosa.

c) O SNR irá aumentar com a intensidade de campo magnético $w_{0}$ ou seja, para campos maiores o SNR será maior, indicando melhor imagem. 
d) O SNR irá diminuir com o aumento do FOV, ou seja, quanto maior for o raio da bobina e seu comprimento $l$ e $r_{0}$, o SNR irá diminuir, diminuindo a qualidade de imagem.

Outros fatores podem influenciar o SNR, visto que aqui não foi comentado sobre a homogeneidade do campo magnético, consequentemente a homogeneidade do voxel ou ângulos pequenos de ponta, pois refere-se a uma área cilíndrica.

\subsubsection{Trabalhos Relacionados}

Com o avanço da tecnologia, foram criadas novas bobinas de recepção de imagem denominadas de phased array.

Em 1997, Chris D. Constantinides (CONSTANTINIDES; ATALAR; MCVEIGH, 1997) realizou um estudo para comparar a resposta do SNR de acordo com as bobinas de 2 e de 4 canais, utilizando uma ressonância de 1,5 Tesla de corpo inteiro. Como objeto de pesquisa foi utilizado um phantom cilíndrico de água colocado no centro espacial de cada bobina, de forma a obter a melhor imagem do phantom e menor ruído como resultado. Observou-se que, a bobina de 4 canais apresentou um SNR, aproximadamente, $20 \%$ melhor do que a bobina de 2 canais. Em razão disso, a maioria dos equipamentos atuais de RM trabalham com bobinas de phased array para exames de longa amplitude, como exames de coluna e abdômen.

Em 2000, Vadin Kuperman(KUPERMAN, 2000), utilizando as bobinas de phased array, demonstrou que os três mais importantes parâmetros que definem a qualidade espacial da imagem são a resolução espacial, o contraste da imagem e o SNR.

O SNR depende de uma série de fatores incluindo a intensidade do campo magnético, tipos de bobinas, parâmetros da imagem e tipos de pulsos escolhidos. Os parâmetros de imagem e os tipos de pulso escolhidos podem ser reprogramados facilmente pelo operador do equipamento.

O único fator que não pode ser reprocessado, e que depende individualmente de cada local que a ressonância está instalada, se refere aos fatores físicos, externos ao equipamento e que influenciam diretamente na imagem, gerando ruído.

Kupeman (KUPERMAN, 2000), estudou o SNR para imagens tridimensionais (3D) e fez o comparativo entre o SNR bidimensional (2D) com o tridimensional (3D) e verificou que 
o SNR 3D é sempre menor que o 2D. Há,na Figura 25, um exemplo de degradação de SNR em imagem de ressonância magnética de 1,5T realizado em uma maçã.

Na Figura 25 (a) foi utilizado um determinado campo de visão (FOV) e na Figura 25 (b) este campo foi diminuído 4 vezes. Com a diminuição do FOV, $\left(r_{0}\right)$ e $(l)$, o SNR aumentou muito, pois a intensidade de ruído diminuiu, aumentando muito a intensidade de sinal (saturação).

Figura 25 - Exemplo diminuição do SNR pela diminuição do FOV.

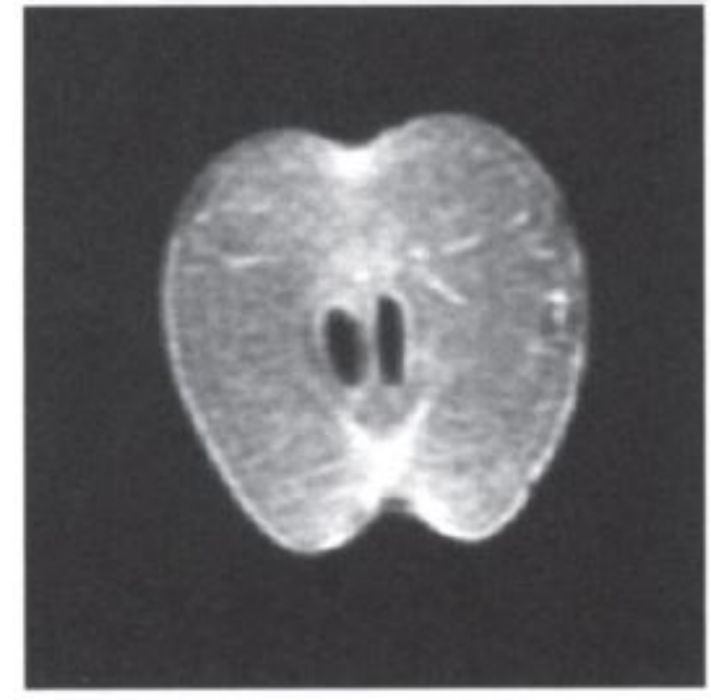

a

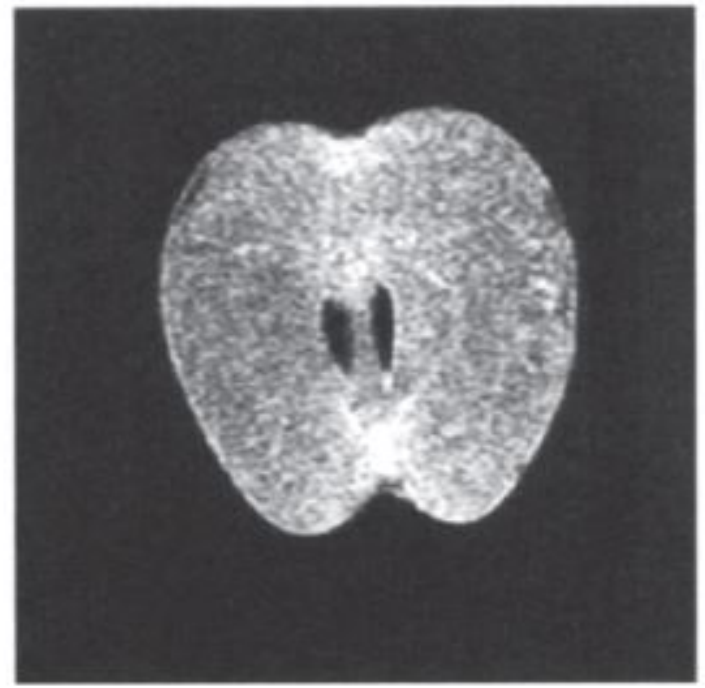

$\mathrm{b}$

Fonte: Kuperman, 2000.

Com a evolução das bobinas de RF, em 2000 Schnell (SCHNELL; RENZ; VESTER MARKUS ERMERT, 2000) apresentou um estudo em que ele fez a comparação de vários tipos de bobinas e suas respectivas respostas para o valor de SNR, apresentando suas melhores respostas para diferentes tipos de pulsos. Como conclusão, obteve-se que bobinas comuns apresentam melhor SNR entre 30 a 40MHz.

As bobinas chamadas loop apresentam uma melhor resposta de SNR para frequências de $50 \mathrm{MHz}$ e as bobinas birdcage para frequências de até 70MHZ. Para campos magnéticos de maior intensidade, as frequências de trabalho são maiores também. Assim para uma ressonância de 1,5T a frequência de trabalho é de $63 \mathrm{MHz}$ de acordo com a Lei de Larmor (MCROBBIE et al., 2006).

Em 2001, Vaughan (VAUGHAN et al., 2001) apresentou uma comparação entre ressonâncias de 4T e de 7T em exames de crânio e a constatação foi de que, comparado com a ressonância de 4T, a ressonância de 7T apresentava um SNR 1,6 vezes maior. 
Como o tempo de aquisição, é um grande problema para os equipamentos de ressonância magnética em geral, em 2003, Ohliger (OHLIGER; GRANT; SODICKSON, 2003) apresentou um estudo para realizar a aquisição de imagens em ressonância magnética em paralelo, através de bobinas separadas em um mesmo corpo.

No trabalho, os autores supracitados descreveram um modelo de bobina para servir de projeto para a realização de outras bobinas e o SNR calculado para este tipo de bobina. Há, nas Figuras 26 e 27, a bobina utilizada pelo experimento e sua respectiva curva de sensitividade e SNR.

Figura 26 - Bobina utilizada por Ohliger em sua tese.
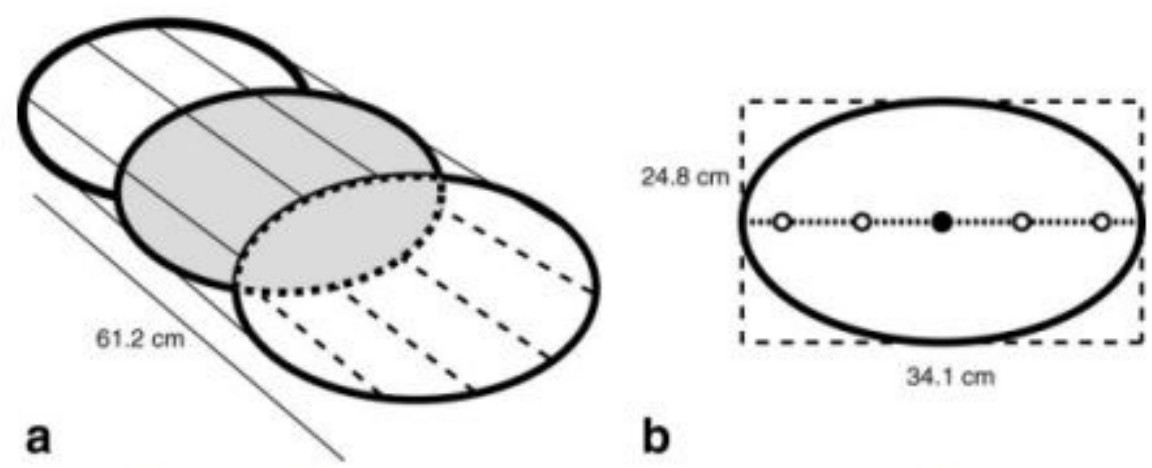

b

a: Schematic diagram of the simulated sample used in this study. It consists of an elliptic cylinder with uniform conductivity, permittivity, and permeability. The cylinder is $61.2 \mathrm{~cm}$ long and has semi-major and semi-minor axes of $12.4 \mathrm{~cm}$ and $17.05 \mathrm{~cm}$, respectively. b: FOV used in all calculations, which is a rectangle just large enough to contain the entire sample. Shown schematically is the central point-of-interest (filled circle) and four aliasing points (empty circles) that would result from a 5 -fold uniform undersampling in the $x$ direction.

Fonte: Ohliger, Grant e Sodickson, 2003.

Figura 27 - Gráfico da resposta da bobina da tese de Ohliger.
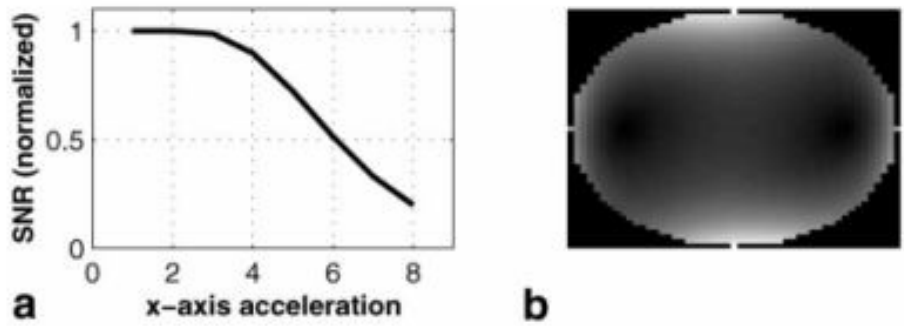

b

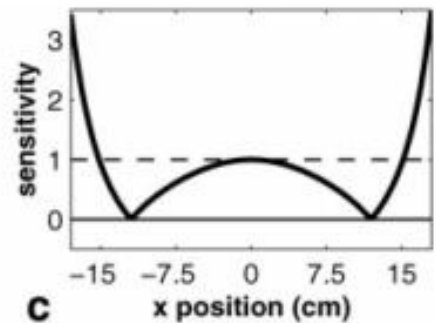

a: Optimal SNR at the center of the uniform ellipse at $1.5 \mathrm{~T}$ as a function of the degree of undersampling along the $\mathrm{x}$-axis. Electrical properties match those of liver at $1.5 \mathrm{~T}$. b: Absolute value of the optimal left-hand circularly polarized magnetic field for a 3 -fold undersampling along the $\mathrm{x}$-axis. This corresponds to the sensitivity of a coil designed to maximize the SNR at the center of the ellipse. The net field is unity at the center of the ellipse and goes to zero at all of the potential aliasing points. c: Profile along a horizontal line through the center of the plot in $\mathbf{b}$.

Fonte:Ohliger, Grant e Sodickson, 2003. 
Em 2004, Gutberlet (GUTBERLET et al., 2004) realizou um trabalho comparando duas ressonâncias de corpo inteiro, sendo uma de 1,5T e a outra de 3.0T, verificando o comportamento do SNR e do CNR (contrast to noise ratio).

Obvervou-se que, o SNR para a ressonância de campo maior apresentou uma elevação em todos os procedimentos realizados. Com relação ao CNR, não houve aumento expressivo do valor. A indicação de Gutberlet é para usar a ressonância de 3T apesar de ter o SNR maior, mas com o tempo de aquisição de imagem menor. Ainda sugerem trabalhar com bobinas de aquisição em paralelo para diminuir ainda mais o tempo de aquisição, sem comprometer o SNR.

Em 2007, Olaf Dietrich (DIETRICH et al., 2007) apresentou um estudo realizado com RM de corpo inteiro de 1,5T destacando as formas de calcular o SNR, utilizando imagens de phantom e in vivo, comparando as funcionalidade das bobinas de multi-canais, e também o paralelismo de aquisição de imagens, com filtros e reconstrução.

De acordo com Olaf Dietrich (DIETRICH et al., 2007), vários métodos para se calcular o SNR foram descritos anteriormente, mas o mais importante é o método que calcula estatisticamente duas regiões distintas das imagens, sendo uma fora da área de análise (fundo) para se medir o ruído e outra da região da área analisada para se medir a intensidade do sinal.

Este tipo de análise é totalmente válido e usado para imagens $2 \mathrm{D}$ e 3D e para bobinas simples e de quadratura, com a aquisição proveniente diretamente das transformadas de Fourier e reconstrução em magnitude. Para novos casos de utilização de bobinas phased array e novas técnicas de reconstrução como de imagens paralelas, a utilização do processo de duas regiões para a determinação do SNR pode ser afetado, pois o fundo da imagem que representa o ruído também será pós-processado, podendo gerar um falso fundo de ruído.

O trabalho avaliou o uso das duas regiões, descritas no artigo anterior, nas técnicas alternativas de bobinas de superfície (phased array) e no paralelismo de imagens, e também apresentou nova técnica de calculo de SNR baseado na diferença de duas imagens repetidas (idênticas) através de 60 imagens em phantom, das mais diversas formas. As Figuras 28, 29 e 30 mostram os gráficos dos SNRs obtidos para cada caso estudado.

Da mesma forma que as bobinas geradoras de campo magnético dentro do magneto das ressonâncias devem ficar imersas no sistema criogênico para que o material das bobinas se transformem em supercondutores, diminuindo a resistividade, em 2010, Ye Li (LI; GUO; JIANG, 2010) demonstraram a eficiência de uma bobina de recepção que ficava imersa em Nitrogênio líquido, a 77 Kelvin. 
Figura 28 - Gráfico dos estudos de Dietrich.
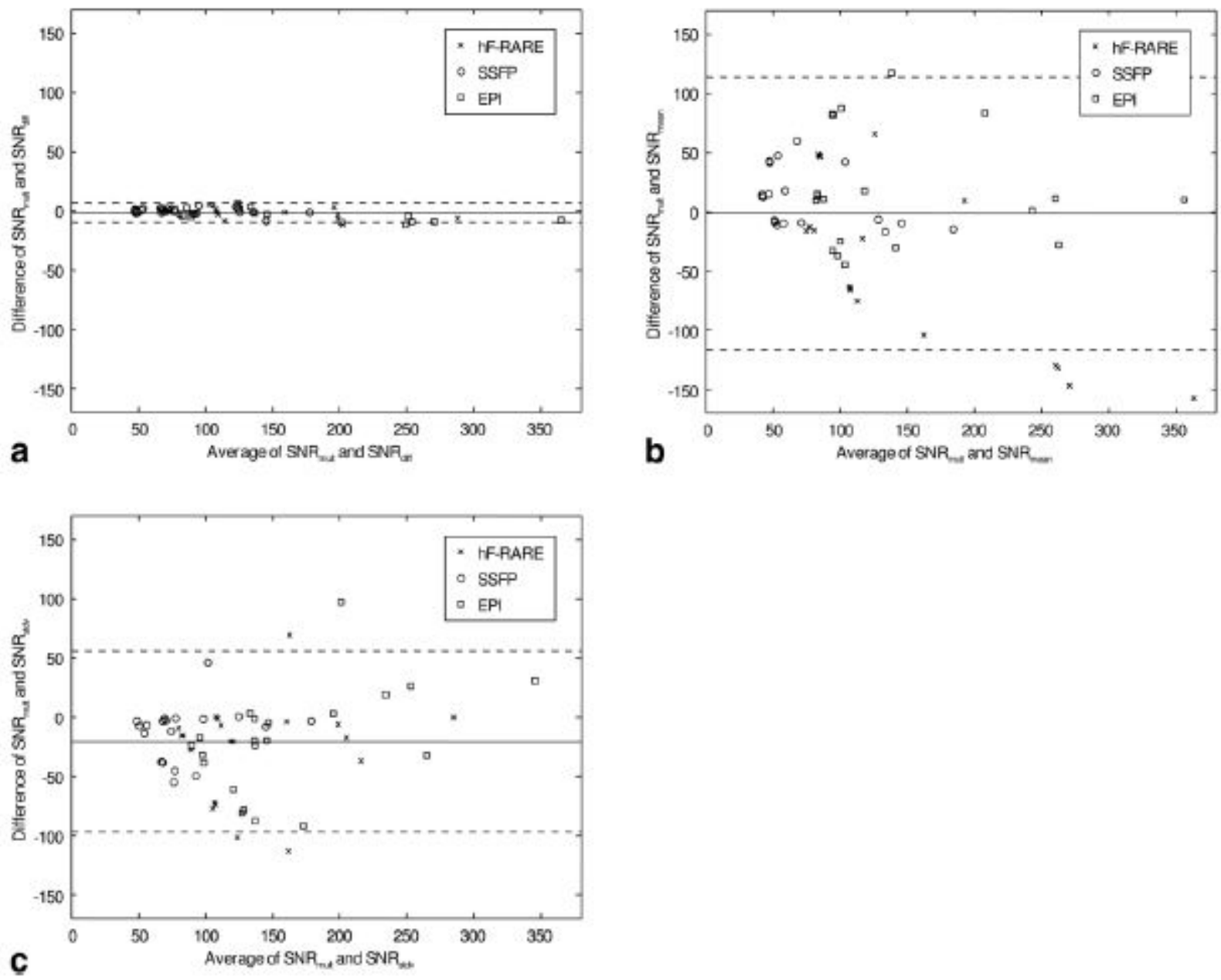

Bland-Altman plots showing the agreernent between SNRmult (the standard of reference) and SNRdur (a). SNR man (b). and $\mathrm{NNR}_{\text {stav }}$ (c) for the phantom measurements. Data for all sequences, acquisttion techniques, and reconstruction filters are combined. Note that $\mathrm{SNR}_{\text {dirl }}$ agrees much better with $\mathrm{SNR}_{\text {mull }}$ than $\mathrm{SNR}_{\text {moan }}$ and $\mathrm{SNR}_{\text {star. }}$

Fonte:Dietrich et al., 2007.

Devido a diminuição da resistividade do material de construção, a bobina apresentou uma eficiência de, aproximadamente, $34 \%$ em relação a uma mesma bobina em temperatura normal, conforme exemplificado na Figura 31.

Em 2006, Lindegaard (LINDEGAARD et al., 2006) apresentou um trabalho envolvendo ressonância de extremidade de baixo campo $(0,2 \mathrm{~T})$, para análise da evolução da artrite reumatoide precoce. Levou em consideração vários aspectos, e chegou a conclusão de que, mesmo com baixo campo, estas ressonâncias de extremidades, dedicadas de baixo custo, são promissoras para avaliação e diagnóstico de artrite reumatoide, e não apresentam risco de erosões, como ocorre nos exames de Raios-X, também, utilizados para este tipo de diagnóstico, devido à radioatividade emitida nas articulações. 
Figura 29 - Tabela dos estudos de Dietrich.

SNR Patios (and SD) of Different Acquisition Techniques and Reconstruction Filters in Phantom Measurements*

\begin{tabular}{|c|c|c|c|c|}
\hline \multirow{2}{*}{ SNR ratio } & \multicolumn{4}{|c|}{ SNR ratio based on $(\%)$} \\
\hline & $\overline{S N R_{m a t}(S D)}$ & $\mathrm{SNR}_{\text {dit }}(\mathrm{SD})$ & $\mathrm{SNR}_{\text {maan }}(\mathrm{SD})$ & $\mathrm{SNR}_{\text {stav }}(\mathrm{SD})$ \\
\hline \multicolumn{5}{|l|}{ Acquisition technique } \\
\hline $\mathrm{SNR}(\mathrm{BCH}) / \mathrm{SNR}(1 \mathrm{CH})$ & $54.9(0.5)$ & $53.8(1.6)$ & $22.4(5.2)$ & $62.5(13.2)$ \\
\hline SNR(GRAPPAWSNR(nonaccelerated) & $66.9(2.9)$ & $67.1(4.7)$ & $138.3(4.3)$ & $123.9(8.6)$ \\
\hline SNR(mSENSE)/SNR(nonaccelerated) & $66.0(4.5)$ & $66.4(5.7)$ & $218.5(15.4)$ & $76.9(4.5)$ \\
\hline \multicolumn{5}{|l|}{ Reconstruction filter } \\
\hline SNR(Hanning)/SNR(none) & $146.4(7.1)$ & $145.7(11.6)$ & $145.8(6.3)$ & $142.0(6.9)$ \\
\hline SNR(Large FOV)/SNR(none) & $101.1(2.6)$ & $101.4(4.7)$ & $105.5(3.4)$ & $116.1(4.6)$ \\
\hline SNR(Normalization) VSNR(none) & $100.7(2.6)$ & $100.4(5.4)$ & $92.3(18.4)$ & $91.2(17.7)$ \\
\hline SNR(Elliptical)/SNR(none) & $107.1(5.3)$ & $106.9(6.6)$ & $106.4(6.5)$ & $107.8(7.8)$ \\
\hline
\end{tabular}

Significant differences $(P<0.05)$ in comparison to $\mathrm{SNR}_{\text {mue }}$ ratios are in bold.

Fonte:Dietrich et al., 2007.

Figura 30 - Imagens dos estudos de Dietrich.
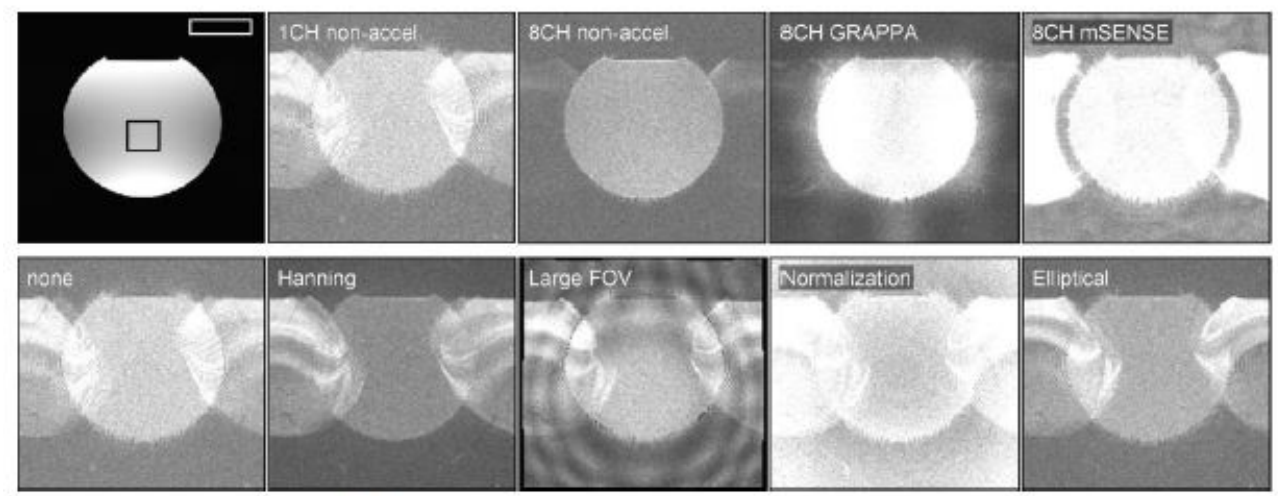

ROI positions and spattal notse distribution. The black ROI was used for SNR calculations with the methods SNR mete

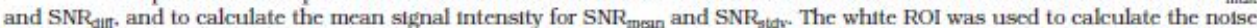
intensity for SNR mean and SNR stov. The notse maps show the SD calculated ptxel by pixel from 95 repetitions of an identical acquisition for different acquisition techniques without a reconstruction filter (top row) and for different reconstruction filters based on data of the $1 \mathrm{CH}$ head coll accuustitions (bottom row).

Fonte:Dietrich et al., 2007.

Em 2009, Suzuki (SUZUKI et al., 2009) fez estudos utilizando ressonâncias de extremidades em pacientes com artrite reumatoide. E, chegou a conclusão de que, as imagens de osso de uma ressonância de 1,5T são superiores a de uma ressonância de extremidades de $0,3 \mathrm{~T}$, mas para o estudo de artrite reumatoide, a ressonância de extremidades, chamada de compacTscan, permitiria uma resolução mais alta, e imagens de sensibilidade e um diagnóstico mais preciso.

A RM de extremidades de baixo campo registra uma sensibilidade inferior à ressonância magnética de corpo inteiro, em termos da avaliação do edema ósseo, e diferentes sensibilidades foram relatadas entre diferentes modelos de equipamentos verificados. Compararam a imagem de $0,3 \mathrm{~T}$ e a de corpo inteiro de 1,5 $\mathrm{T}$ em três pacientes e obteve-se quase os mesmos resultados. 
Figura 31 - Resposta da bobina de Li.

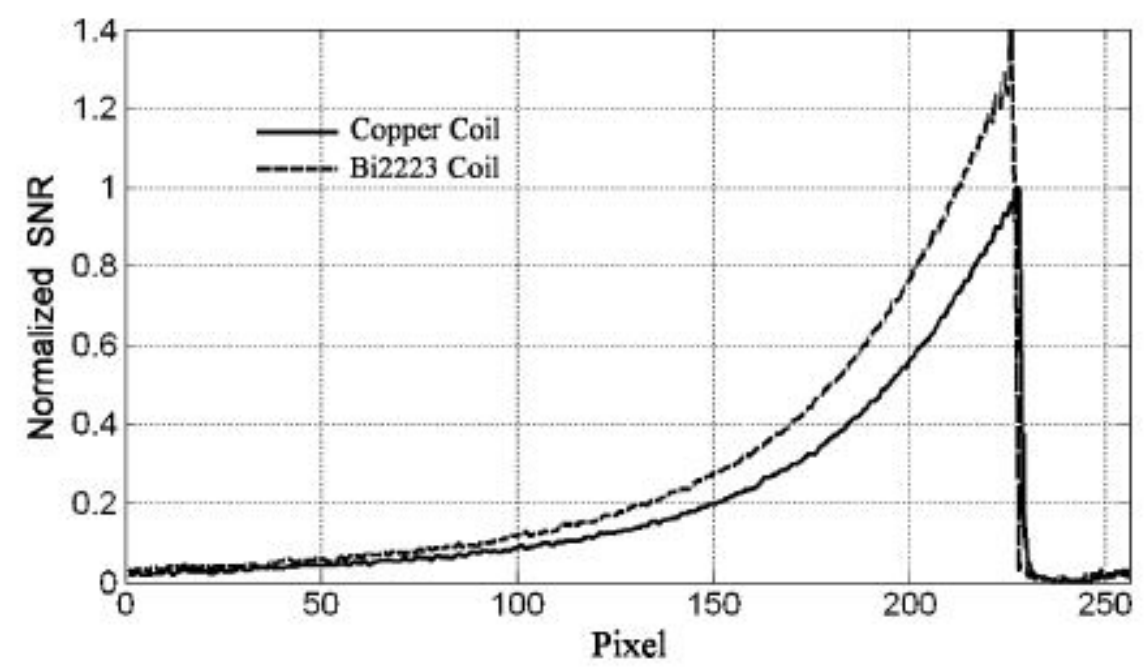

Fig. 6. Normalized SNR of pixels on the centric line of images.

Fonte:Li, Guo e Jiang, 2010.

A RM de extremidades de baixo campo é conveniente para pacientes e reumatologistas, e seu uso na prática diária poderá ajudar os médicos a fazer um diagnóstico precoce da artrite reumatoide e uma estimativa mais precisa da atividade da doença.

Em 2011, Frank Goerner (GOERNER; CLARKE, 2011) apresentaram mais cinco métodos para medir o SNR, em continuação ao artigo de Olaf Dietrich (DIETRICH et al., 2007) a partir de phantoms e imagens in vivo. Chegaram nas mesmas conclusões anteriores, de que para imagens em paralelismo não se deve utilizar somente as amostras de dentro da imagem, mas de amostras de fundo e de imagem.

Em 2012, Esben Plenge (PLENGE et al., 2012) apresentou um trabalho em que estudava alguns métodos de Super Resolução em imagens de ressonância magnética. Propôs uma possibilidade de poder melhorar a resolução, SNR e tempo de aquisição ao mesmo tempo. No processo da resolução, parte-se de uma imagem de baixa resolução e por processos matemáticos chega-se a uma imagem de alta resolução. Neste processo, o uso do cálculo de SNR convencional não pode ser usado ou não é o melhor indicado no uso da SSR (Super Resolution Reconstruction) (DIETRICH et al., 2007). Neste caso, eles propõem o uso de métodos de backprojection interativo ou métodos de resolução algébricos ou métodos dos mínimos quadrados regularizados. 
A conclusão que chegam é que há várias possibilidades de interpretação, e que para cada tipo específico de exame poderá haver um método SNR com melhor resultado.

Em 2013, A.J.McCann (MCCANN; WORKMAN; MCGRATH, 2013) elaboraram um estudo usando imagens de 7 sistemas diferentes de ressonância, entre 0,2T a 3T e compararam um novo processo de cálculo de SNR, através do processo de subtração de uma imagem suavizada e fazendo a comparação entre os dois processos. Entre os estudos realizados, os dados que foram verificados neste estudo foram:

a) Qualidade da imagem - Como as medidas se comparam ao padrão-ouro;

b) Robustez - Consistência do desempenho no intervalo típico de imagens de controle de qualidade;

c) Implementação fácil - A necessidade de acesso a qualquer funcionalidade não padrão do scanner ou software avançado de pós-processamento;

d) Subjetividade - Dependência de medições em decisões baseadas em inspeção visual de imagem ou operações arbitrárias;

e) Otimização - tempo necessário para aquisição e análise de imagens.

Foram usados phantoms cilíndricos como os da Figura 32. As imagens obtidas foram na quanFigura 32 - Phantoms usados por McCann.

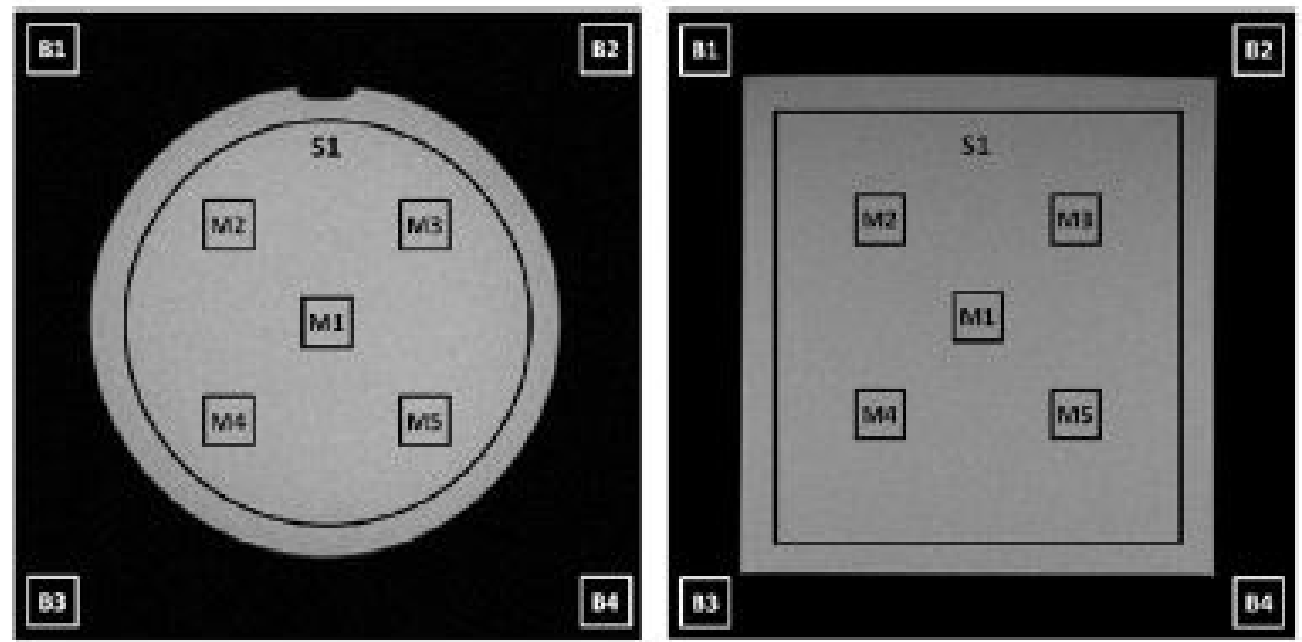

Definition of ROls used for determination of SNR in (left) axial and (right) sagithal/ coronal slices.

Fonte:McCann, Workman e McGrath, 2013.

tidade e sequências apresentadas na Figura 33. Demonstrou-se que existem grandes falhas em vários métodos da medição SNR para controle de qualidade da RM. A técnica introduzida se 
Figura 33 - Imagens usadas por McCann.

\begin{tabular}{llr}
\hline & & Number of image pairs \\
\hline Manufacturer & GE & 26 \\
& Siemens & 116 \\
& Philips & 21 \\
Static field strength & $0.2 \mathrm{~T}$ & 6 \\
& $1.5 \mathrm{~T}$ & 150 \\
\multirow{5}{*}{ Coil } & $3.0 \mathrm{~T}$ & 7 \\
& Integrated body & 75 \\
& Large body array & 3 \\
\multirow{5}{*}{ Phantom } & Quadrature head & 78 \\
& Eight-channel head & 7 \\
Slice orientation & Ionic solution & 79 \\
& Oil & 84 \\
& Axial & 59 \\
& Sagittal & 52 \\
\hline
\end{tabular}

${ }^{a}$ Siemens Concerto only.

Fonte:McCann, Workman e McGrath, 2013.

mostrou um substituto aceitável para a subtração de imagem dupla e superior a outras abordagens de imagem única publicadas. São aplicadas etapas de pós-processamento.

O tempo de aquisição das imagens foi reduzido em 50\% em comparação com as técnicas de imagem dupla, isso representa uma economia aproximada de 30 a 40 minutos.

Para teste de aceitação, a técnica de subtração de imagem dupla é recomendada para estabelecer SNR robusto. As medidas de controle de qualidade podem ser comparadas.

Pelo estudo de Marijke Welvaert (WEVAERT; ROSSEEL, 2013), realizou-se uma grande análise entre o SNR e o CNR e tentou-se relacionar ou determinar uma relação entre os dois fatores. Um consenso sobre uma definição comum de SNR / CNR, para dados de imagens de RM, pode ser difícil de conseguir, uma vez que a medição depende muito de como são definidos o sinal de interesse e o ruído.

Em 2014, Fuleah A. Razzaq (RAZZAQ et al., 2014) apresentou um estudo utilizando, para a remoção de ruído, Wavelets e filtros Gaussianos, de forma direta ou em locais específicos da imagem para a diminuição do ruído e consequentemente aumento do SNR. Por esse estudo, o ideal é utilizar sua aplicação em conjunto com os sistemas de diminuição dos ruídos apresentados anteriormente.

No mesmo ano de 2014, Sutter (SUTTER et al., 2014) fez um estudo comparativo entre as imagens de ressonância de corpo inteiro e ressonância de extremidades, utilizando como 
referência os mesmos pacientes nos dois sistemas. Foram realizados apenas exames de joelho e pé. Levou-se em conta o tempo de aquisição, artefato de movimentação, acústica, satisfação do cliente e supressão de gordura.

A ressonância de extremidades apresentou maior satisfação em acústica, comodidade do paciente, mas um pouco mais de ruído de movimentação em comparação à ressonância de corpo inteiro.

A ressonância de corpo inteiro apresentou um tempo de aquisição menor (as bobinas de gradiente são muito mais potentes, gerando um campo magnético em maior intensidade com menor tempo), apresentou muito mais ruído sonoro (menor satisfação do cliente), e menor quantidade de ruído de movimentação nas imagens. Como conclusão médica, os dois sistemas apresentam boas imagens para laudo.

Em 2015, Ning Ren Jin (JIN; SAYBASILI; BI, 2015) apresentou um ótimo trabalho referente a resolução espacial, tempo de aquisição e SNR. Como conclusão deste trabalho, eles apresentam na Figura 34 uma tabela de informação do que aumenta, diminui ou do que fica indiferente com relação ao tempo de aquisição, SNR e resolução espacial.

Figura 34 - Tabela de Jin.

Typical tradeoffs among SNR, spatial resolution, acquisition time and spatial coverage

\begin{tabular}{l|l|l|l|l}
\hline Increase parameters & SNR & Spatial resolution & Acquisition time & Spatial coverage \\
\hline FOV & + & - & 0 & + \\
\hline FOV and matrix size & + & 0 & + & + \\
\hline Slice thickness & + & - & 0 & + \\
\hline TR & + & 0 & + & 0 \\
\hline TE & - & 0 & 0 & 0 \\
\hline NEX & + & 0 & + & 0 \\
\hline Matrix size & - & + & + & 0 \\
\hline Readout BW & - & 0 & - & 0 \\
\hline Partial Fourier & - & 0 & - & 0 \\
\hline Asymmetric echo & - & 0 & - & 0 \\
\hline Field strength & + & 0 & 0 & 0 \\
\hline Phased-array coil & + & 0 & 0 & 0 \\
\hline
\end{tabular}

Icons in the table represent responses (+ increase; - decrease; o no difference) of these factors to the increase of parameters in the first column of the table

Fonte:Jin, Saybasili e Bi, 2015.

Ainda em 2015, Mathew (MATHEW; BIRD, 2015) realizou um novo estudo de vários tipos de casos em reumatologia. Inicialmente foi utilizado um protótipo de ressonância magnética de extremidades de 0,2T chamada MV-R construída pela MagneVu (Carlsbad, CA, USA), sem ter um campo uniforme, com um FOV muito limitado. O tempo de aquisição era longo. 
Com a melhora dos equipamentos, passaram a usar equipamentos da fabricante Esaote de $0,2 \mathrm{~T}$ em seus estudos. A ressonância de extremidades é potencialmente uma ferramenta poderosa para uso em clínicas e testes.

Oferece as vantagens de operação (devido ao baixo campo magnético), menor custo e maior conforto do paciente. As desvantagens incluem redução do SNR (aumento do ruído em relação ao sinal), questões técnicas relacionadas à supressão de gordura (mais especificamente em sequências com pulsos de gradiente mais exigentes chamados de sequência T2).

À medida que a tecnologia avança e as sequências melhoram, a ressonância magnética tem o potencial de se tornar uma parte importante da avaliação dos resultados em artrites.

Em 2016, pela sua tese (LIU, 2016), Thomas T. Liu forneceu uma explicação do que pode gerar ruído na aquisição da imagem de ressonância magnética. Entre as fontes de ruído, ele apresentou o ruído de fundo, o ruído de movimento, o ruído de fluxo sanguíneo e o ruído de desvios e flutuações de baixa frequência.

Neste artigo, a linha entre sinal e ruído nem sempre é clara. O desafio na distinção entre sinal e ruído decorre do fato de que o cérebro, que é o objeto de estudo, é o gerador de sinais de interesse e ruído.

Portanto, minimizar as contribuições dessas fontes de ruído, arrisca a remoção de informações sobre a atividade cerebral subjacente. Como a RM continua a evoluir, será importante que pesquisadores permaneçam atento a esse problema e desenvolvam novas abordagens de análise que consideram mais efetivamente a interação entre sinal e ruído.

Em 2017, Bastien Guerin (GUERIN et al., 2017) estudou a interferência de dipolos que geram energias eletromagnéticas próximos de um phantom de cabeça e a interferência destes efeitos eletromagnéticos em relação ao uSNR (ultimate SNR) e ao fator (uGF) utilizando ressonâncias de 0,5 à 21 Tesla. Como finalização, apresentou a resposta do uSNR, uGF em relação aos diversos campos magnéticos apresentados.

Mais recentemente, em 2019, Wald (WALD et al., 2019) fez um levantamento dos tipos de ressonância de baixo custo e portáteis. Ele comenta sobre as ressonâncias de extremidades, mas somente de baixo campo e também de muito baixo campo. Não especifica as ressonâncias de extremidades de alto campo (por não serem de baixo custo). E, conclui que uma série de avanços de design técnico e de inovações no sistema de topologia estão mudando significativamente o cenário do que a ressonância magnética do futuro pode parecer. 


\subsubsection{Considerações Complementares}

Com base na revisão bibliográfica, nota-se que o SNR é o principal fator para a qualificação de imagem de ressonância magnética. Além disso, observa-se que a maior parte (quase que a totalidade) apresenta estudos de SNR utilizando ressonâncias de corpo inteiro ou ressonâncias de extremidades de campo baixo.

Os trabalhos sobre ressonância de extremidades apresentam como estudo a utilização destas ressonâncias nos estudos de doenças relacionadas com artrites.

O trabalho em questão acrescenta mais informações sobre as ressonâncias de extremidades de alto campo e suas qualidades, bem como novos resultados utilizando este tipo de equipamento de RM nuclear em conjunto com estudos de estatística multivariada para análise discriminante do ruído nessas imagens. 


\section{MATERIAIS e MÉTODOS}

Nesta etapa são descritos os equipamentos, materiais e métodos utilizados para a realização dos experimentos deste trabalho.

\subsection{EQUIPAMENTO DE RM}

Para a realização deste estudo, foram investigados aparelhos de ressonância magnética nuclear de extremidades, de alto campo magnético (1T), marca ONI, modelo MSK Extreme, com as seguintes características:
a) Massa do magneto de $635 \mathrm{~kg}$;
b) Frequência de trabalho de $42,6 \mathrm{MHz}+/-500 \mathrm{~Hz}$;
c) Dimensões: $500 \mathrm{~mm}$ profundidade, $600 \mathrm{~mm}$ diâmetro externo e $280 \mathrm{~mm}$ diâmetro interno;
d) Potência da bobina de gradiente: $15 \mathrm{mT} / \mathrm{m}$;
e) Taxa de giro do gradiente: $60 \mathrm{~T} / \mathrm{m} / \mathrm{s}$;
f) Shimming passivo;
g) Bobina de $180 \mathrm{~mm}$;
h) Potência do amplificador de rf: 500W peak rms;
i) Largura de banda da imagem: variável de $5 \mathrm{kHz}-100 \mathrm{kHz}$;
j) Ruído do pré-amplificador: $<0,5 \mathrm{~dB}$;
k) Sequências de imagens permitidas: Spin Echo, Driven Equilibrium Spin Echo, Fast Spin Echo, Fast Spin Echo Inversion Recovery, Driven Equilibrium Fast Spin Echo, 2D Gradient Echo, 3D Gradient.

Um exemplo deste tipo de equipamento é ilustrado na Figura 35.

\subsection{PHANTOM}

Para a realização da aquisição das imagens utilizou-se como referência um objeto padrão chamado de Phantom. Trata-se de uma garrafa de material plástico contendo em seu interior água desmineralizada somada de sulfato de cobre em uma determinada e conhecida proporção (MCROBBIE et al., 2006). 
Figura 35 - Sistema MSK/Orthone 1.0T.

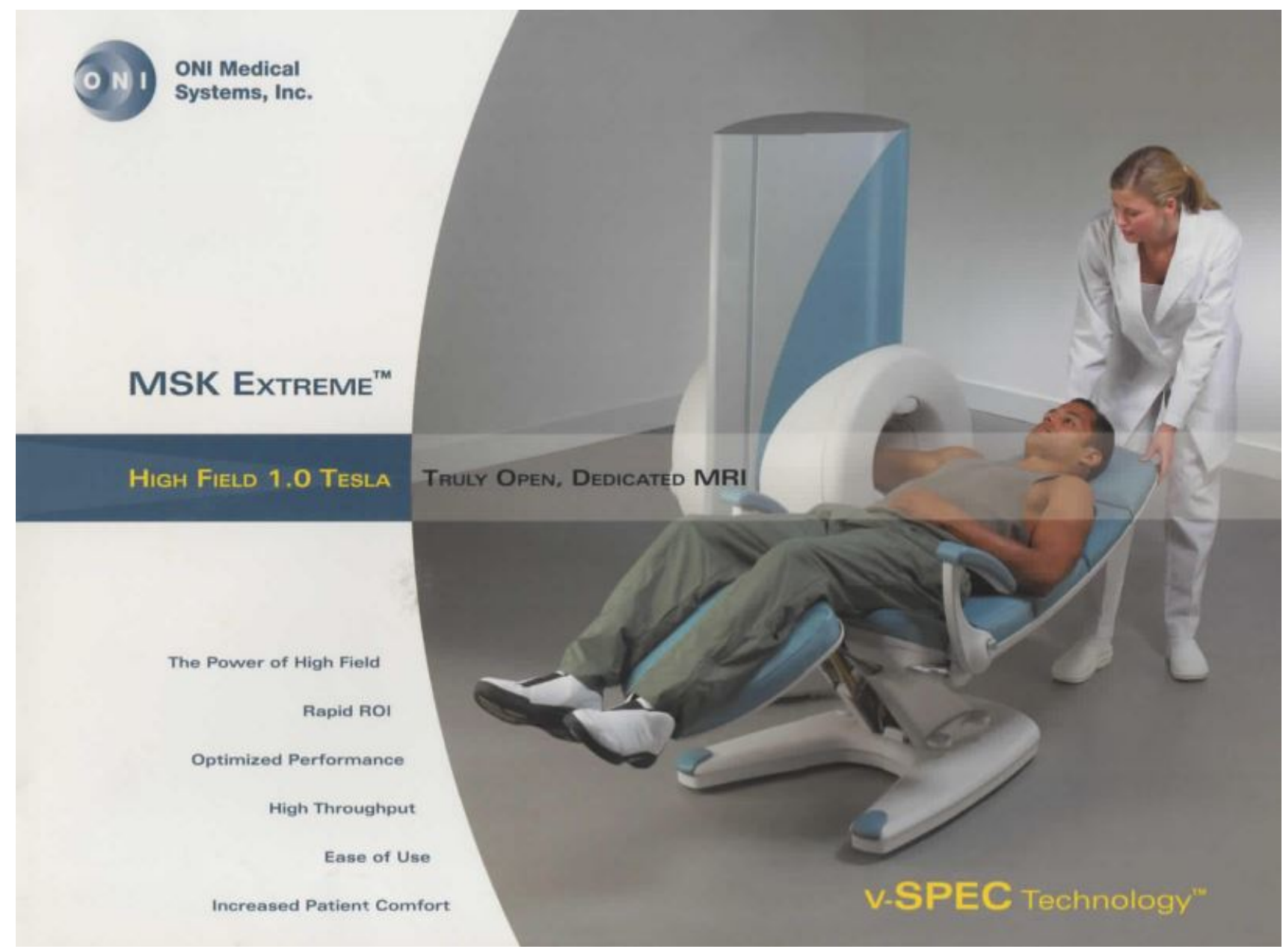

Fonte:M. S. Oni, 2005.

Ao ser aplicada à esta solução um campo magnético e em seguida pulsos de rádio frequência, a mesma responderá ao sistema de ressonância magnética uma certa quantidade de energia, que será captada pela bobina de rádio frequência do equipamento.

Por ser conhecida a concentração da solução de dentro do Phantom, pode-se estimar a quantidade de resposta do Phantom para o sistema de ressonância magnética, e assim, determinar se o equipamento se encontra dentro das características corretas para seu funcionamento (ONI, S., 2007). Caso o equipamento não apresente a resposta desejada para o Phantom analisado, haverá a necessidade de se estudar e verificar os possíveis motivos causadores do erro. Alguns dos problemas que podem acarretar a não resposta desejada são (ONI, 2003):
a) Problema com o sistema do amplificador de RF;
b) Problema com a bobina de RF;
c) Posicionamento incorreto do Phantom;
d) Cabos e conexões; 
Não havendo nenhum problema na aquisição das imagens, as mesmas serão analisadas de forma a verificar a sua qualidade.

\subsection{IMAGENS}

As imagens resultantes das aquisições têm aspectos visuais muito parecidos e correspondem à Figura 36. Estas imagens são compostas de:

a) Fundo preto;

b) Uma figura circular na região central representando a área de um corte axial realizado no phantom;

c) Um quadrado na parte interna da figura circular da região central, indicando a área de aquisição do sinal da imagem (IS);

d) Quatro retângulos localizados em volta da figura central da imagem, dentro do fundo preto. Os dois retângulos situados à direita e esquerda da figura central representam a área de onde são retirados os dados referentes ao ruído da imagem. Os dois retângulos situados nas partes superior e inferior da figura central representam a área de onde foram retirados os dados referentes ao fantasma (ghost) da imagem, que representa uma possível vibração no magneto (que pode ser bobina de gradiente mal fixada, ou vibração estrutural de onde o magneto está instalado).

Durante a aquisição da imagem, o equipamento de RM coleta as informações referentes ao phanton utilizado (IS), e também todas as informações referentes ao ruído da imagem (IN) que podem ser caracterizados por vários fatores como explicados anteriormente na seção 2.4.1.

\subsection{MÉTODOS}

Há vários fatores que podem interferir no (SNR) em imagens de RM.

Para poder ter um padrão na aquisição e na análise das imagens, foi utilizado durante todo este trabalho um único tipo de aquisição que consiste em um protocolo chamado DQA (Daily Quality Assurance) (ONI, M. S., 2005). Este protocolo foi utilizado para verificar as condições técnicas do equipamento e confirmar se o equipamento encontra-se totalmente calibrado e apto para a realização de exames. Este protocolo foi utilizado com bobina de $180 \mathrm{~mm}$ de diâmetro, pois o tamanho (diâmetro) da bobina interfere diretamente no SNR). 
Figura 36 - Imagem de DQA.

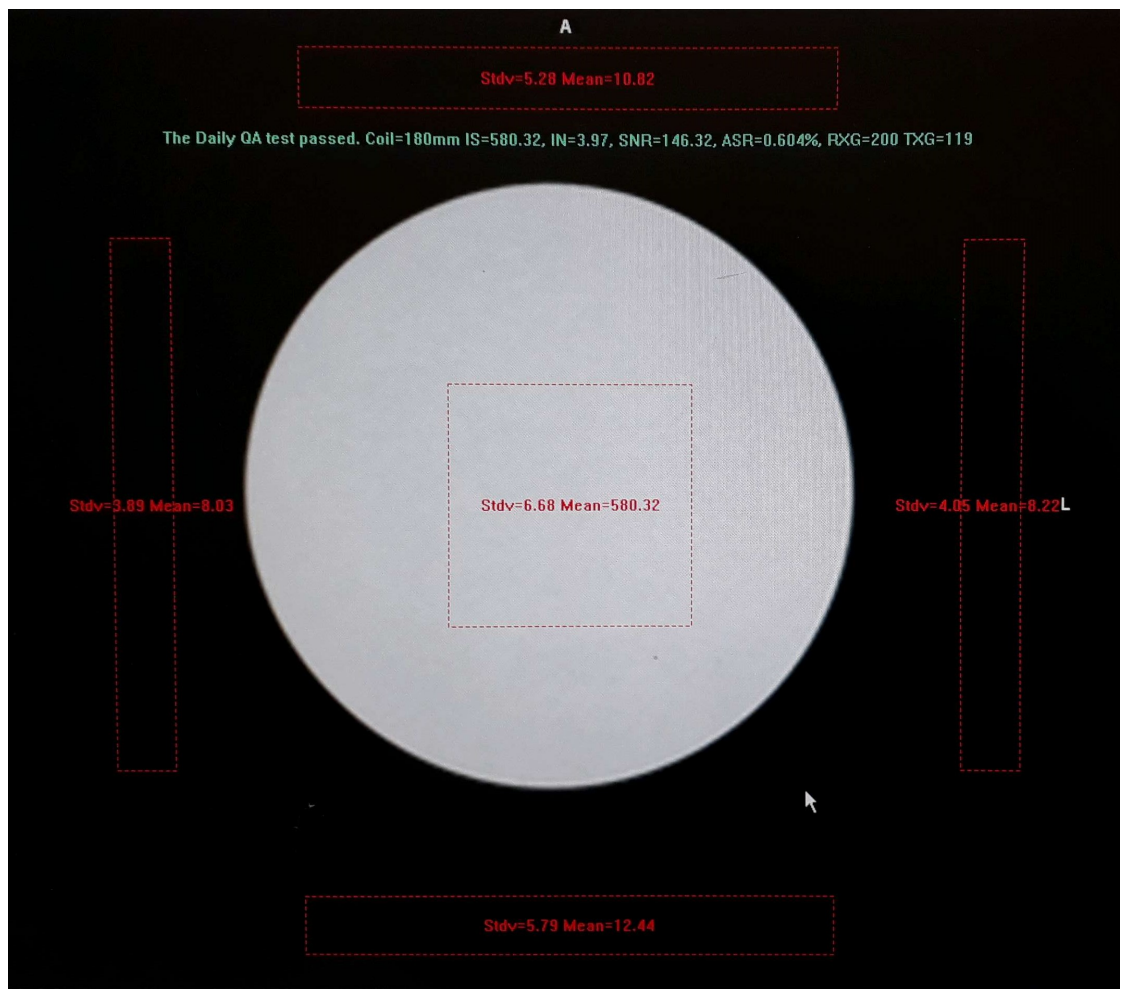

Fonte:Andrioli, 2021.

\subsubsection{Aquisição e Pré-classificação de Imagens}

O protocolo DQA (ONI, M. S., 2005) determina outros fatores que atuam diretamente no SNR da imagem como:
a) Tempo de aquisição de 4:19 minutos;
b) 256 linhas de aquisição;
c) 256 colunas de aquisição;
d) Espessura do corte em 5mm; (a quantidade de linhas x quantidade de colunas $\mathrm{x}$ espessura do corte, determinam o volume (voxel) a ser analisado;
e) Campo de visão FOV (Field of Vision) de 140mm;
f) Nex igual a 1 (quantidade de vezes que um voxel será coletado e analisado);
g) Tempo de relaxamento de 1000ms (tempo de retorno do Spin à posição inicial);
h) Tempo de excitação de 20ms Tempo de excitação do spin com RF);
i) Relação do FOV de 1 (imagem quadrada)( número de linhas número de colunas);
j) Banda passante de $25 \mathrm{kHz}$;
k) Bobina de $180 \mathrm{~mm}$ de diâmetro. 
Figura 37 - Protocolo de DQA

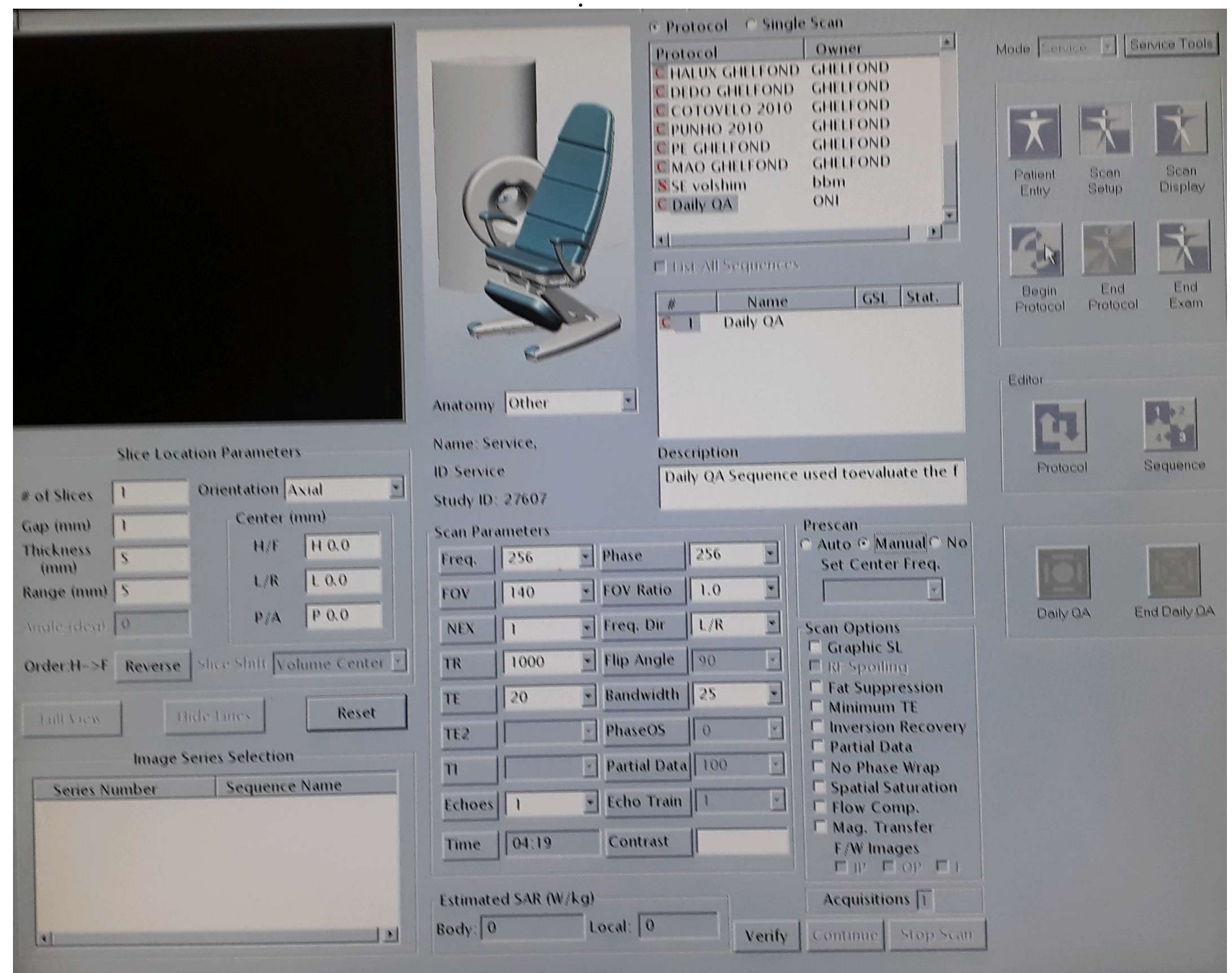

Fonte:Andrioli, 2021.

A Figura 37 ilustra a tela do protocolo de DQA utilizado em todo este trabalho.

Com os fatores fixos acima, analisou-se a quantidade de sinal (IS) e ruído (IN) de imagens dos equipamentos instalados em locais diferentes. As diferenças que aparecerão nas imagens são referentes à quantidade de ruído coletadas por cada aquisição.

A quantidade de ruído depende de alguns fatores relacionados a efeitos externos ao equipamento, principalmente relacionados com a eficiência e eficácia da gaiola de Faraday (gaiola de RF) como:

a) Qualidade do filtro de energia da gaiola (filtro que bloqueia sinais externos, principalmente de $60 \mathrm{~Hz}$ );

b) Luzes acesas no interior da gaiola (filamento das lâmpadas vibrando com os pulsos de campo eletromagnético); 
c) Porta da gaiola aberta (ou mal fechada) (não impedindo a entrada de RF externas para dentro da gaiola de $\mathrm{RF}$ );

d) Outros fatores referentes à construção da gaiola.

Através do protocolo DQA, coletou-se um total de 45 imagens de 3 equipamentos de RM extremidades ONI de 1.0T distintos, classificadas em imagens boas e ruins por um especialista em equipamentos de RM, conforme se segue.

As imagens demonstradas boas foram assim pré-classificadas em acordo com os seguintes critérios:

a) Apresentar geometria circular característica da imagem de Phantom de RM;

b) Não apresentar a presença de artefatos;

c) Não apresentar ruído na imagem;

d) Apresentar homogeneidade de imagem na área interna que representa o phantom.

Estas imagens foram coletadas considerando os itens básicos necessários para aquisição, como:

a) Gaiola de RF em pleno funcionamento;

b) Porta da gaiola de RF fechada;

c) Filtros da gaiola em perfeitas condições.

As 26 imagens boas de phantons coletadas pelos equipamentos são apresentadas na Figura 38 .

As imagens demosntradas ruins foram pré-classificadas porque:
a) Apresentaram geometria circular não uniforme;
b) Apresentaram a presença de artefatos;
c) Apresentaram ruído na imagem;
d) Não apresentaram homogeneidade na área interna ao phantom.

Estas imagens foram coletadas considerando que alguns dos itens básicos necessários para a coleta das imagens estavam danificados ou fora das condições de funcionamento, como:
a) Gaiola de RF em funcionamento precário;
b) Porta da gaiola de RF não totalmente fechada;
c) Filtros da gaiola em condições precárias. 
Figura 38 - Imagens boas de phantons.

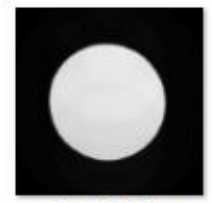

bno001.jpg

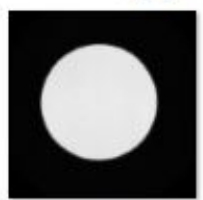

bno009.jpg

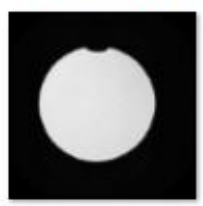

bno018.jpg

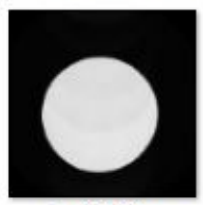

bpo010.jpq

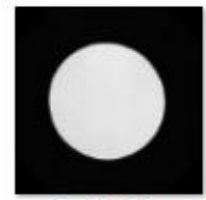

bno002.jpg

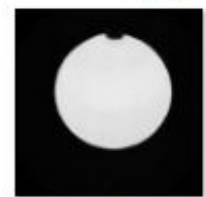

bno010.jpg

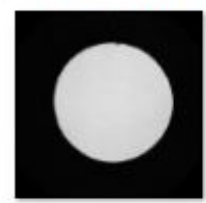

bno019.jpg

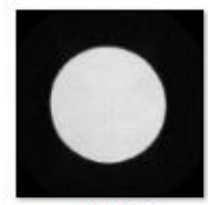

rpa001.jpq

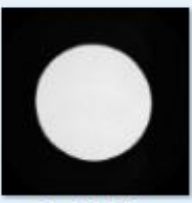

bno003.jpg

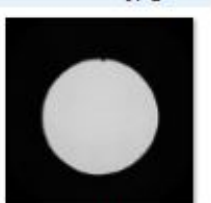

bno011.jpg

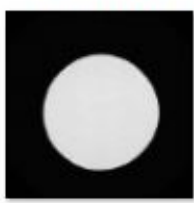

bpo002.jpg

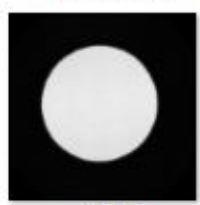

rpa002.jpq

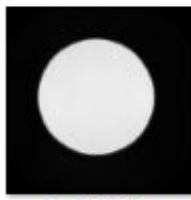

bno005.jpg

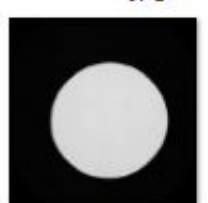

bno012.jpg

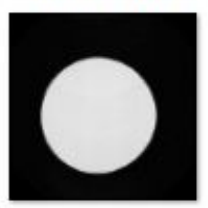

bpo004.jpg

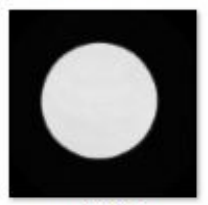

rpa003.jpq

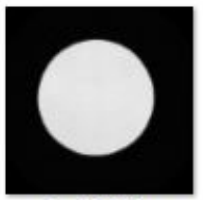

bno006.jpg

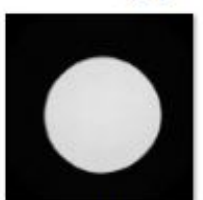

bno013.jpg

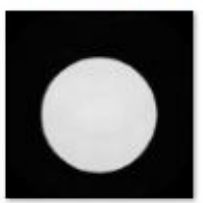

bpo005.jpg

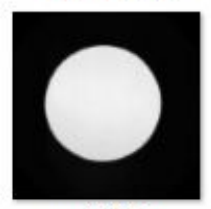

rpa004.jpq

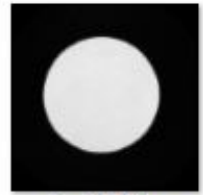

bno007.jpg

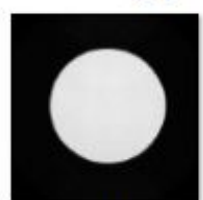

bno014.jpg

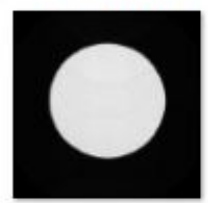

bpo006.jpg

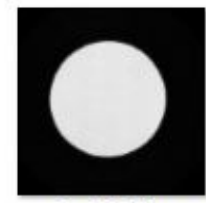

bno008.jpg

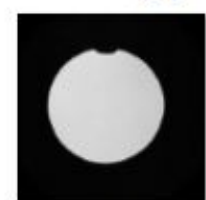

bno017.jpg

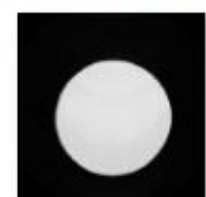

bpo009.jpg

Fonte:Andrioli, 2021.

As 19 imagens ruins de phantons coletadas pelos equipamentos são apresentadas na Figura 39.

Há a necessidade de se padronizar todas imagens em um único formato. As imagens médicas, por convenção internacional, são apresentadas no formato DICOM que é a sigla para Digital Imaging and Communications in Medicine, e que representa um conjunto de normas criado para padronizar o formato eletrônico utilizado no armazenamento e na comunicação das imagens.

Neste trabalho, as imagens DICOM foram convertidas para o padrão JPG que é um acrônimo de Joint Photographics Experts Group, um método de compressão de imagens que permite comprimir um arquivo e obter como resultado final uma imagem com qualidade. Todas as imagens em formato JPG têm 256 linhas por 256 colunas. Cada imagem será convertida em um vetor linha com 65.536 atributos (resultante da matriz de 256x256). O final da aquisição das 45 imagens resulta então em uma matriz de dados de 45 linhas e 65.536 colunas. 
Figura 39 - Imagens ruins de phantons.

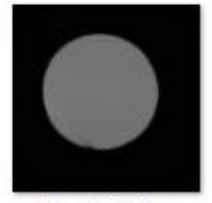

bno004.jpg

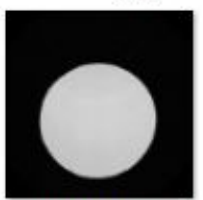

bpo011.jpg

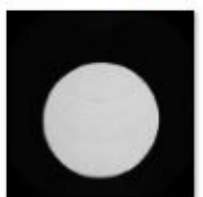

rf1006.jpg

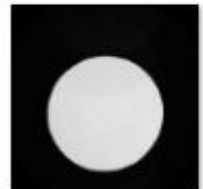

bno015.jpg

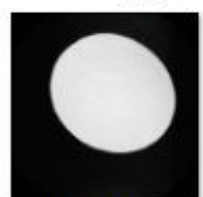

bsh002.jpg

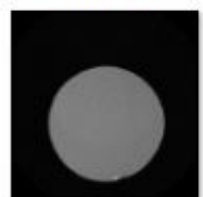

If1007.jpg

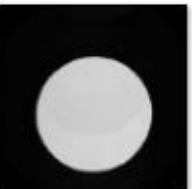

bno016.jpg

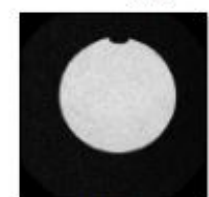

rfl001.jpg

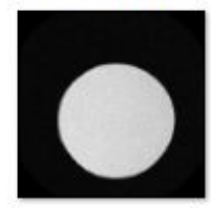

Ifl008.jpg

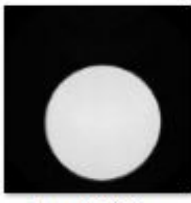

bpo001.jpg

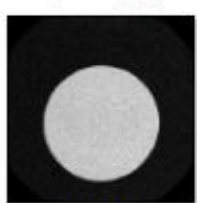

Ifl002.jpg

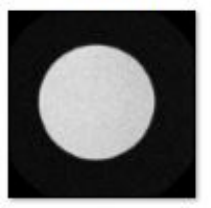

Ifl009.jpg

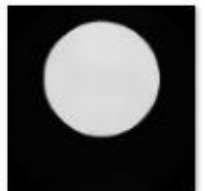

bpo003.jpg

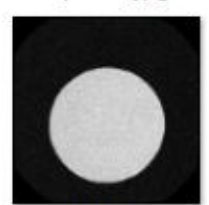

rfl003.jpg

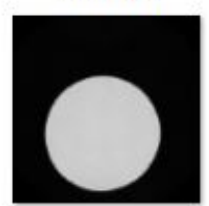

rpo001.jpg

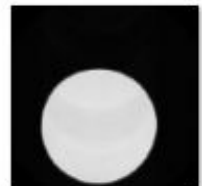

bpo007.jpg

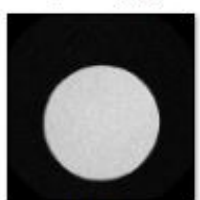

rf1004.jpg

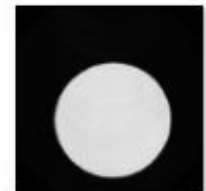

bpo008.jpg

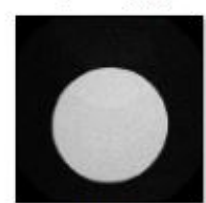

Ifl005.jpg

Fonte:Andrioli, 2021.

\subsection{CÁlCULO E ANÁLISE DO SNR}

Finalizada a coleta da imagem pelo protocolo DQA, o próprio equipamento permite realizar os cálculos sobre a imagem adquirida, para verificar se a mesma está dentro ou fora do padrão de qualidade especificado pelo fabricante para este equipamento.

De acordo com as especificações do fabricante, para uma bobina de 180mm, o DQA deve apresentar um SNR acima de 105 e um ASR abaixo de 1. Com base nas Figuras 36 e 40, o SNR é calculado da seguinte forma:

$$
S N R=\frac{I S M}{\frac{(N L S+N R S)}{2}}
$$

a) $\quad I S S=$ IntensitSignalStdv $=$ Desvio padrão da intensidade do Sinal;

b) $\quad I S M=$ IntensitSignalMean = Média da intensidade do Sinal;

c) $\quad N L S=$ IntensitNoiseStdv = Desvio padrão da intensidade do Ruído Esquerdo;

d) $\quad N L M=$ IntensitNoiseMeanRight $=$ Média da intensidade Ruído Direito;

e) $\quad N R S=$ IntensitNoiseStdvRight $=$ Desvio padrão da intensidade do Ruído Direito; 
Figura 40 - Dados de DQA.

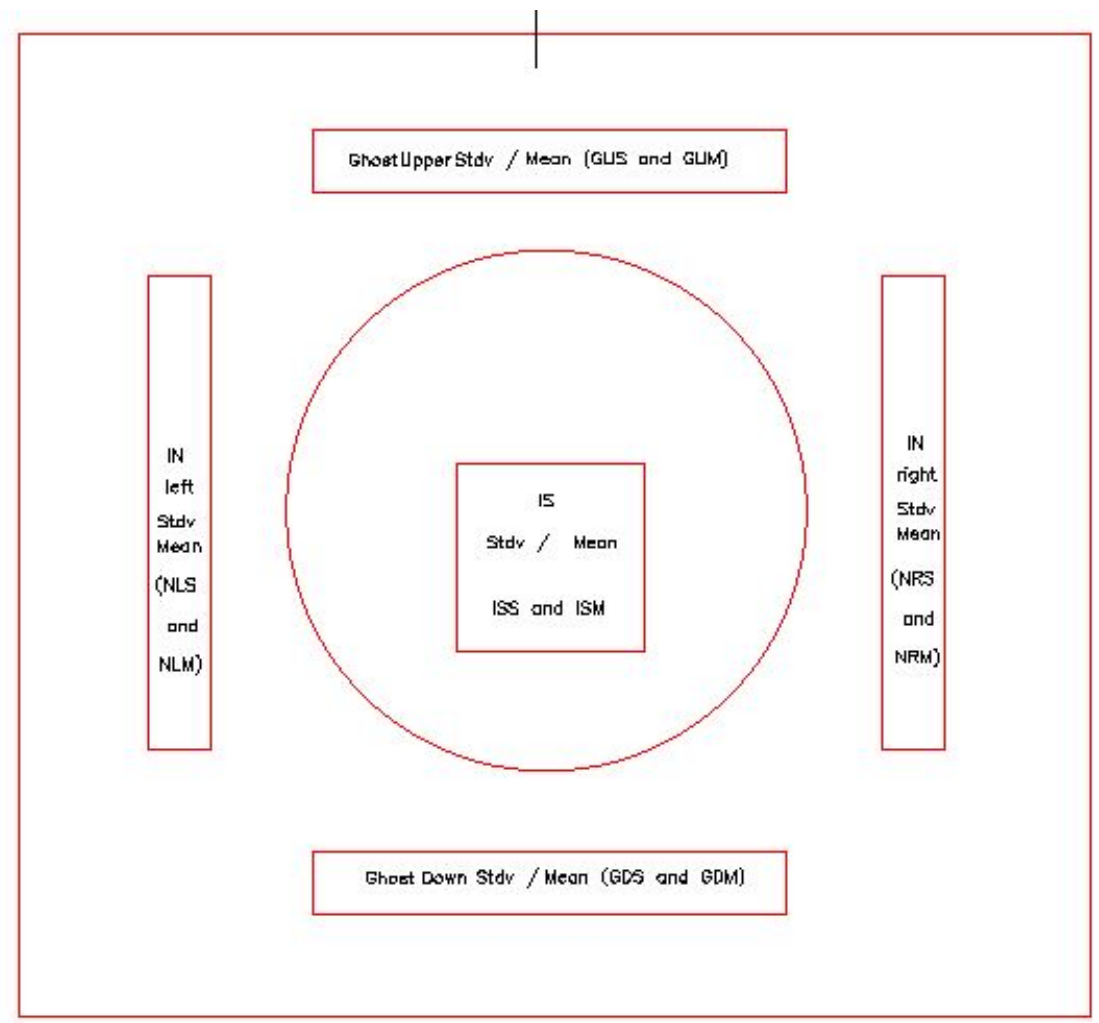

Fonte:Andrioli, 2021.

f) $\quad N R M=$ IntensitNoiseMeanRight $=$ Média da intensidade do Ruído Direito;

g) $\quad G U S=$ IntensitGhostStdvUpper $=$ Desvio parão da intensidade do Fantasma Superior;

h) $\quad G U M=$ IntensitGhostMeanUpper $=$ Média da intensidade do Fantasma Superior;

i) $\quad G D S=$ IntensitGhostStdvDown $=$ Desvio padrão da intensidade do Fantasma Inferior;

j) $\quad G D M=$ IntensitGhostMeanDown = Média da intensidade do Fantasma Inferior.

Com relação às Figuras 36 e 40, o ASR é calculado pela seguinte forma:

$$
A S R=\left(\frac{\left(\left(\frac{(G U M+G D M)}{2}\right)-\left(\frac{(N L M+N R M)}{2}\right)\right)}{I S M}\right) X 100
$$


O equipamento de RM utiliza para determinar a qualidade da imagem o padrão SNR que também é utilizado para a verificação da calibração do equipamento.

Para verificar a calibração do equipamento, verifica-se o valor apresentado pelo SNR em um exame de phantom com a bobina de $180 \mathrm{~mm}$.

Pelo fato do phantom ser de material conhecido e uniforme, o valor do SNR deve estar entre 105 e 120 através do protocolo DQA (ONI, M. S., 2005).

\subsection{ANÁLISE ESTATÍSTICA MULTIVARIADA}

A análise estatística univariada avalia cada variável independentemente. Neste trabalho, utiliza-se a análise estatística multivariada em que todas as variáveis das amostras ou aqui imagens são analisadas simultaneamente.

Cada imagem pode ser representada como pontos no espaço n-dimensional. Como cada imagem tem 256 linhas x 256 colunas de resolução, o número de variáveis n será de (256 x 256) 65536.

De acordo com (FUKUNAGA, 1990), problemas podem surgir com pequenas amostras e muitas variáveis, conhecido como problemas de poucas amostras. Há várias técnicas e métodos adotados para a análise multivariada de dados desse tipo de problema(GIRALDI; THOMAZ; RODRIGUES, 2008); (SATO et al., 2009); (FISHER, 1936) e (HASTIE; TIBSHIRANI; FRIEDMAN, 2009). Neste trabalho, são abordados os métodos PCA, LDA e MLDA, descritos a seguir.

\subsubsection{Análise de Componentes Principais (PCA)}

O PCA (Principal Components Analysis) é uma das técnicas de estatística multivariada mais conhecidas que permite extrair linearmente informações relevantes de uma base de dados multivariada (GREGORI, 2016). Uma descrição abrangente desta técnica pode ser encontrada em (FUKUNAGA, 1990).

O PCA é um procedimento de extração de recursos que permite explicar a estrutura de covariância de um conjunto de variáveis através de um pequeno número de combinações lineares dessas variáveis. 
Trata-se de uma técnica estatística que tem sido usada em diversos problemas de reconhecimento de padrões em imagem, especialmente para redução da dimensionalidade dos dados (THOMAZ C.E.AND KITANI et al., 2006).

Esta análise permite reduzir a dimensionalidade e revelar importantes informações confundidas em uma base de dados grande e complexa. O PCA, também, possibilita eliminar as informações redundantes de um sinal. Em outras palavras, funciona como um filtro estatístico (JONSON; WICHERN, 2007),(SHELENS, 2014) e (GREGORI, 2016).

Neste estudo, o PCA foi utilizado com o intuito de redefinir o sinal referente às imagens de ressonância magnética em JPG, mantendo as informações mais relevantes que no caso são as quantidades de sinal e ruído das imagens.

A metodologia PCA pode ser entendida como uma forma de aprendizado não supervisionado, que recebe como entrada, uma base de dados sem nenhuma referência ou algum critério de agrupamento, e maximiza no espaço as direções que ocorrem as maiores variâncias dos dados.

Geometricamente, o PCA pode ser entendido como uma transformação linear do sistema de coordenadas, a partir de uma base de dados original para um novo sistema de coordenadas rotacionado em relação ao original (GREGORI, 2016).

Este novo sistema de coordenadas é composto por vetores ortogonais entre si, mostrando as direções onde ocorrem as maiores variâncias da base de dados original.

Na Figura 41, exemplifica-se a relação entre as informações dos dados, determinadas pelas coordenadas $y_{1}$ e $y_{2}$, e as coordenadas $z_{1}$ e $z_{2}$ que são autovetores denominados como as componentes principais resultantes do PCA. A primeira componente principal $z_{1}$ representa a direção de maior variância e a segunda componente $z_{2}$ é a segunda de maior variância e ortogonal à primeira, assim sucessivamente.

O objetivo do PCA é encontrar a direção de maior variância dos dados (FUKUNAGA, 1990).

Como o banco de dados deste trabalho consiste em 45 imagens $(\mathrm{N}=45)$, ao final do PCA teremos 44 componentes principais, porque aqui $(\mathrm{N} \ll n)$ no máximo o número de componentes principais será a quantidade total de amostras menos 1 .

Neste trabalho, tem-se 45 imagens formando a matriz.

$$
X=\left[\begin{array}{lllll}
x_{1} & x_{2} & x_{3} & \ldots & x_{t}
\end{array}\right]^{T}
$$


Figura 41 - Gráfico PCA.

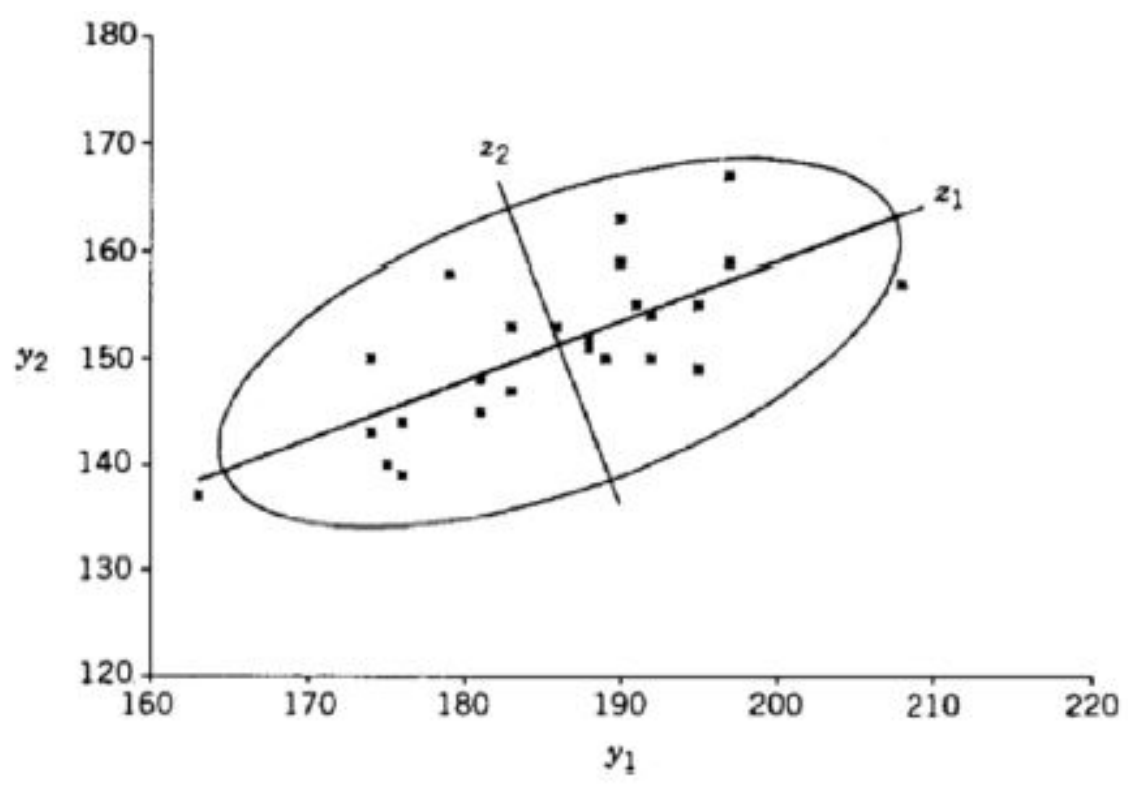

Fonte:Rencher, 2002.

Como as imagens tem 256 linhas por 256 colunas tem-se a seguinte matriz final.

$$
X=\left[\begin{array}{ccccc}
x_{1,1} & x_{1,2} & x_{1,3} & \ldots & x_{1, n} \\
x_{2,1} & x_{2,2} & x_{2,3} & \ldots & x_{2, n} \\
x_{\ldots} & x_{\ldots} & x_{\ldots} & \ldots & x_{\ldots} \\
x_{N, 1} & x_{N, 2} & x_{N, 3} & \ldots & x_{N, n}
\end{array}\right]
$$

tem-se:

a) $\quad N=$ quantidade de linhas $=$ quantidade de imagens $=45$

b) $\quad n=$ quantidade de colunas $=$ quantidade de pixels $=65536$

Considerando a matriz de dados X, descrita na equação (9), a matriz de covariância pode ser determinada por:

$$
S=\frac{1}{N-1} \cdot \sum_{1}^{N}\left(x_{i}-\bar{x}\right)^{T}\left(x_{i}-\bar{x}\right)
$$

em que:

a) $\quad x_{i}=$ imagem coletada 
b) $\quad \bar{x}=$ imagem média global calculada por:

$$
\bar{x}=\frac{1}{N} \cdot \sum_{1}^{N} x_{i}
$$

São respectivamente, $\mathrm{P}$ e $\Lambda$ as matrizes de autovetores e autovalores de $\mathrm{S}$, de forma que:

$$
P^{T} S P=\Lambda
$$

Através de (FUKUNAGA, 1990), prova-se que o resultado dos p autovetores de $S$,em que $p \leq \operatorname{minn},(N-1)$, correspondem aos p maiores autovalores que minimizam o erro quadrático médio da reconstrução do sinal com relação a outros possíveis p vetores ortogonais.

Assim, definido os autovetores, tem-se uma nova matriz de dados $\mathrm{Y}$ projetados nas componentes principais selecionadas.

As componentes principais p podem substituir as variáveis originais $\mathrm{n}$, constituindo-se uma nova base de dados reduzida, dada por $\mathrm{N}$ imagens e p características mais expressivas do sinal. A nova matriz de dados é dada pela equação a seguir:

$$
Y=X P
$$

em que:

a) $\quad X=$ matriz original das imagens;

b) $\quad P=$ matriz de autovetores;

Anteriormente ao PCA, o número de informações era dado por 45 imagens de 256 linhas por 256 colunas, totalizando 2.949.120 dados. Ao final do PCA, considerando todas as 44 componentes principais válidas, as informações se resumem a 45 imagens de 44 componentes, totalizando 1980 informações, servindo realmente de filtro de informações.

A Figura 42, mostra uma ilustração esquemática desses cálculos que reduzidamente:

a) Calcula o vetor médio dos dados; 
Figura 42 - Processo PCA.

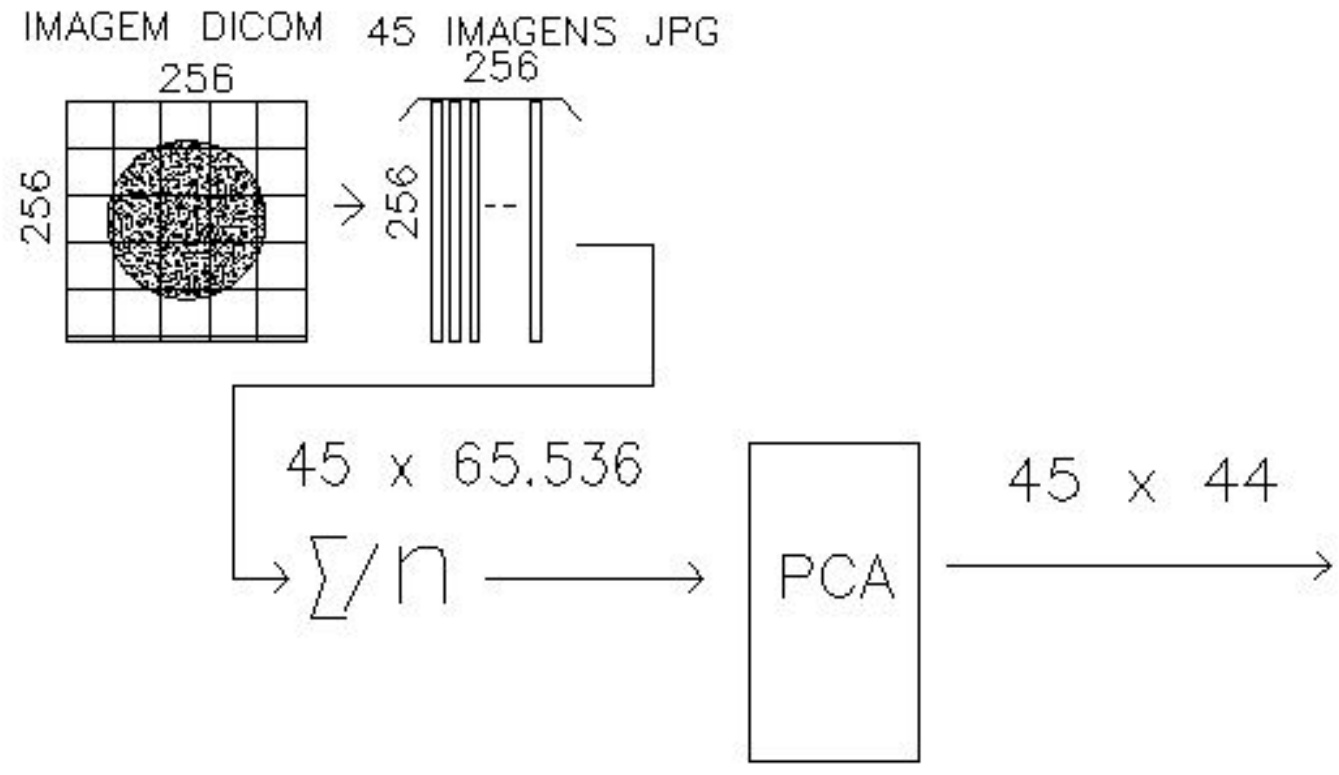

Fonte:Andrioli, 2021.

b) Subtrai o vetor médio dos dados;

c) Calcula a matriz de covariância;

d) Calcula os autovetores da matriz de covariância;

e) Projeta os dados obtidos nesses autovetores.

\subsubsection{Análise de Discriminantes Lineares (LDA)}

O método LDA (Linear Discriminant Analysis), também conhecido como método de Fisher e, segundo (FUKUNAGA, 1990), é um método supervisionado de estatística multivariada que tem por finalidade encontrar o hiperplano de maior separação entre os grupos analisados.

O cálculo desse hiperplano de separação considera o conhecimento prévio (ou aqui préclassificação) da classe/grupo de cada amostra. A análise LDA é paramétrica, ou seja, considera distribuição de probabilidade.

O hiperplano é uma dimensão separadora no espaço original que divide esse espaço em duas metades. Essas metades são formadas pelas entradas das duas classes distintas (imagens boas e imagens ruins). 
Segundo (FISHER, 1936), o método baseia-se na diminuição do espalhamento das amostras com relação ao grupo ao qual pertencem e, também, na maximização da distância da média entre estes grupos. Em outras palavras, calcula-se as matrizes de espalhamento interclasses e intra-classes com objetivo de separar os grupos de amostragem pela maximização da separabilidade entre classes enquanto minimiza-se a variabilidade dentro das mesmas.

Para (RENCHER, 2002), através do LDA pode-se alcançar dois objetivos principais que são:

a) Separar os grupos por meio de funções lineares, utilizando as variáveis discriminantes;

b) Prever ou alocar as observações individuais ou um vetor de valores, classificandoos dentro dos seus mais prováveis grupos ou classes.

A análise inicia-se com os dados oriundos do PCA (matriz Y), com dados p-dimensionais, mantendo as características principais das imagens analisadas. Nesta base de dados encontramse as $\mathrm{N}$ imagens investigadas.

Aplica-se o LDA para determinar a direção que melhor separam as imagens no subespaço dimensional (FUKUNAGA, 1990).

As matrizes de espalhamento inter-classes $S_{b}$ e intra-classes $S_{w}$ são definidas como:

$$
S_{b}=\sum_{i=1}^{g} N_{i}\left(\overline{y_{i}}-\bar{y}\right)^{T}\left(\overline{y_{i}}-\bar{y}\right)
$$

$\mathrm{e}$

$$
S_{w}=\sum_{i=1}^{g} \sum_{j=1}^{N_{i}}\left(y_{i, j}-\overline{y_{i}}\right)^{T}\left(y_{i, j}-\overline{y_{i}}\right)
$$

onde:
a) $\quad g=$ número de grupos analisados $=2$ (boas e ruins)
b) $\quad N_{i}=$ quantidade de amostras do grupo $i=26$ (boas) e 19 (ruins)
c) $\quad \bar{y}=$ média total;
d) $\quad \overline{y_{i}}=$ média das amostras do grupo $i$;
e) $\quad y_{i, j}=\operatorname{amostra} j$ do grupo $i$ 
A relação que deve ser maximizada e proposta por (FISHER, 1936) é dada pela equação (16).

$$
L=\operatorname{argmax} \frac{\left|P^{T} S_{b} P\right|}{\left|P^{T} S_{w} P\right|}
$$

Esta razão é possível através do cálculo da inversa da matriz de espalhamento intraclasse $S_{w}$ e é neste ponto que, da mesma forma que no PCA, podem ocorrer instabilidades de cálculo devido a quantidade de amostras ser muito menor que a quantidade de variáveis. Para um sistema estável, considera-se que a quantidade de amostras deva ser igual ou superior à cinco vezes o número de variáveis de acordo com (FUKUNAGA, 1990). Para resolver este problema, na próxima seção é apresentado o método MLDA.

\subsubsection{Análise de Máximos Discriminantes Lineares (MLDA)}

A técnica denominada Maximum uncertainty Linear Discriminant Análisis foi criada por (THOMAZ C.E.AND KITANI; GILLIES, 2006) para resolver o problema de análise de amostras com pequenas quantidades. Esta técnica consiste em substituir a matriz de espalhamento $S_{w}$ por outra regularizada $S_{w}^{*}$, aumentando o espalhamento e mantendo as variações mais relevantes nas amostras.

Segue na Figura 43 um exemplo da disposição espacial do MLDA.

A nova matriz $S_{w}^{*}$ é calculada da seguinte forma:

a) Seleciona-se os autovetores $\Phi$ e os autovalores $\Lambda$ de $S_{p}$;

$$
S_{p}=\frac{S_{w}}{N-g}
$$

em que:

- $\quad S_{w}=$ matriz de espalhamento;

- $\quad N=$ numero total de imagens;

- $\quad g=$ número de grupos avaliados.

b) Calcula-se a média dos autovalores $\bar{\lambda}$ dada por;

$$
\bar{\lambda}=\frac{\lambda_{1}+\lambda_{2}+\ldots \lambda_{p}}{p}
$$


Figura 43 - Exemplo MLDA.

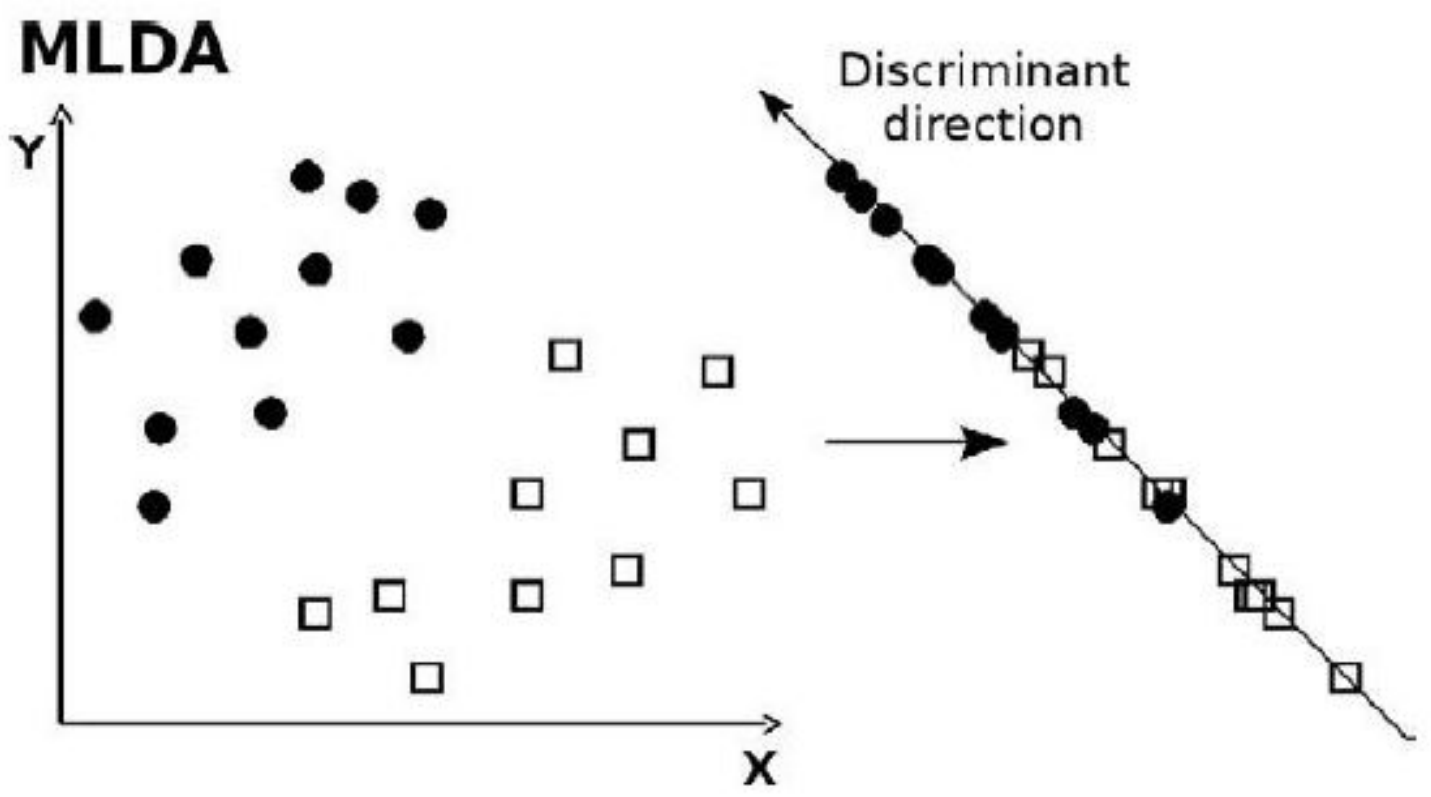

Fonte:Sato et al., 2009.

c) Calcula-se a nova matriz de autovalores;

$$
\Lambda^{*}=\operatorname{diag}\left[\max \left(\lambda_{1}, \bar{\lambda}\right) \ldots ., \max \left(\lambda_{p}, \bar{\lambda}\right)\right]
$$

d) Calcula-se a matriz de espalhamento interclasses regularizada;

$$
S_{w}^{*}=\left(\Phi \Lambda^{*} \Phi^{T}\right)(M-g)
$$

e) Projeta-se os dados obtidos;

Com a matriz $S_{w}^{*}$ calculada, substitui-se $S_{w}$ da equação (16) por $S_{w}^{*}$ e regulariza-se para situações em que onde $\mathrm{N}<\mathrm{p}$.

Uma vez que a matriz L tenha sido calculada, pode-se representar as características mais discriminantes do sinal codificado das imagens $y_{i, j}$, conforme a equação:

$$
z_{i, j}=\left(y_{i, j}-\bar{y}\right) L
$$


em que:

a) $\quad z_{i, j}=$ são as características mais discriminantes da amostra do grupo L;

b) $\quad l \leq \min (p,(g-1))$;

Uma ideia geral desses cálculos estatísticos multivariados é apresentado na Figura 44. Figura 44 - Diagrama do Trabalho.

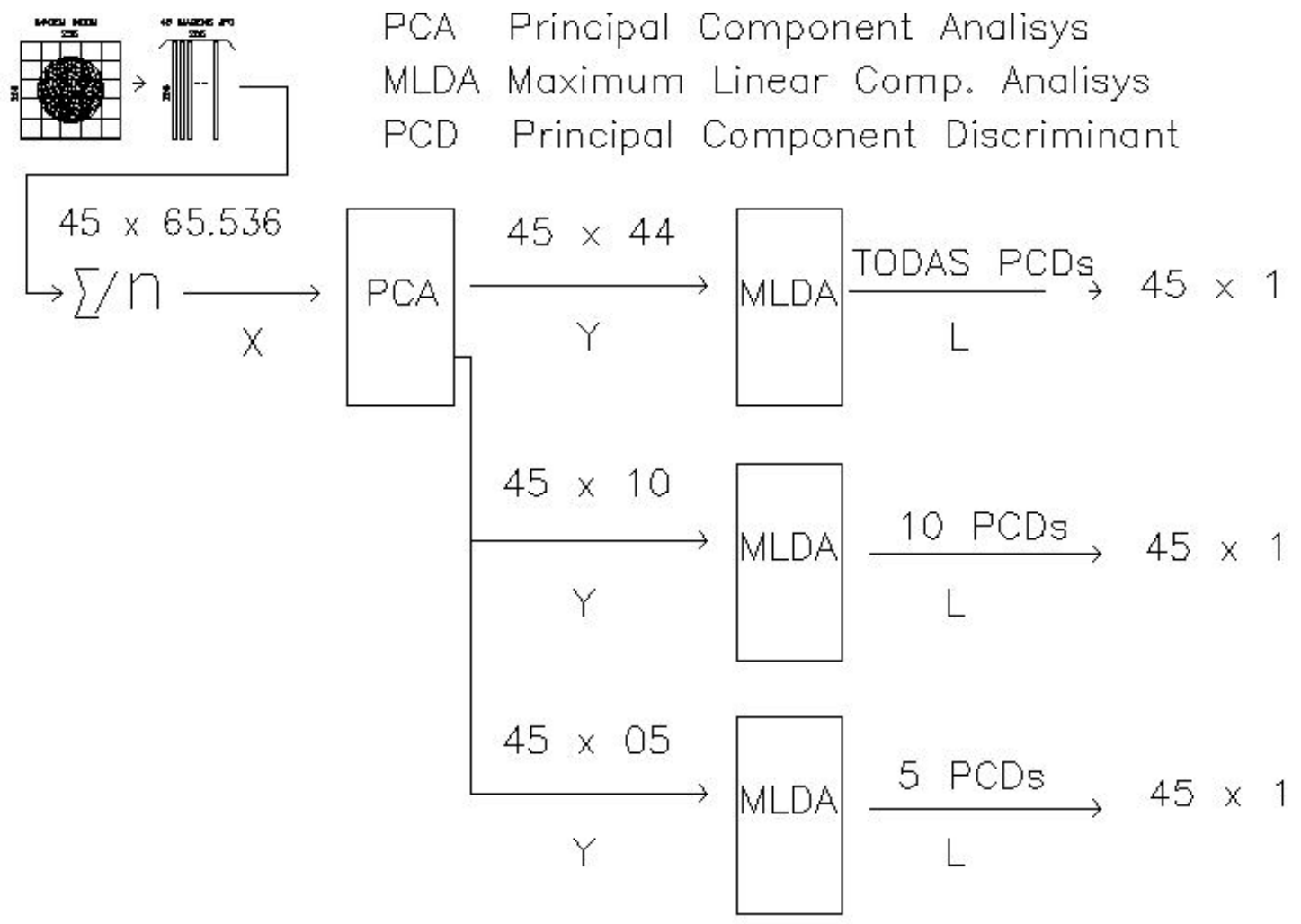

Fonte:Andrioli, 2021. 


\section{RESULTADOS}

Seguem nas Figuras 45, 46, 47 e 48 as imagens referentes à primeira, segunda e às duas últimas componentes principais, resultantes do PCA.

A primeira e segunda componentes principais são as que apresentaram maiores índices, ou seja, são informações presentes na maioria das imagens. As imagens da primeira e segunda componentes principais apresentadas, mostram as informações mais contidas en todas as imagens.

As duas últimas componentes principais representam as informações que apresentam índices menores, ou que não sáo tão presentes em todas as imagens. Neste caso, elas representam as diferenciações presentes nas imagens, ou seja, o ruído que estamos estudando.

Figura 45 - Imagem Primeira Componente PCA.

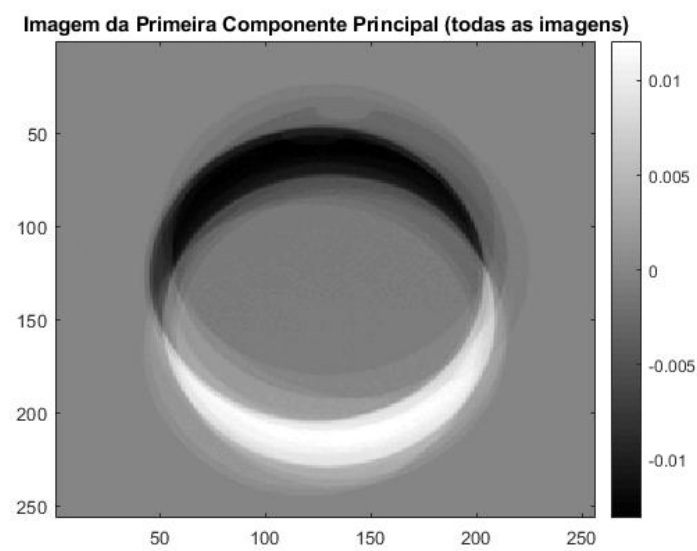

Fonte:Andrioli, 2021

Como resposta do PCA para as duas primeiras componentes principais temos os seguintes gráficos das Figuras 49 e 50.

Os dados resultantes do PCA ( 45 x 44) são considerados como entrada para o processo de MLDA. Como resposta do processo de MLDA temos um gráfico de barras apresentado na Figura 51.

Realizou-se um comparativo entre a variância representada pelo PCA e a discriminância representada pelo MLDA. Observou-se que, a variância decai exponencialmente entre as primeiras principais componentes e as componentes subsequentes.

O MLDA não apresenta este mesmo comportamento. Observou-se que, o MLDA apresenta valores diferenciados para até as componentes que se apresentavam com pouca variância, mas que por algum motivo se destacavam das demais componentes. 
Figura 46 - Imagem Segunda Componente PCA.

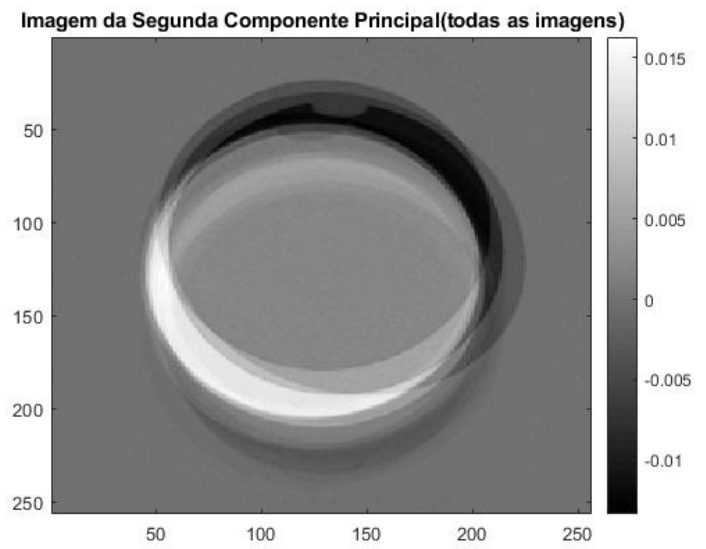

Fonte:Andrioli, 2021.

Figura 47 - Imagem 43a Componente PCA.

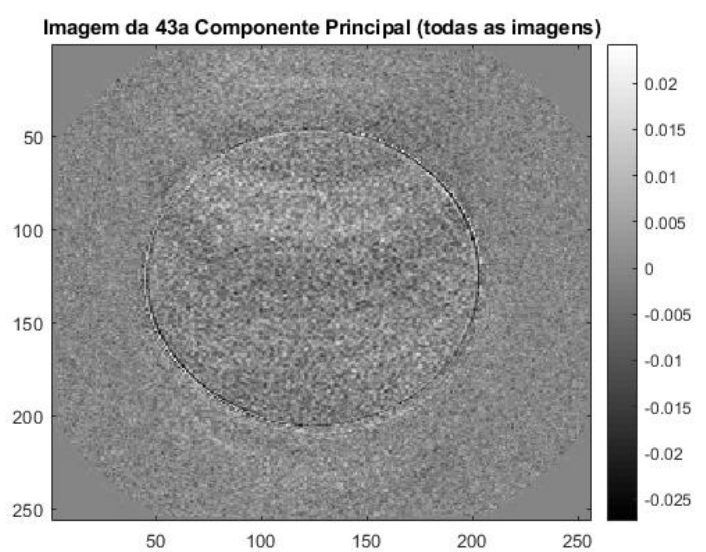

Fonte:Andrioli, 2021.

Segue na Figura 52 o gráfico da Variância em comparação com a Disriminância para as amostras coletadas.

\subsection{ANÁLISE DOS COMPONENTES PRINCIPAIS (PCA)}

Verificando os resultados obtidos em resposta ao PCA, pode-se verificar pelos gráficos das Figuras 49 e 50 que o PCA não conseguiu separar adequadamente através da variância as imagens boas das imagens ruins. Esta etapa do trabalho serviu para realmente funcionar como um filtro, diminuindo consideravelmente a quantidade de informação de entrada e assim facilitar o trabalho do processo seguinte, o MLDA. 
Figura 48 - Imagem 44a Componente PCA.

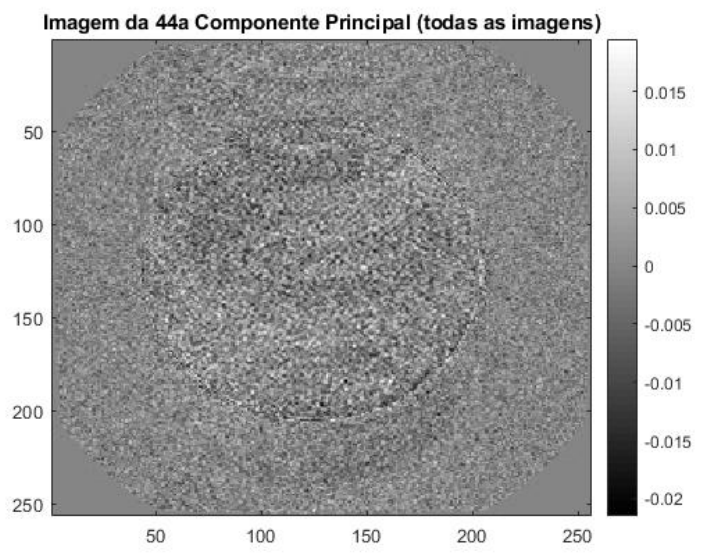

Fonte:Andrioli, 2021.

Figura 49 - Gráfico PCA 1a (x 1) e 2a (o 2) componentes.

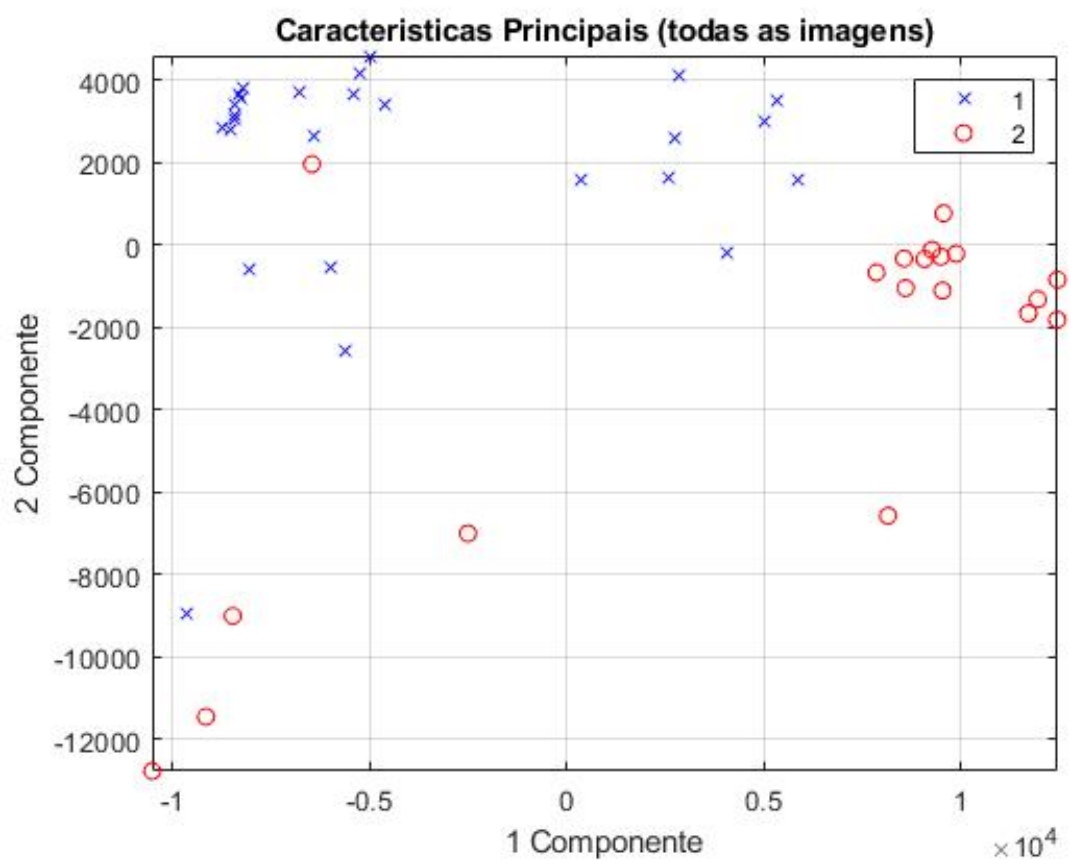

Fonte:Andrioli, 2021.

Apesar das imagens de ressonância magnética serem imagens consideradas com volume considerável de informação, no caso deste trabalho, foram usadas 45 imagens e o volume de informação inicial foi grande.

Considerando a análise de maiores quantidades de imagens, este processo de PCA sempre servirá como um filtro muito importante para a diminuição da quantidade de informação a ser processada pelo MLDA. 
Figura 50 - Gráfico PCA 3a (x 3) e 4a (o 4) componentes.

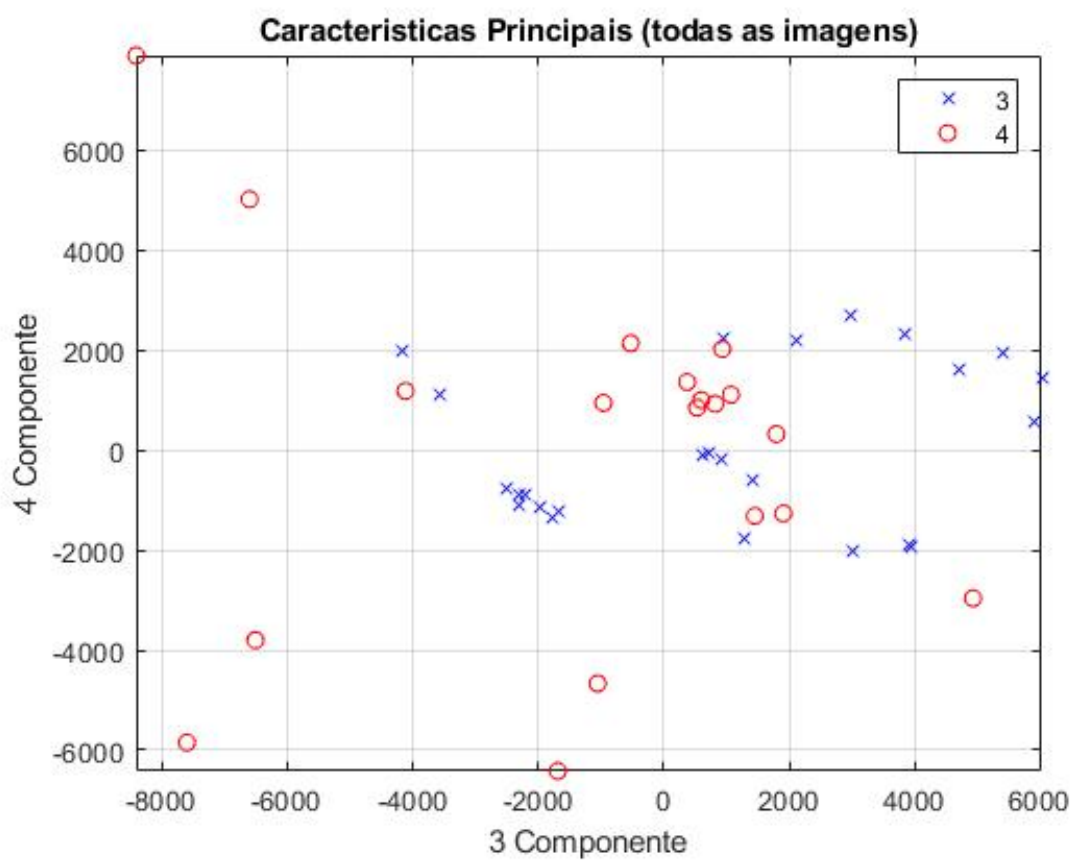

Fonte:Andrioli, 2021.

Figura 51 - Gráfico MLDA para todas as componentes principais.

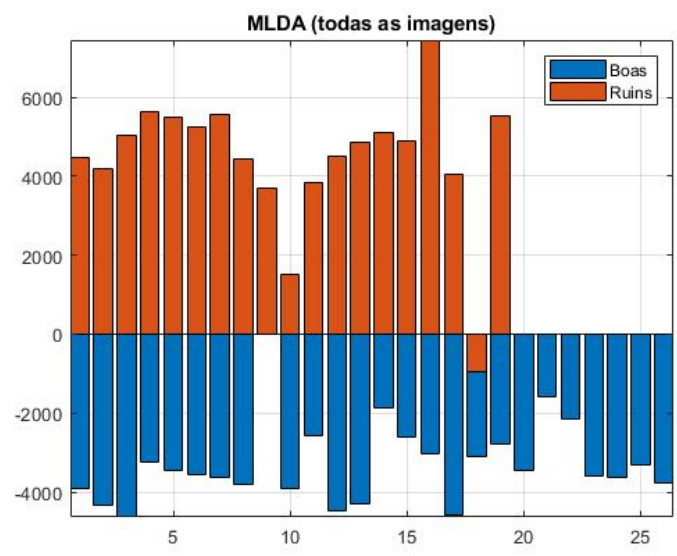

Fonte:Andrioli, 2021.

Verifica-se que, para a separação das imagens, no caso específico deste trabalho, as componentes de menor valor de variância (componentes 44 e 43 do PCA) serão fundamentais, porque o ruído de fundo se assemelha com as imagens apresentadas por estas componentes de acordo com as Figuras 47 e 48.

Observa-se que o processo de MLDA, usando todas as componentes principais do PCA, separou satisfatoriamente as imagens boas e ruins. 
Figura 52 - Gráfico da Variância e Discriminância para todas as imagens.

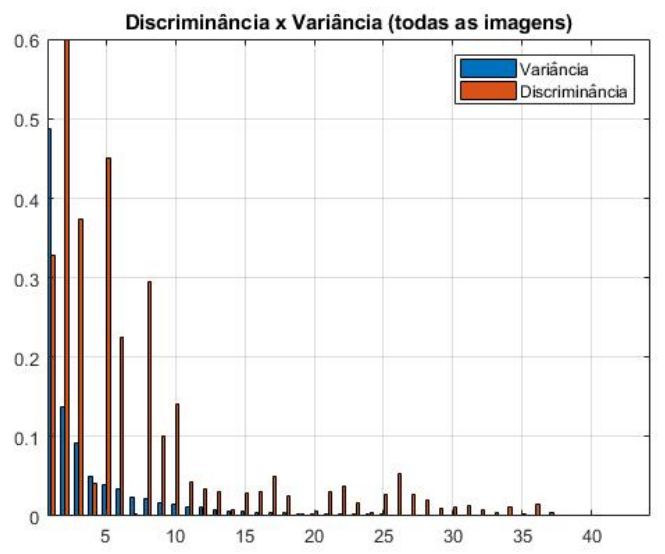

Fonte:Andrioli, 2021.

Pelo gráfico da Figura 51 pode-se verificar que o processo de MLDA classificou como imagens boas 25 das 26 imagens boas analisadas, e 18 imagens ruins do total de 19 imagens ruins.

\subsection{ANÁLISE DO SNR e MLDA}

Como informado neste trabalho, o equipamento analisa a qualidade de imagem pelo SNR e se o SNR estiver acima de 105 para a bobina de $180 \mathrm{~mm}$, o equipamento indica automaticamente que passou no teste de qualidade de imagem.

Na Figura 53, é apresentada a relação do SNR x MDLA. Pelo gráfico, observa-se plenamente a separação apresentada pelo gráfico de código de barras do MLDA da Figura 51.

No gráfico da Figura 54 fica explícita a separação das imagens boas e ruins pelo MLDA.

Observando o gráfico, considerando como limiar a posição 0 no campo do MLDA, observa-se que apenas duas imagens (sendo uma considerada boa e outra ruim pelo especialista) que se encontram fora da classificação como correta, pelo MLDA. Considerando como segundo classificador o valor de 105 para o SNR como determinante para as imagens boas (como classificado autimaticamente pelo equipamento), temos o gráfico da Figura 55.

O gráfico é separado em quatro áreas. No sentido horizontal, as duas áreas superiores representam as imagens consideradas boas pelo processo de SNR e as duas áreas inferiores (abaixo do valor de 105) são as imagens ruins.

No sentido vertical, as duas áreas à esquerda do valor 0 são consideradas imagens boas pelo MLDA e as duas áreas à diretia (acima do valor 0) são as imagens ruins. 
Figura 53 - Gráfico SNR x MLDA para todas as imagens.

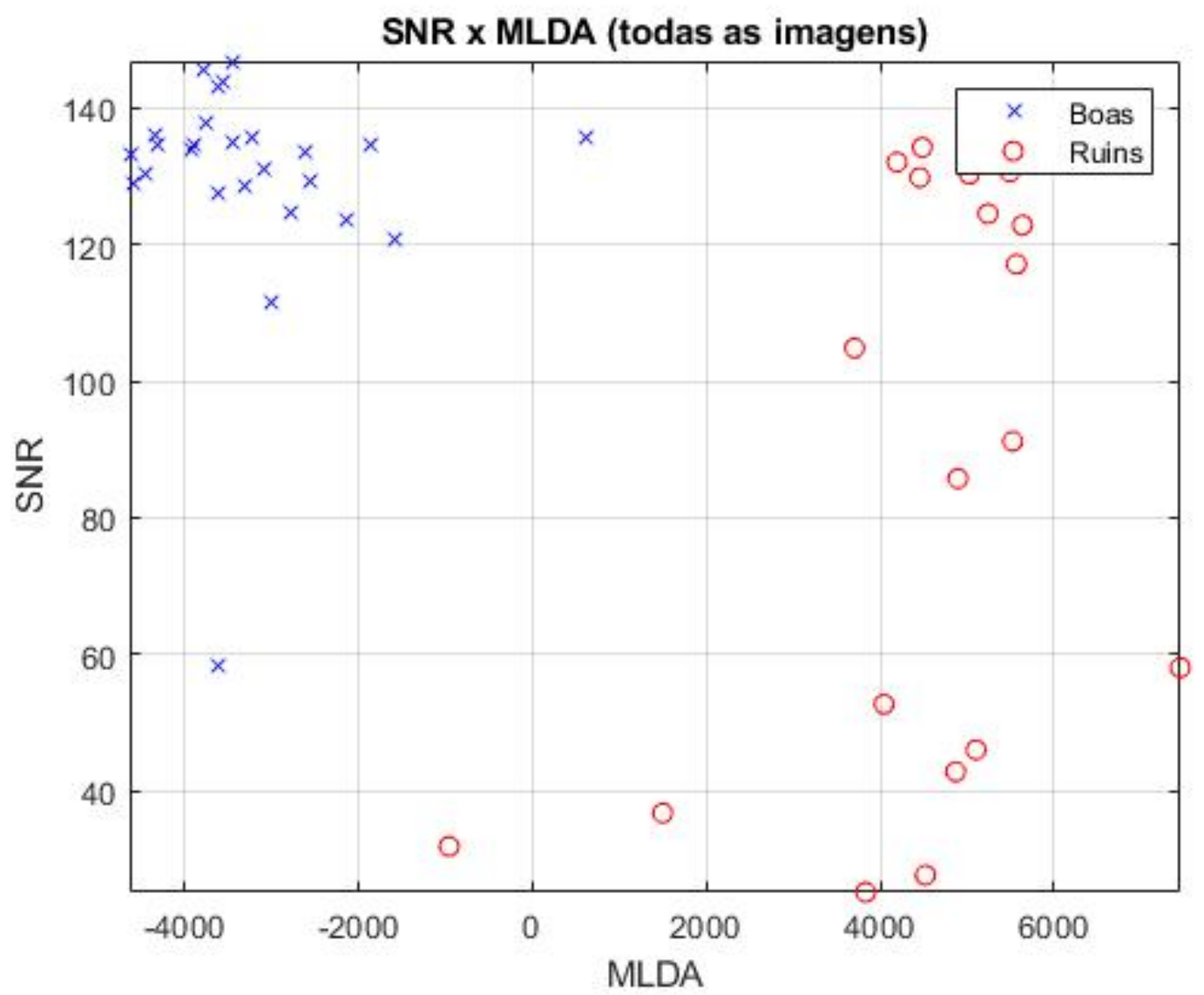

Fonte:Andrioli, 2021.

Cosniderando os dois processos de classificação (SNR e MLDA) concui-se pelo gráfico que as imagens situadas na área superior à esquerda representam as imagens boas pelos dois processos e as imagens localizadas na área inferior e à direita são as imagens ruins pelos dois processos de classificação.

Localizadas na área superior à direita são as imagens consideradas boas pelo SNR mas ruins pelo MLDA e as imagens posicionadas na área inferior e à direita são as imagens consideradas ruins pelo SNR mas boas pelo MLDA conforme exemplificado na Figura 56.

A explicação para estes resultados é dada a seguir:

Pelo gráfico (detalhe da área 1) são 8 imagens consideradas ruins pelo especialista e pelo MLDA por apresentarem erros de posicionamento, artefatos, geometria errada e demais problemas de imagem como demostrado na Figura 57, mas que pelo SNR seriam consideradas boas por apresentarem valor acima de 105 (ONI, M. S., 2005). 
Figura 54 - Gráfico SNR x MLDA Boas e Ruins.

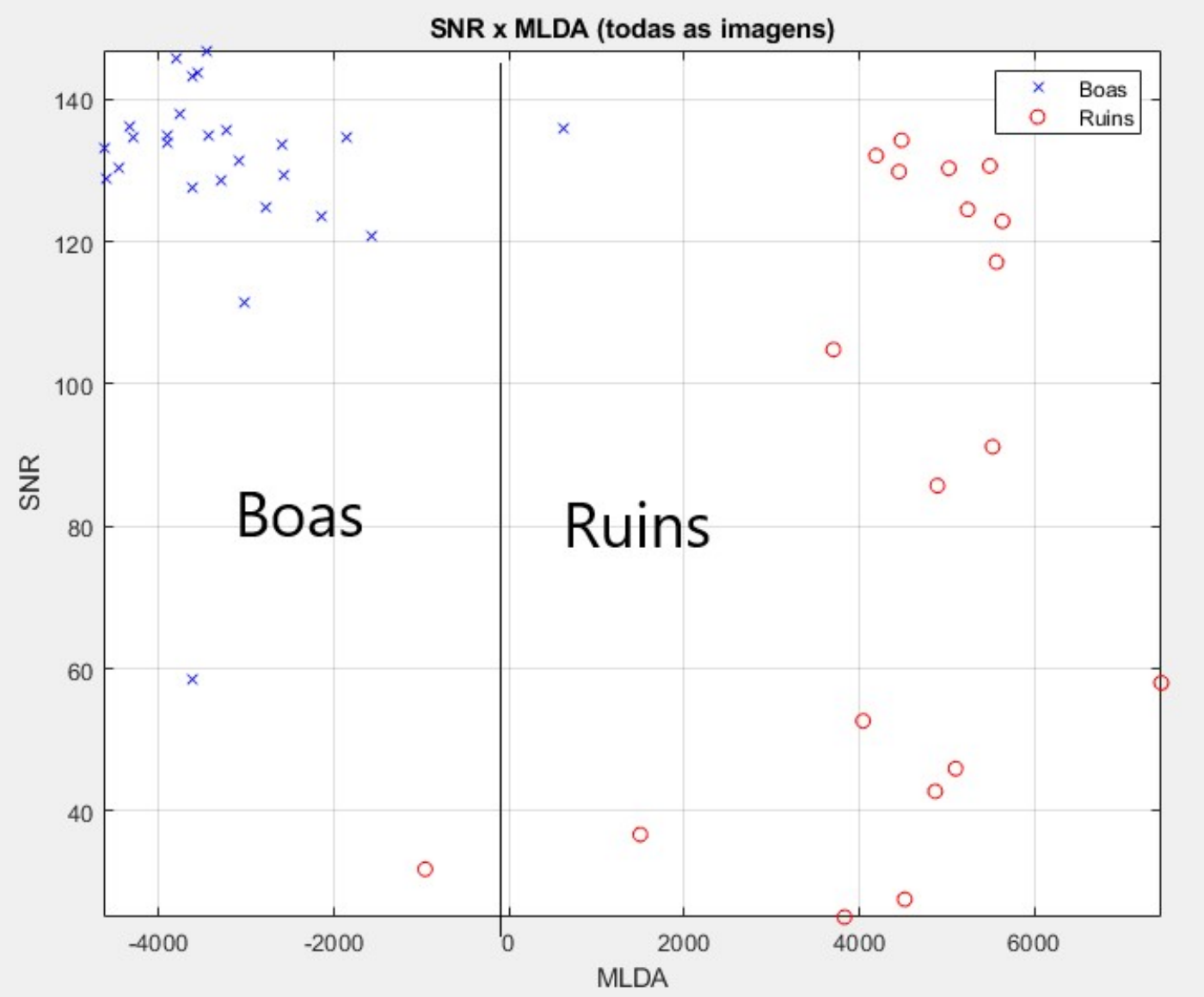

Fonte:Andrioli, 2021.

No mesmo gráfico da Figura 56 (detalhe da área 2) é apresentada uma imagem em que o especialista e o MLDA consideraram como boa (conforme exemplificada na Figura 58, mas pelo SNR é considerada ruim por apresentar valor abaixo de 105 (ONI, M. S., 2005).

\subsection{CONFIABILIDADE DO SISTEMA}

\subsubsection{Processo Leave One Out}

Para confirmar a confiabilidade do sistema, foi realizado o teste de leave-one-out, que consiste em retirar uma das amostras de classificação do sistema, realizar a classificação sem a amostra retirada e posteriormente calcular a amostra em relação ao sistema, verificando se a mesma se encontra como boa ou ruim. Isso é possível, aplicando à amostra o mesmo processo que todas as outras amostras receberam.

A Figura 59 representa o processo de leave one out realizado, sendo: 
Figura 55 - Gráfico SNR e MLDA das Imagens Boas e Ruins.

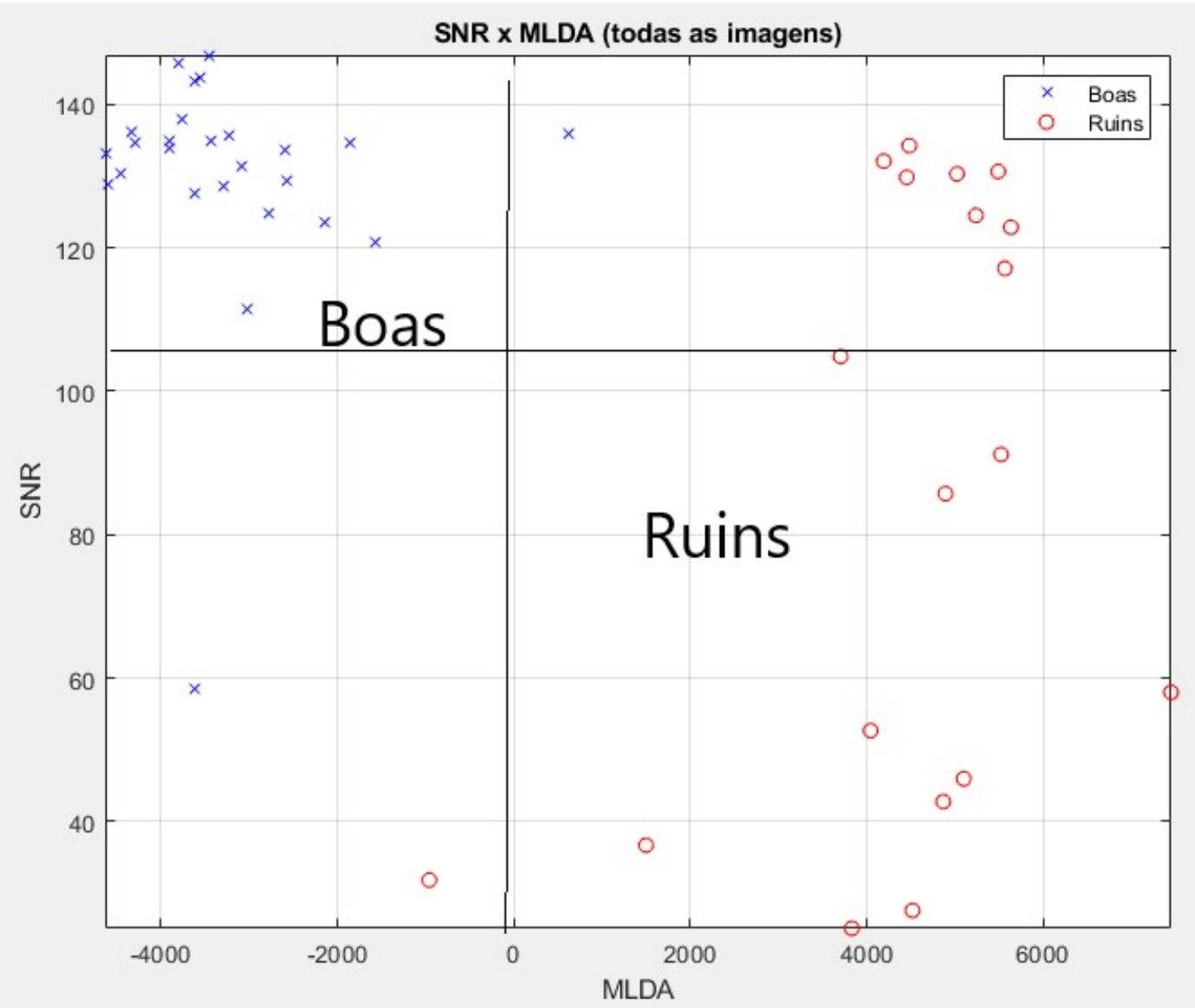

Fonte:Andrioli, 2021.

a) $\quad X=$ Imagens boas e ruins;

b) $\quad P=$ Valores da Variância;

c) $\quad Y=$ Classificação das imagens com os valores da variância aplicados;

d) $\quad L=$ Valores da Discriminância;

e) $\quad Z=$ Classificação das imagens com os valores da discriminância aplicados;

f) $\quad B=$ Imagem única selecionada;

g) $\quad C=$ Classificação da imagem selecionada com os valores da variância aplicados;

h) $\quad D=$ Classificação da imagem selecionada com os valores da discriminância aplicados;

Ao final, verifica-se se o valor de D está mais próximo dos valores das imagens boas ou ruins, através da aplicação do cálculo da distância Euclidiana (ou distância métrica).

Como inicialmente se conhece, a condição da imagem B, se ela é boa ou ruim, verificase a resposta do sistema e confirma-se se o mesmo acertou ou errou na análise. As respostas 
Figura 56 - Detalhe do gráfico SNR e MLDA das Imagens Boas e Ruins.

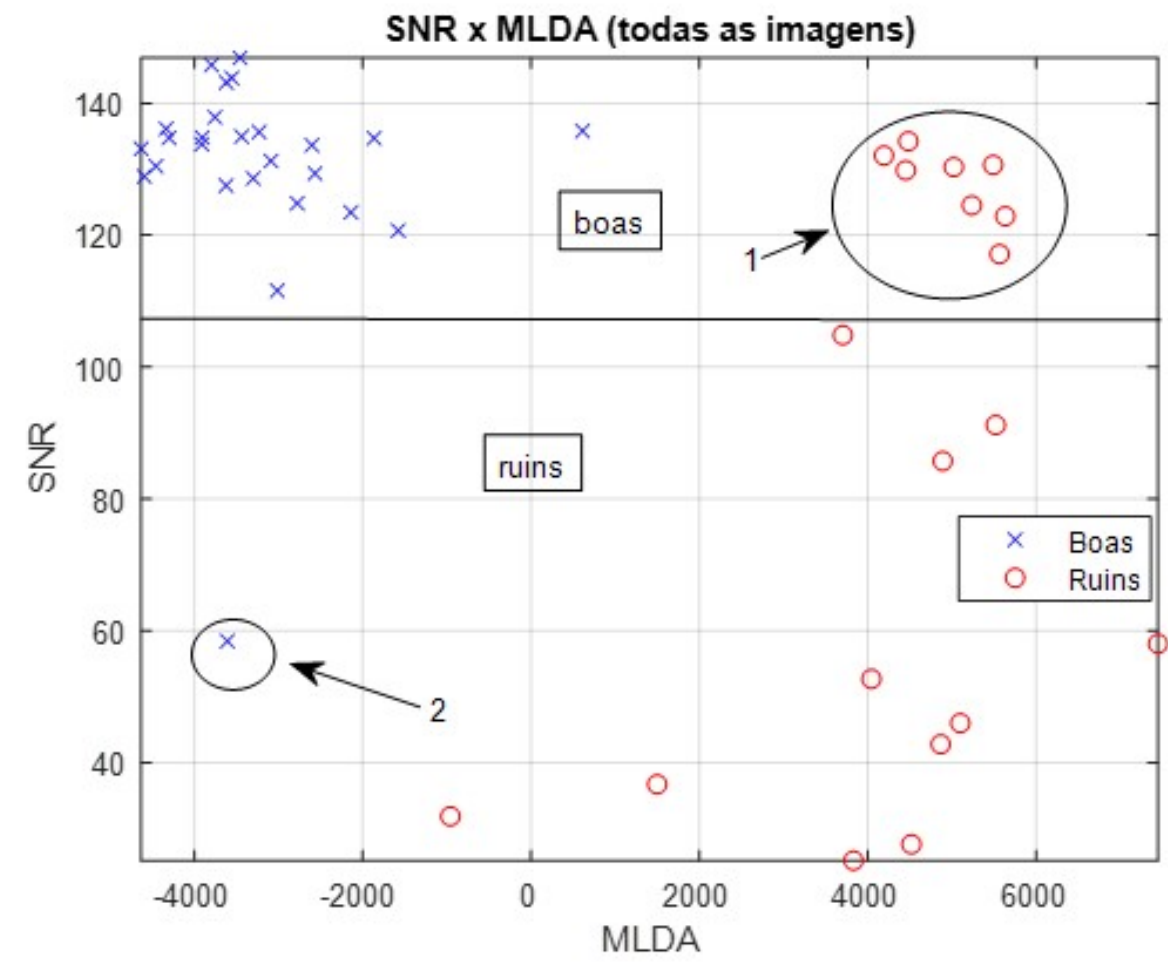

Fonte:Andrioli, 2021.

Figura 57 - Imagens ruins pelo MLDA mas boas pelo SNR.

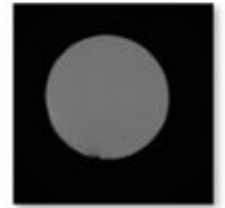

bno004.jpg

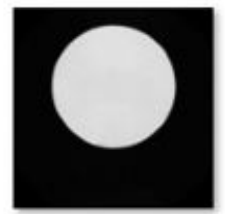

bpo003.jpg

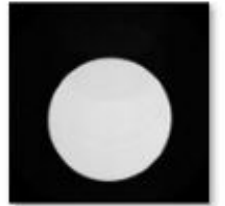

bno015.jpg

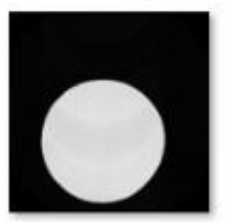

bpo007.jpg

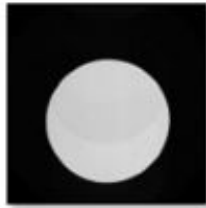

bno016.jpg

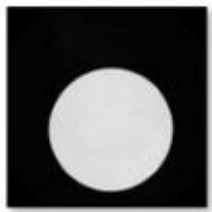

bpo008.jpg

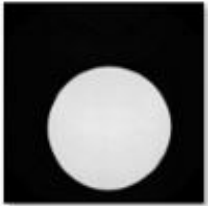

bpo001.jpg

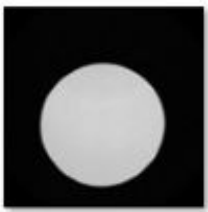

bpo011.jpg

Fonte:Andrioli, 2021.

para cada amostra realisada encontra-se na Figura 61 e o gráfico que expressa esta tabela na Figura 60. 
Figura 58 - Imagem boa pelo MLDA mas ruim pelo SNR.

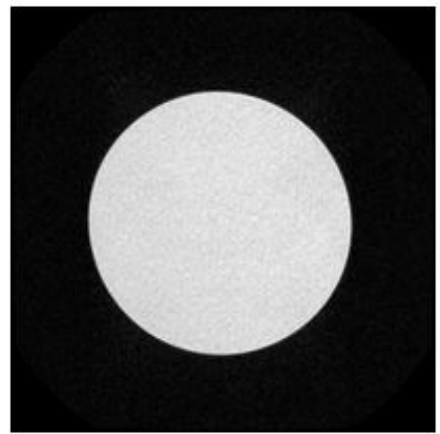

Fonte:Andrioli, 2021.

Figura 59 - Processo Leave-one-out

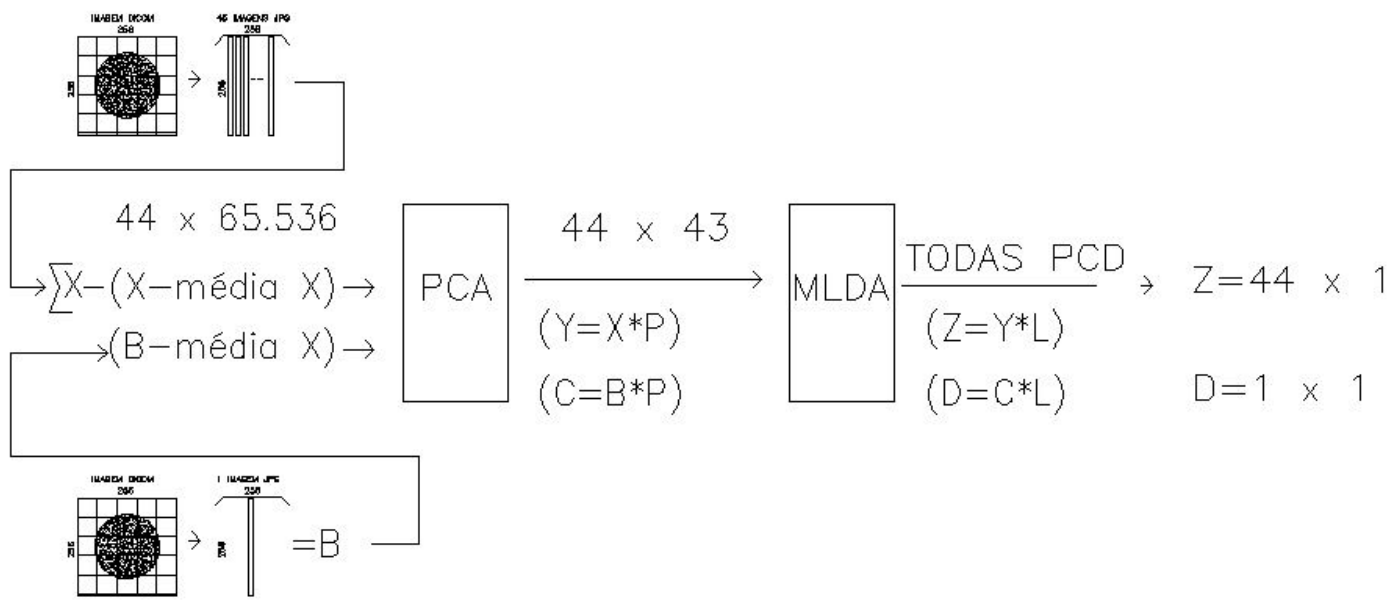

Fonte:Andrioli, 2021.

\subsubsection{Acurácia}

Trata-se da proporção de resultados corretos que o classificador alcançou. Ou seja, a razão entre as predições corretas pelo total. No exemplo deste trabalho, seria o número de classificações corretas, dentre todas as imagens coletadas. O sistema acertou 42 imagens das 45 analisadas, apresentando uma acurácia de 93,33\%.

Um exemplo de classificação de imagem utilizado neste trabalho é dado na figura 62. A imagem verificada separadamente (rpa004) foi classificada pelo especialista como uma imagem boa e foi classificada pelo código também como imagem boa. 
Figura 60 - Gráfico Leave-one-out

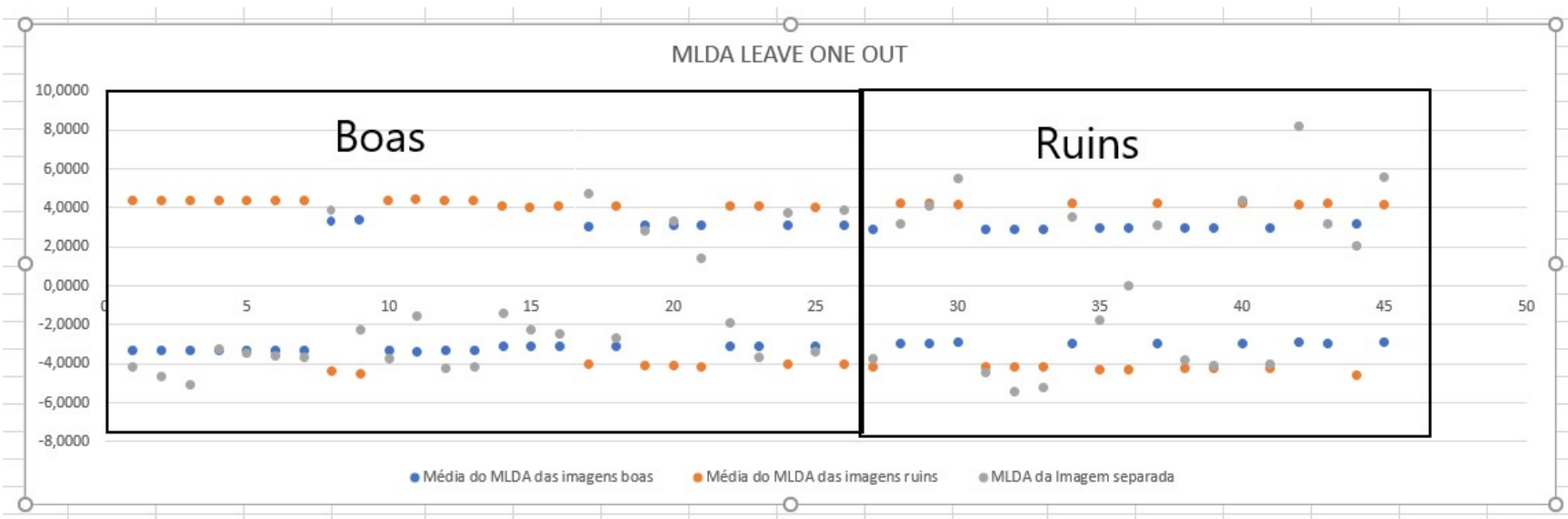

Fonte:Andrioli, 2021.

\subsubsection{Redução do Sistema pelos dez e cinco valores mais discriminantes}

Para efeito de pesquisa, foram feitos testes no sistema utilizando como selecionador os dez e cinco componentes principais e os resultados são apresentados nas Figuras 63 e 64.

Os resultados obtidos em relação à quantidade de imagens classificadas como boas e ruins para as 10 componentes principais apresentaram ser iguais aos resultados obtidos usando todas as componentes principais, sendo apenas uma imagem considerada ruim pelo especialista, mas boa pelo MLDA.

Quando foram usadas apenas as 5 componentes principais, duas imagens apresentaram diferenças em relação ao resultado utilizando todas as componentes principais.

Isso siginifa que, podemos usar as 10 principais componentes para estudo das imagens, diminuindo muito a quantidade de informação (dados) a serem processados. Em sistema de grande quantidade de imagens, isso representa dimunuição de memória e tempo de processamento, sem a perda da qualidade dos resultados. 
Figura 61 - Análise Leave-one-out

\begin{tabular}{|c|c|c|c|c|c|c|c|c|c|c|c|c|}
\hline $\begin{array}{l}\text { Todas as componentes } \\
\text { principais }\end{array}$ & & & & & & & & & & & & \\
\hline $\begin{array}{l}\text { Código } \\
\text { PCAMEN CS1BOA520121 e } \\
\text { PCAMEN OS1RUIME20121 } \\
\text { amostra retirada abaixo }\end{array}$ & Total de & Total de & le $T$ & Total de & Resul tado & \begin{tabular}{|l|} 
Média do \\
MLDA \\
das \\
imagens \\
boas (z \\
boas)
\end{tabular} & \begin{tabular}{|l|} 
Média do \\
MLDA \\
das \\
imagens \\
ruins (z) \\
ruins) \\
\end{tabular} & $\begin{array}{l}\text { MDA da } \\
\text { Imagem } \\
\text { separada } \\
\text { (D) }\end{array}$ & \begin{tabular}{|l|} 
Distância \\
para as \\
imagens \\
boas
\end{tabular} & \begin{tabular}{|l|} 
Distância \\
para as as \\
imagens \\
ruins
\end{tabular} & $\mid \begin{array}{l}\text { Result ado } \\
\text { (distância } \\
\text { Euclidiana } \\
\text { menor) }\end{array}$ & $\begin{array}{l}\text { Posi ção } \\
\text { da } \\
\text { imagem }\end{array}$ \\
\hline bno001 & 44 & & 25 & 19 & 24 & $-3,3300$ & 4,3316 & $-4,1490$ & 0,819 & 8,5306 & Boa & 1 \\
\hline bno002 & 44 & & 25 & 19 & 24 & $-3,3264$ & 4,3768 & $-4,6692$ & 1,3428 & 9,046 & Boa & 2 \\
\hline bno003 & 44 & & 25 & 19 & 24 & $-3,3240$ & 4,3737 & $-5,0484$ & 1,7244 & 9,4221 & Boa & 3 \\
\hline bno005 & 44 & & 25 & 19 & 24 & $-3,3242$ & 4,3739 & $-3,2120$ & 0,1122 & 7,5659 & Boa & $\exists$ \\
\hline bno006 & 44 & & 25 & 19 & 24 & $-3,3244$ & 4,3742 & $-3,4909$ & 0,1665 & 7,8651 & Boa & 5 \\
\hline bno007 & 44 & & 25 & 19 & 24 & $-3,3234$ & 4,3729 & $-3,6066$ & 0,2832 & 7,9795 & Boa & 6 \\
\hline bno008 & 44 & & 25 & 19 & 24 & $\mid-3,3231$ & 4,3726 & $-3,6811$ & 0,358 & 8,0537 & Boa & \\
\hline bno009 & 44 & & 25 & 19 & 24 & 3,3224 & $-4,3715$ & 3,8756 & 0,5532 & 8,2471 & Boa & 目 \\
\hline bno010 & 44 & & 25 & 19 & 25 & 3,4224 & $-4,5032$ & $-2,2770$ & 5,6994 & 2,2262 & Ruim & s \\
\hline bno011 & 44 & & 25 & 19 & 24 & $-3,3282$ & 4,3793 & $-3,7229$ & 0,3947 & 8,1022 & Boa & 10 \\
\hline bno012 & 44 & & 25 & 19 & 24 & $-3,3870$ & 4,4566 & $-1,5433$ & 1,8387 & 6,0049 & Boa & 11 \\
\hline bno013 & 44 & & 25 & 19 & 24 & $-3,3159$ & 4,3630 & $-4,2431$ & 0,9272 & 8,6061 & Boa & 12 \\
\hline bno014 & 44 & & 25 & 19 & 24 & $-3,3146$ & 4,3613 & $-4,1925$ & 0,8779 & 8,5538 & Boa & 13 \\
\hline bno017 & 44 & & 25 & 19 & 24 & $-3,0908$ & 4,0669 & $-1,4008$ & 1,69 & 5,4677 & Boa & 14 \\
\hline bno018 & 44 & & 25 & 19 & 24 & $-3,0810$ & 4,0547 & $-2,2716$ & 0,8094 & 6,3263 & Boa & 15 \\
\hline bno019 & 44 & & 25 & 19 & 24 & $-3,1045$ & 4,0854 & $-2,4427$ & 0,6618 & 6,5276 & Boa & 16 \\
\hline bpo002 & 44 & & 25 & 19 & 24 & 3,0458 & $-4,0116$ & 4,7484 & 1,6996 & 8,76 & Boa & 17 \\
\hline bpo004 & 44 & & 25 & 19 & 24 & \begin{tabular}{|l|}
3,0993 \\
\end{tabular} & 4,0780 & $-2,6706$ & 0,4287 & 6,7486 & Boa & 18 \\
\hline bpo005 & 44 & & 25 & 19 & 24 & 3,1116 & $-4,0942$ & 2,8312 & 0,2804 & 6,9254 & Boa & 19 \\
\hline bpo006 & 44 & & 25 & 19 & 24 & 3,0904 & $-4,0663$ & 3,2948 & 0,2044 & 7,3611 & $B 0 a$ & 20 \\
\hline bpo009 & 44 & & 25 & 19 & 24 & 3,1421 & $-4,1343$ & 1,4438 & 1,6933 & 5,5631 & Boa & 21 \\
\hline bpo010 & 44 & & 25 & 19 & 24 & $-3,1287$ & 4,1167 & $-1,8803$ & 1,2454 & 5,997 & Boa & 22 \\
\hline rpa001 & 44. & & 25 & 19 & 24 & $-3,0929$ & 4,0696 & $-3,6636$ & 0,5707 & 7,7332 & Boa & 23 \\
\hline rpa002 & 44 & & 25 & 19 & 24 & 3,0789 & $-4,0512$ & 3,7688 & 0,6699 & 7,82 & Boa & 24 \\
\hline $\mathrm{rpaC03}$ & 44 & & 25 & 19 & 24 & $-3,0797$ & 4,0522 & $-3,3794$ & 0,2997 & 7,4316 & Boa & 25 \\
\hline rpa004 & 44 & & 25 & 19 & 24 & 3,0759 & $-4,0472$ & 3,8700 & 0,7941 & 7,9172 & Boa & 26 \\
\hline bno004 & 44 & & 26 & 18 & 25 & 2,9002 & $-4,1891$ & $-3,7080$ & 6,6052 & 0,4811 & Ruim & 1 \\
\hline bno015 & 44 & & 26 & 18 & 25 & $-2,9593$ & 4,2746 & 3,1722 & 6,1315 & 1,1024 & Ruim & 2 \\
\hline bno016 & 44 & & 26 & 18 & 25 & $-2,930 \mathrm{~B}$ & 4,2334 & 4,0853 & 7,0161 & 0,1481 & Ruim & 3 \\
\hline bpo001 & 44 & & 26 & 18 & 25 & $-2,8634$ & 4,1650 & 5,5073 & 8,3907 & 1,3423 & Ruim & 4 \\
\hline bpo003 & 44 & & 26 & $1 \mathrm{~B}$ & 25 & 2,8721 & $-4,1486$ & $-4,4178$ & 7,2899 & 0,2692 & Ruim & 3 \\
\hline bpo007 & 44 & & 26 & 18 & 25 & 2,8797 & $-4,1596$ & $-5,4096$ & 8,2895 & 1,2502 & Ruim & \\
\hline bpo008 & 44 & & 26 & 18 & 25 & 2,8919 & $-4,1772$ & $-5,1963$ & $8,08 \mathrm{B2}$ & 1,0191 & Ruim & 7 \\
\hline bpo011 & 44 & & 26 & 18 & 25 & $-2,9326$ & 4,2359 & 3,5463 & 6,4789 & 0,6896 & Ruim & 园 \\
\hline bshoar & 44 & & 26 & 18 & 25 & 2,9767 & $-4,2996$ & $-1,7657$ & 4,7624 & 2,5139 & Ruim & s \\
\hline ffloor & 44 & & 26 & 18 & 26 & 2,9870 & $-4,3146$ & 0,0002 & 2,9668 & $4,314 \mathrm{~B}$ & Boa & 10 \\
\hline rf 000 & 44 & & 26 & 18 & 25 & $-2,9533$ & 4,2659 & 3,1018 & 6,0551 & 1,1641 & Ruim & 11 \\
\hline rf 1003 & 44 & & 26 & 18 & 25 & 2,9491 & $-4,2599$ & $-3,8014$ & 6,7505 & 0,4585 & Ruim & 12 \\
\hline ifloo4 & 44 & & 26 & 18 & 25 & 2,9393 & $-4,2456$ & $-4,0811$ & 7,0204 & 0,1645 & Ruim & 13 \\
\hline rf 005 & 44 & & 26 & 18 & 25 & $-2,9309$ & 4,2336 & 4,3630 & 7,2939 & 0,1294 & Ruim & 14 \\
\hline iflo06 & 44 & & 26 & 18 & 25 & 2,9345 & $-4,2388$ & $-4,0161$ & 6,9507| & 0,2227 & Ruim & 15 \\
\hline rf 1007 & 44 & & 26 & 18 & 25 & $-2,8781$ & 4,1572 & 8,2126 & 11,0907 & 4,0554 & Ruim & 16 \\
\hline rf 008 & 44 & & 26 & 18 & 25 & $-2,9367$ & 4,2419 & 3,1499 & 6,0866 & 1,092 & Ruim & 17 \\
\hline if 1009 & 44 & & 26 & 18 & 25 & 3,1921 & $-4,6108$ & 2,0284 & 1,1637 & 6,6392 & Boa & 10 \\
\hline poळ01 & 車 & & 26 & 18 & 25 & $-2,8909$ & 4,1757 & 5,5496 & 8,4405 & 1,3739 & Ruim & \\
\hline
\end{tabular}

Fonte:Andrioli, 2021. 
Figura 62 - Gráfico do MLDA para uma amostra boa.

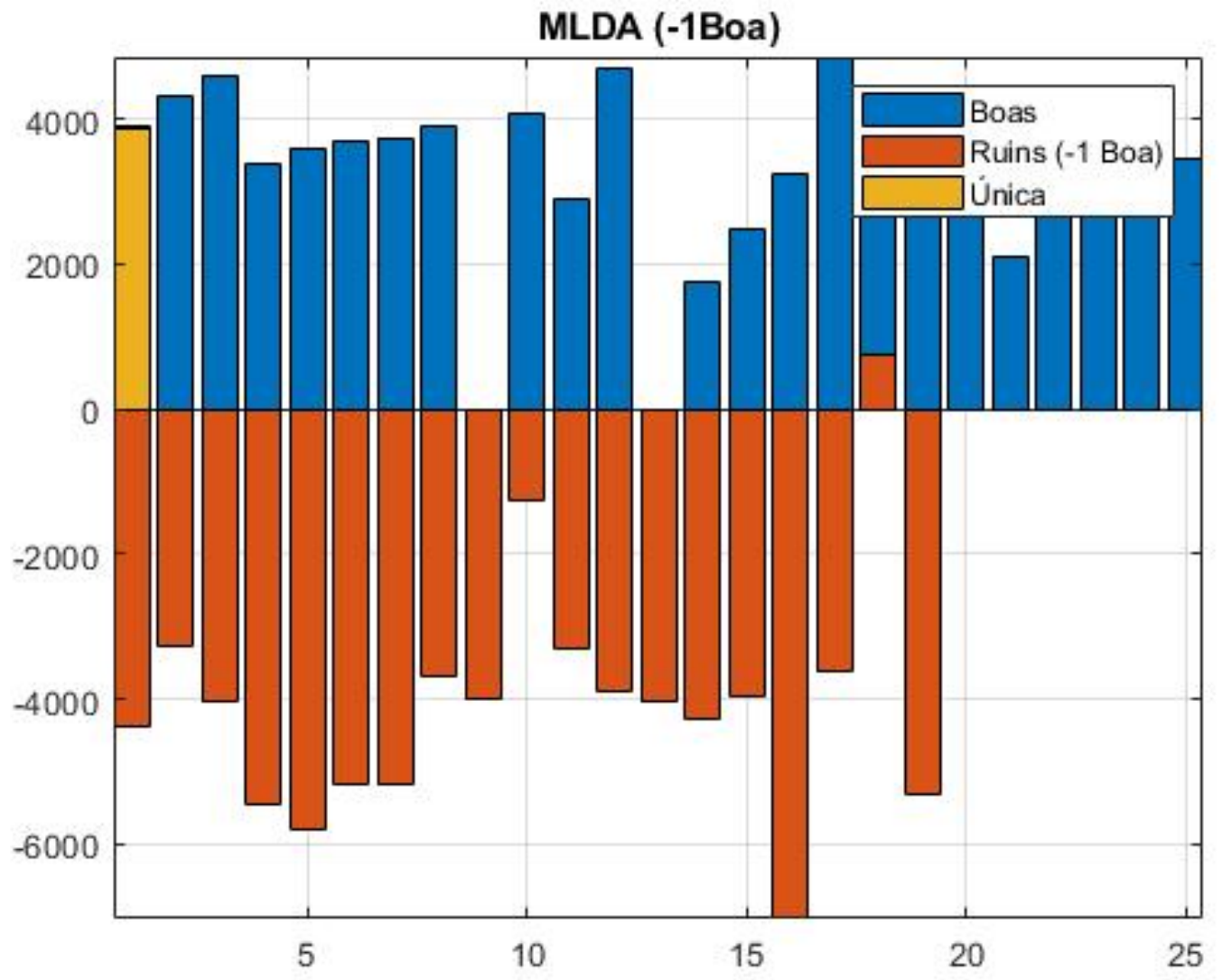

Fonte:Andrioli, 2021. 
Figura 63 - Gráfico MLDA para as 10 Componentes principais.

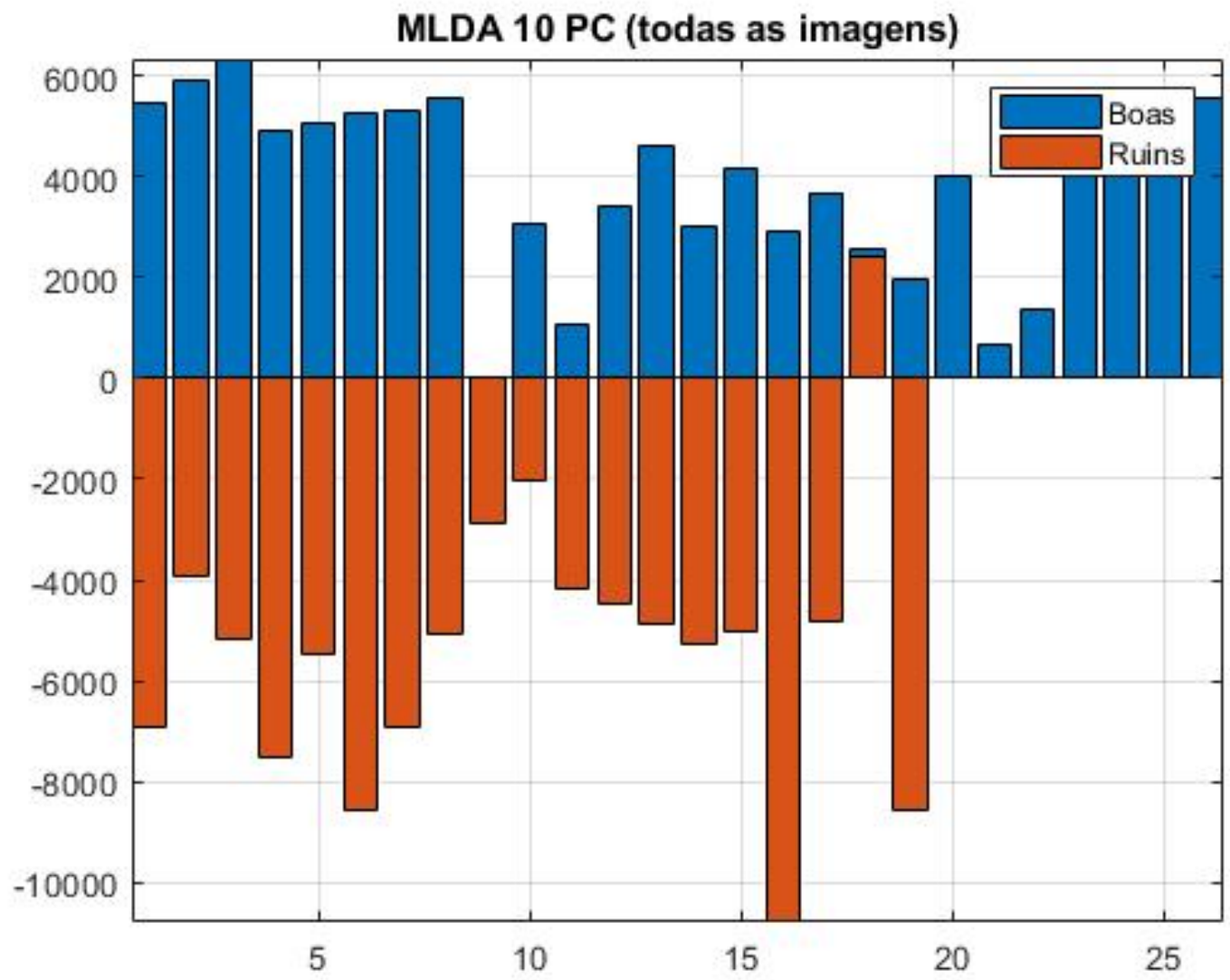

Fonte:Andrioli, 2021. 
Figura 64 - Gráfico MLDA para as 5 componentes principais.

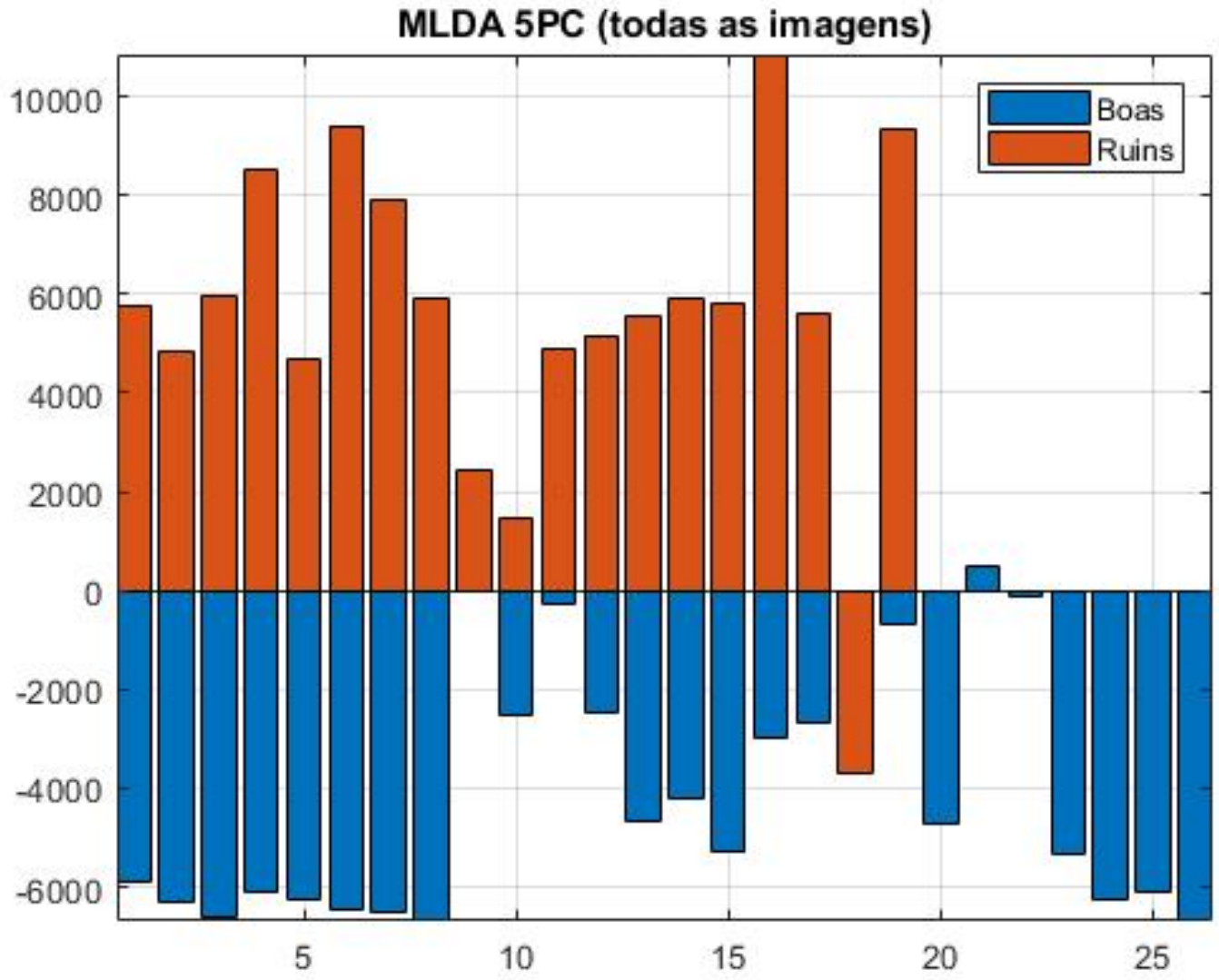

Fonte:Andrioli, 2021. 


\section{CONCLUSÃO}

Constatou-se que, vários fatores que atuam na qualidade da imagem de ressonância passam desapercebidos pela SNR, mas são considerados durante a Análise Estatística Multivariada (PCA + MLDA) como a geometria da imagem, o posicionamento, as bordas, os artefatos entre outros.

O processo só tem eficiência e acurácia apresentada, se e somente se, for aplicado o PCA e em seguida o MLDA.

Como verificado, o uso do (PCA + MLDA) e SNR garantem uma confiabilidade muito maior na qualidade de imagem, todos os equipamentos deveriam ter incorporados ao seu software, o código de (PCA + MLDA) para análise da qualidade da imagem, permitindo que o equipamento entre em funcionamento, apenas após ser aprovado pelos dois testes de qualidade, a SNR e o (PCA + MLDA).

A base utilizada para o estudo foi de 45 imagens, e os resultados obtidos foram extremamente satisfatórios. Porém, se a base de dados for maior, a acurácia será maior ainda.

Esse trabalho limitou-se a estudar ruídos de rádio frequência e interferência eletromagnética, e realizar a análise de imagens em equipamentos de ressonância magnética de extremidades de 1.0T (campo alto), pelo fato de se conhecer o especialista nesse tipo de equipamento, mas poderá ser aplicado em outros equipamentos radiológicos de imagem e em imagens patológicas, desde que acompanhado por um especialista.

A base de dados atual encontra-se disponível de forma aberta para novos trabalhos, que poderão ser realizados usando como proposta a análise dos ruídos apresentados por outros fatores, como interferência ferromagnética, vibração, temperatura da sala, entre outros. 


\section{REFERÊNCIAS}

ANDRIOLI, C. Apontamentos de instalação de ONI. Apontamentos de instalação. [S.1.], mar. 2021.

BLOCH, Felix et al. Nuclear Induction. Physical review, v. 70, p. 460-474, 1946.

CONSTANTINIDES, Chris; ATALAR, Ergin; MCVEIGH, Elliot R. Signal-to-noise measurements in magnitude images from NMR phased arrays. Magnetic Ressonance in Medicine, ISMRM, v. 36, p. 852-857, 1997.

DIETRICH, Olaf et al. Comparison of different cardiac MRI sequences at 1.5 T/3.0 T with respect to signal-to-noise and contrast-to-noise ratios - initial experience. Journal od Magnetic Ressonance Imaging, Wiley, v. 26, p. 375-385, 2007.

FISHER, R. A. The use of multiple measurements in taxonimic problems. Annals of Eugenics, Public Library of Science, v. 7, n. 2, p. 179-188, 1936.

FRANKILN, Benjamin. Notes. Classroom notes. [S.1.], mar. 1790.

FUKUNAGA, K. Introduction to Statistical Pattern Recognition. [S.1.]: Cambridge University Press, 1990.

GIRALDI, G.; THOMAZ, C.E.; RODRIGUES, P.S. Dimensionality reduction, classification and recosnstruction problems in statistical learning approaches. [S.1.]: Revista de Informatica Teórica e Aplicada, 2008.

GOERNER, Frank L.; CLARKE, Geoffrey D. Measuring signal to noise ratio in partially paralell imaging MRI. Medical Physics, American Association of Physicists in Medicine, v. 38, p. 5049-5057, 2011.

GONCALVES, S.I. MRI:Principles and Applications- Attifacts in MRI- Identification, Explanation, Solution. [S.1.]: University Hospital Coimbra, 2011.

GREGORI, I.R.S. Trepidação em veículos equipados com embreagens a seco: uma abordagem multivariada do sinal de torque no comportamento do atrito dos materiais de fricção. [S.1.], 2016. Disponível em: <https://repositorio.fei.edu.br/handle/FEI/277>.

GUERIN, Bastien et al. The ultimate signal-to-noise ratio in realistic body models. Magnetic Ressonance in Medicine, Wiley, v. 78, p. 1969-1980, 2017.

GUTBERLET, Matthias et al. Comparison of different cardiac MRI sequences at 1.5 T/3.0 T with respect to signal-to-noise and contrast-to-noise ratios - initial experience. Rofo, Pubmed, v. 176, p. 801-808, 2004.

HASTIE, T.; TIBSHIRANI, R.; FRIEDMAN, J. The Elements of Statistical Learning:Data Mining, Inference and Prediction. [S.1.]: Springer, 2009. 
JIN, Ning ren; SAYBASILI, Haris; BI, Xiaoming. Sparse Coding for Improved Signal-to-Noise Ratio in MRI. Basic Principles of Cardiovascular MRI, Springer, p. 41-62, 2015.

JONSON, R.A; WICHERN, D.W. Applied Multivariante Statistical Analysis. [S.l.]: Person, 2007.

JUNIOR, Durval Rodrigues. LOM3228 -MÉTODOS EXPERIMENTAIS DA FÍSICA I. Escola de Engenharia de Lorena. [S.l.], mar. 2010.

KUMAR, A.; WELTI, D.; ERNST, R.R. NMR Fourier zeugmatography. Journal of magnetic resonance, v. 18, p. 69-83, 1975.

KUPERMAN, Vadim. Magnetic Ressonance Imaging. [S.1.]: Academic Press, 2000.

LAUTERBUR, P.C. Resonance Absorption by Nuclear Magnetic Moments in a Solid. Nature, v. 242, p. 190-191, 1973.

LI, Ye; GUO, Yan; JIANG, Xiaohua. Signal-to-Noise Ratio Improvement by Bi-2223 Surface RF Coil in 0.3T MRI System. IEEE Transactions on Applied Superconductivity, v. 20, p. 818-821, 2010.

LINDEGAARD, H. M. et al. Low-cost, low-field dedicated extremity magnetic resonance imaging in early rheumatoid arthritis: a 1-year follow-up study. Ann Rheum Dis, PubMed, v. 65 , p. 1208-1212, 2006.

LIU, Thomas T. Noise contributions to the fMRI signal: An overview. NeuroImage, Science Direct, v. 143, p. 141-151, 2016.

MANSFIELD, B.P.; MAUDSLEY, A. A. Medical imaging by NMR. British Journal of Radiology, v. 50, p. 188-194, 1976.

MARCOVSKI, Alberto. Noise in MRI. Magnetic Ressonance in Medicine, ISMRM, v. 36, p. 494-497, 1996.

MATHEW, Ashish J.; BIRD, Paul. Is dedicated extremity 1.5-T MRI equivalent to standard large-bore 1.5-T MRI for foot and knee examinations? Indian Journal of Rheumatology, Elsevier, v. 10, p. 140-146, 2015.

MCCANN, Adam J.; WORKMAN, Adam; MCGRATH, Catherine M. A quick and robust method for measurement of signal-to-noise ratio in MRI. Physics in Medicine Biology, IOP Science, v. 58, p. 3775-3790, 2013.

MCROBBIE, Donald et al. Mri from picture to proton. [S.1.]: Academic Press, 2006.

MEDICAL, Oni. Magnet Shimming Guide. [S.1.], 2007. Disponível em: <http://onicorp.com>. 
NGUYEN PATRICIA K.AND WU, Joseph C. Radiation exposure from imaging tests: is there an increased cancer risk? Medicine, Expert Review of Cardiovascular Therapy, v. 9, p. 177-183, 2011.

OHLIGER, Michael A.; GRANT, Aaron K.; SODICKSON, Daniel K. Ultimate intrinsic signal-to-noise ratio for parallel MRI: electromagnetic field considerations. Magnetic Ressonance in Medicine, PubMed, v. 50, p. 1018-1030, 2003.

ONI. Optimizing Image Quality. [S.1.], 2003. Disponível em: <http://onicorp.com>.

ONI, M. S. Orthone Overview revision A. [S.1.], 2005. Disponível em: <http://onicorp.com>.

ONI, Systems. Higt Field 1.0 Tesla dedicated MRI. [S.1.], 2007. Disponível em: $<$ http://onicorp.com>.

PLENGE, Esben et al. Super-resolution methods in MRI: can they improve the trade-off between resolution, signal-to-noise ratio, and acquisition time? Magnetic Ressonance in Medicine, Wiley, v. 68, p. 1983-1993, 2012.

PURCELL, Edward M.; TORREY, Henry Cutler; POUND, Robert V. Resonance Absorption by Nuclear Magnetic Moments in a Solid. Physical review, v. 69, p. 37-38, 1946.

RAZZAQ, Fuleah A. et al. Sparse Coding for Improved Signal-to-Noise Ratio in MRI. International Conference on Neural Information Processing, Springer, p. 258-265, 2014.

RENCHER, A.C. Methods of Multivariante Analysis. [S.1.]: Wiley Interscience, 2002.

SATO, J. R. et al. Evaluating SVM and MLDA in the extraction of discriminant regions for mental state prediction. Neuroimage, Elsevier, v. 46, n. 1, p. 105-114, 2009.

SCHNELL, Wilfried; RENZ, Wolfgang; VESTER MARKUS ERMERT, Helmut. Ultimate signal-to-noise-ratio of surface and body antennas for magnetic resonance imaging. IEEE, v. 48 , p. $418-428,2000$.

SHELENS, J. A tutorial on principal component analysis. [S.1.: s.n.], 2014.

SUMITOMO, H. I. OPERATION MANUAL SRDK-305 Series CRYOCOOLER. [S.1.], 2003. Disponível em: <http://sumitomo.com>.

SUTTER, Reto et al. Is dedicated extremity 1.5-T MRI equivalent to standard large-bore 1.5-T MRI for foot and knee examinations? AJR. American Journal of Roentgenology, PubMed, v. 203, p. 1293-1302, 2014.

SUZUKI, Takeshi et al. A new low-field extremity magnetic resonance imaging and proposed compact MRI score: evaluation of anti-tumor necrosis factor biologics on rheumatoid arthritis. Modern Reumatology, Springer, v. 19, p. 358-365, 2009. 
THOMAZ C.E.AND KITANI, C.; GILLIES, D.F. A Maximum Uncertainty LDA-based approach for Limited Sample Size problems - with application to Face Recognition. Journal of the Brazilian Computer Society (JBCS), Springer, v. 12, n. 2, p. 7-18, 2006.

THOMAZ C.E.AND KITANI, E.C. et al. Discriminant Principal Components. Journal of the Brazilian Computer Society (JBCS), Springer, v. 1, n. 2, p. 1-12, 2006.

VAUGHAN, J. Thomas et al. 7T vs. 4T: RF power, homogeneity, and signal-to-noise comparison in head images. Magnetic Ressonance in Medicine, PubMed, v. 46, p. 24-31, 2001.

WALD, Lawrence L. et al. Low-cost and portable MRI. Journal of Ressonance Magnetic Imaging, PubMed, v. 26842, p. 1-9, 2019.

WEVAERT, Marijke; ROSSEEL, Yves. On the Definition of Signal-To-Noise Ratio and Contrast-To-Noise Ratio for fMRI Data. Physics in Medicine Biology, PLOS one, v. 8, p. 1-10, 2013. 